DE-FC26-05NT42632

\title{
Low Temperature Combustion with Thermo-Chemical Recuperation to Maximize In-Use Engine Efficiency
}

\author{
Nigel N. Clark, Francisco Posada, Clinton Bedick \\ West Virginia University \\ John Pratapas, Aleksandr Kozlov, Martin Linck and Dmitri Boulanov \\ Gas Technology Institute (GTI)
}

December 1, 2010

Morgantown, WV 


\section{DISCLAIMER}

This report was prepared as an account of work sponsored by an agency of the United States Government. Neither the United States Government nor any agency thereof, nor any of their employees, makes any warranty, express or implied, or assumes any legal liability or responsibility for the accuracy, completeness, or usefulness of any information, apparatus, product, or process disclosed, or represents that its use would not infringe privately owned rights. Reference herein to any specific commercial product, process, or service by trade name, trademark, manufacturer, or otherwise does not necessarily constitute or imply its endorsement, recommendation, or favoring by the United States Government or any agency thereof. The views and opinions of authors expressed herein do not necessarily state or reflect those of the United States Government or any agency thereof. 


\section{Table of Contents}

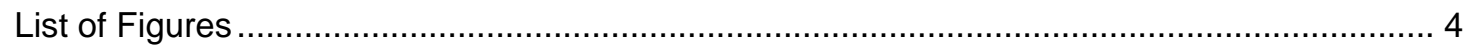

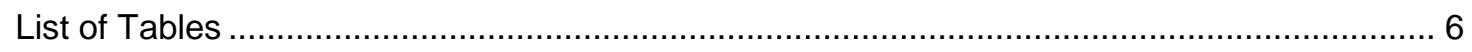

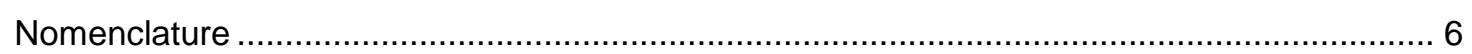

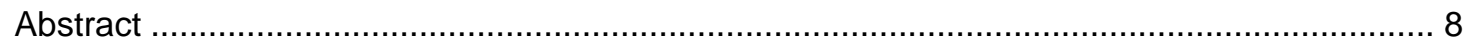

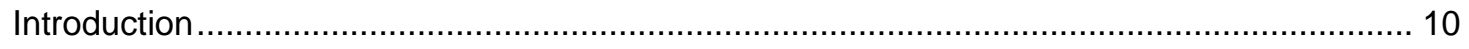

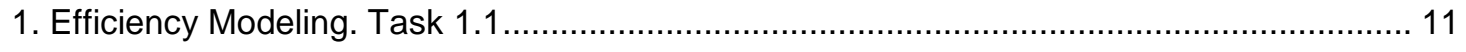

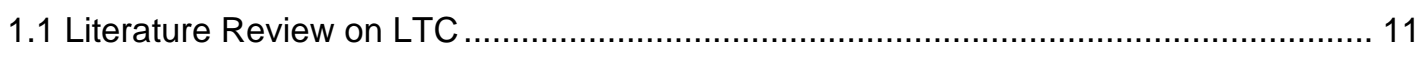

1.2 LTC and CIDI modeling: combustion, heat transfer and cooling burden ........................ 14

1.2.1 LTC Combustion and Heat Transfer Model .......................................................... 14

1.2.2 Advanced LTC Modeling: Single and Multi-zone models ..................................... 18

1.2.3 CIDI Combustion Model and Heat Release Model ............................................... 25

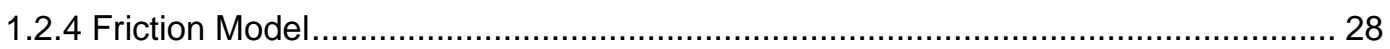

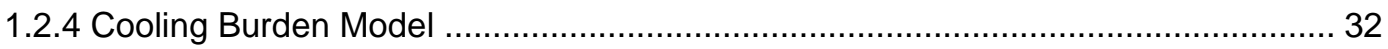

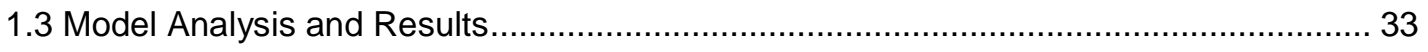

1.3.1 LTC Model Results: Combustion and Heat Transfer Trends................................ 33

1.3.2 Comparisons between Diesel Engine and LTC Engine: Heat Transfer, Friction and

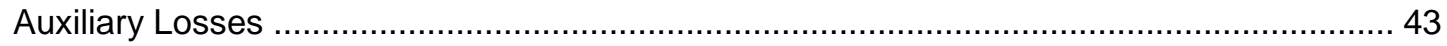

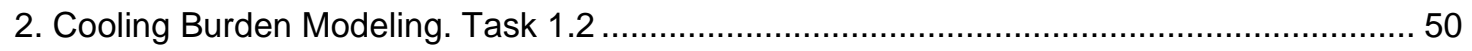

2.1. Comparisons between Diesel Engine and LTC Engine: Total Cooling Burden ............ 50

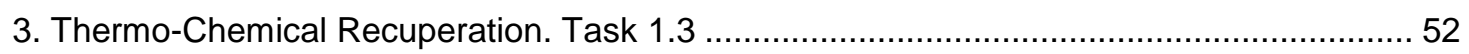

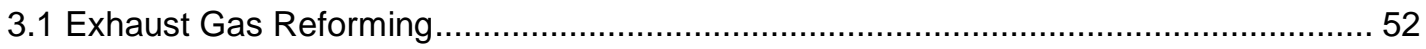

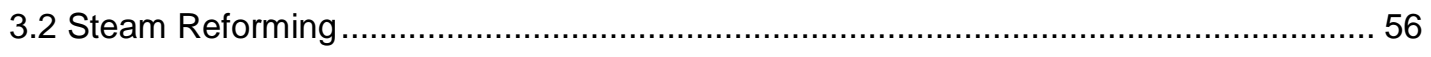

3.2.1 n-Heptane Steam Reforming Model Results ................................................. 57

3.2.2 Experimental Set-Up for $n$-Heptane Steam Reforming ....................................... 59

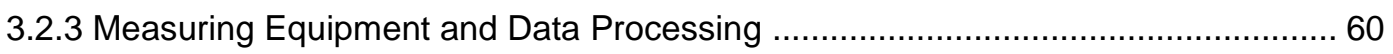

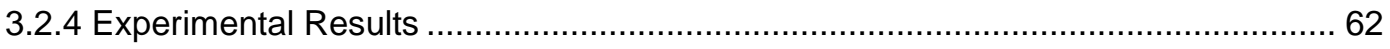

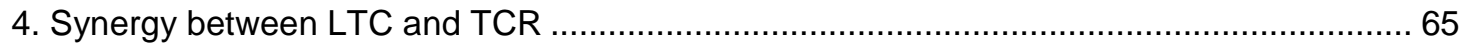

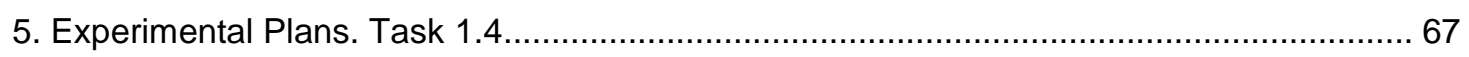

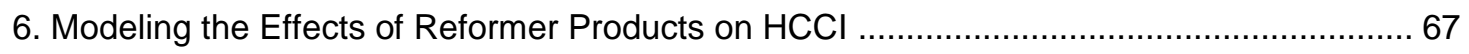

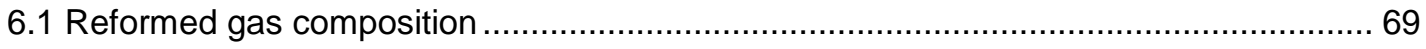

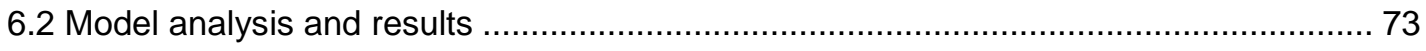

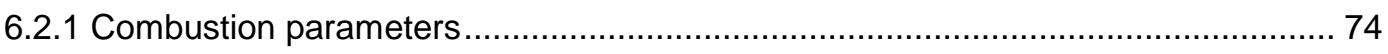

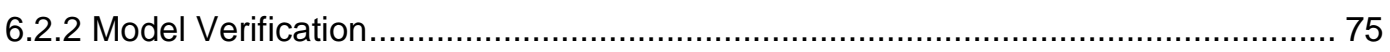

6.2.3 Model results: ideal case composition .............................................................. 76

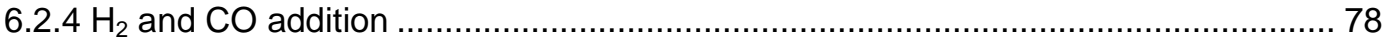

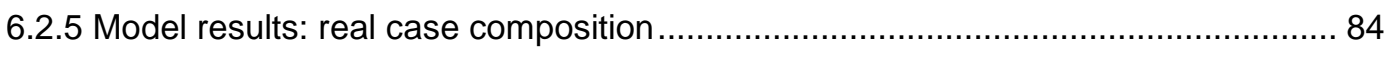




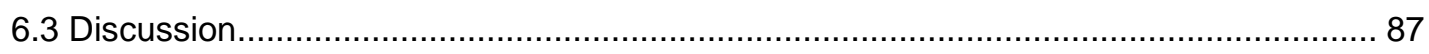

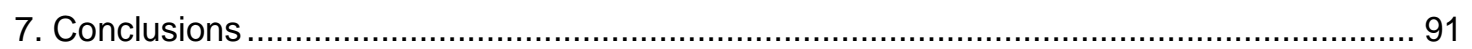

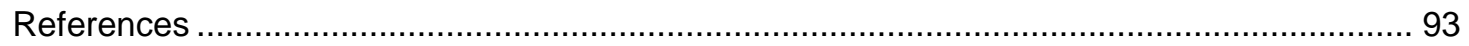




\section{List of Figures}

Figure 1. Multi-zone model representation.

Figure 1: LTC Model Results of In-Cylinder Pressure and Temperature Variations at Different Intake Temperatures

Figure 2: LTC Model Results of In-Cylinder Pressure and Temperature Variations at Different Equivalence Ratios for a Fixed Intake Temperature 35

Figure 3: Influence of EGR on In-Cylinder Pressure and Temperature Histories..... 37

Figure 4: Influence of boost on In-Cylinder Pressure and Temperature Histories. The pressure

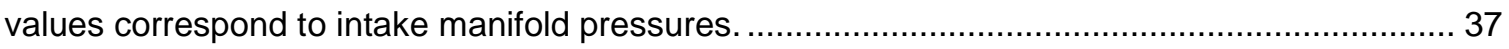

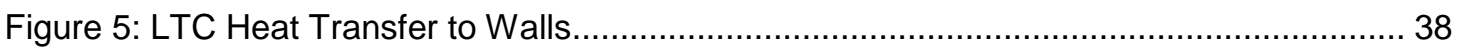

Figure 6: LTC Cumulative Heat Transfer to Walls 38

Figure 7: Influence of boost on heat transfer to walls. The amount of fuel is the same in each case: $26.4 \mathrm{mg}$ fuel per cycle. 39

Figure 9. Calculated temperature and zone mass (as fraction of total mass) for three different $A / F$ values, $A F=43, A F=50$ and $A F=55 . P_{\text {int }}=95 \mathrm{kPa}, T_{\text {int }}=310 \mathrm{~K}, C R=10, P_{\text {exh }}=104 \mathrm{kPa}, 900 \mathrm{rpm}$.

Figure 8: (a) LTC and CIDI Cumulative Heat Transfer to Walls, Low Load Case: $21.89 \mathrm{mg}$ of Fuel per Cycle (b) LTC and CIDI Cumulative Heat Transfer to Walls, High Load Case: $41.79 \mathrm{mg}$ of Fuel per Cycle.

Figure 9: LTC and CIDI Cumulative Heat Transfer to Walls, for naturally aspirated (95kPa) and with boost (190 kPa). Amount of fuel per cycle: $41.57 \mathrm{mg}$ of Fuel per Cycle ............................. 46

Figure 10: Piston-Ring Assembly Friction Force (43.57 mg of fuel) ..................................... 47

Figure 11: Bearing Friction Losses $(43.57 \mathrm{mg}$ of fuel) ......................................................... 47

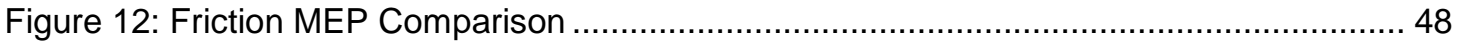

Figure 13: Power Consumed by the Engine Cooling Fan at Different Ambient Temperatures 49

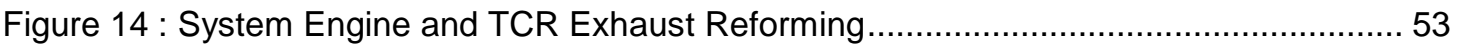

Figure 15: Alpha vs. Beta plots for Oxidation of Fuel at TCR-Exhaust Reforming ................. 55

Figure 16: Reformer Gas Composition, Equilibrium by One Reaction................................... 58

Figure 17: Reformed Fuel Low Heating Value at Equilibrium ............................................ 59

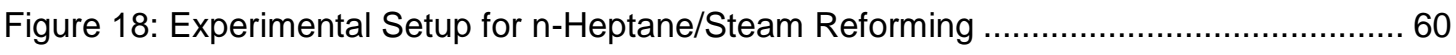

Figure 19: Heptane Conversion Rate Compared to Equilibrium Values................................. 62

Figure 20: Reformed Gas Composition with Catalyst .......................................................... 63

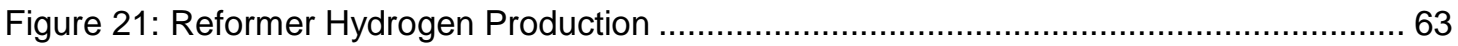

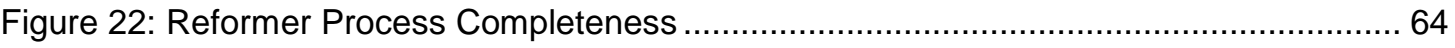

Figure 23 : n-Heptane recuperation system based on steam reforming ................................ 68

Figure 24: n-heptane recuperation system based on steam reforming ................................. 68 
Figure 27 : Reformed Gas Composition with Catalyst ......................................................... 70

Figure 26 : Definition of combustion parameters and its nomenclature ................................. 75

Figure 27 Effect of $R G$ addition on SOC for $n$-heptane. Experimental data from reference [38]. $\mathrm{T}_{\text {INT }}=373 \mathrm{~K}, 700 \mathrm{rpm}, \varphi=0.806, \mathrm{EGR}=40 \%$ 76

Figure 28 : Temperature curves at $\varphi=0.8$ and different values of RG based on ideal case composition. Baseline $\varphi=0.8$

Figure 29 : Rate of heat release for different values of $R G$ based on ideal case composition, $\mathrm{S}: C=2: 1$. Baseline $\varphi=0.8, \mathrm{~T}_{\mathrm{INT}}=370 \mathrm{~K}, 1200 \mathrm{rpm}$ 77

Figure 30 : Relation between $H R_{L}$ as a fraction of total heat release $H R$, and CA50 for different values of $R G$ based on ideal case composition, $S: C=2: 1$. Baseline $\varphi=0.8, T_{\mathbb{N N T}_{T}}=370 \mathrm{~K}, 1200 \mathrm{rpm}$

Figure 31 : Temperature curves at different values of $\mathrm{H}_{2}$ addition ( $\mathrm{No} \mathrm{CO}$ or $\mathrm{H}_{2} \mathrm{O}$ ), Baseline $\varphi=0.8, \mathrm{~T}_{\mathrm{INT}}=370 \mathrm{~K}, 1200 \mathrm{rpm}$ 79

Figure 32 : Temperature curves at different values of $\mathrm{CO}$ addition ( $\mathrm{No} \mathrm{H}_{2}$ or $\mathrm{H}_{2} \mathrm{O}$ ), Baseline $\varphi=0.8, \mathrm{~T}_{\mathrm{INT}}=370 \mathrm{~K}, 1200 \mathrm{rpm}$. 79

Figure 33 : Rate of heat release for different values of $\mathrm{H}_{2}$ addition ( $\mathrm{No} \mathrm{CO}$ or $\mathrm{H}_{2} \mathrm{O}$ ), Baseline $\varphi=0.8, \mathrm{~T}_{\mathrm{INT}}=370 \mathrm{~K}, 1200 \mathrm{rpm}$ 80

Figure 34 : Rate of heat release for different values of $\mathrm{CO}$ addition $\left(\mathrm{No} \mathrm{H}_{2}\right.$ or $\mathrm{H}_{2} \mathrm{O}$ ), Baseline $\varphi=0.8, T_{\text {INT }}=370 \mathrm{~K}, 1200 \mathrm{rpm}$.

Figure 35 : Relation between $\mathrm{HR}_{\mathrm{L}}$ as a fraction of total heat release $\mathrm{HR}$, and the main ignition event timing, CA50, for different values of $\mathrm{H}_{2}$ and $\mathrm{CO}$ addition $\left(\mathrm{No}_{2} \mathrm{O}\right)$, Baseline $\varphi=0.8$, $\mathrm{T}_{\mathrm{INT}}=370 \mathrm{~K}, 1200 \mathrm{rpm}$ 81

Figure 36 : Rate of change of temperature along the temperature domain. 82

Figure 37 : Computed molar fraction of $\mathrm{H}_{2} \mathrm{O}_{2}$ for $\mathrm{H}_{2}$ addition (a) and for $\mathrm{CO}$ addition (b). Baseline $\varphi=0.8, \mathrm{~T}_{\text {intake }}=370 \mathrm{~K}, 1200 \mathrm{rpm}$ 83

Figure 38 : Computed temperature history for real case composition, $R G=10 \%$, at different mixture composition according to reforming temperature. Baseline $\varphi=0.8$ 84

Figure 39 : Computed temperature history for real case composition, $R G=20 \%$, at different mixture composition according to reforming temperature. Baseline $\varphi=0.8$ 85

Figure 40 : Computed temperature history for real case composition, $R G=30 \%$, at different mixture composition according to reforming temperature. Baseline $\varphi=0.8$ 86

Figure 41: Computed temperature history for real case composition, $R G=40 \%$, at different mixture composition according to reforming temperature. Baseline $\varphi=0.8$ 86

Figure 42 : Fig. 19, Computed start of ignition temperatures as a function of $R G$ at constant composition cases: (a) T_SOI ${ }_{L}$ at LTHR regime and (b) $T \_S O I_{H}$ at $H T H R$ regime. Baseline $\varphi=0.8$. $\mathrm{T}_{\mathrm{INT}}=370 \mathrm{~K}, 1200 \mathrm{rpm}$ 
Figure 43 : Computed combustion phasing (CA50) and LTHR fraction ( $\left.H R_{L} / H R\right)$ for different values of RG. Each line represents a single mixture composition. Baseline $\varphi=0.8$. $T_{\mathbb{I N T}}=370 \mathrm{~K}$, $1200 \mathrm{rpm}, \mathrm{P}=1 \mathrm{~atm}$

Figure 44 : Computed combustion phasing (CA50) as a function of RG. Each line represents a single mixture composition. Baseline $\varphi=0.8 . \mathrm{T}_{\mathrm{INT}}=370 \mathrm{~K}, 1200 \mathrm{rpm}$.

\section{List of Tables}

Table 1: Simulation Conditions.

Table 2: Summary of friction losses, heat transfer and work during one cycle for the CIDI and the LTC engine. 50

Table 3: Properties of $n$-Heptane 61

Table 4: Comparison of GC and GTI Chemical Laboratory Analysis Results 61

Table 5: Exhaust Gas Temperatures Calculated from Adiabatic Expansion from Exhaust Valve Open (EVO) Conditions at Different Equivalence Ratios 65

Table 6: Cylinder geometry and simulation conditions 69

Table 7 : Polynomial coefficients used to calculate molar fraction composition at different reforming temperatures. Based on Fig.25 data

Table 8 Real case molar composition at different reforming temperatures and values of RG 72

Table 9 Ideal case molar composition at different values of RG, $\varphi=0.8$ 72

\section{Nomenclature}

CA : $\quad$ Crank angle degrees

CA50: Crank angle at $50 \%$ energy release (CA degrees)

Cl: Compression ignition (engines)

COV: Coefficient of variation

cr: Compression ratio

EGR: Exhaust gas recirculation

$\mathrm{HCCl}$ : Homogeneous charge compression ignition

$\mathbf{H R}_{\mathrm{L}}$ : $\quad$ Magnitude of the energy released during the LTHR regime, calculated as the accumulated value from $S O \mathrm{~L}_{\mathrm{L}}$ up to $\mathrm{SOI}_{\mathrm{H}}$.

HTHR: High temperature heat release

HTHR $_{\text {max }}$ : Maximum heat release rate magnitude

IMEP: Indicated mean effective pressure

IVC: Inlet valve closing

LTHR: Low temperature heat release

$\mathbf{L T H R}_{\text {max }}$ : Maximum heat release rate magnitude 

NOx: Nitrogen Oxides
NTC: Negative temperature coefficient
PINT: $_{\text {IV }} \quad$ Pressure at IVC (intake conditions)
PM: $\quad$ Particulate matter
PRF: $\quad$ Primary reference fuel
RG: $\quad$ Reformed gas (fuel)
S:C : $\quad$ Steam to Carbon ratio
SI: $\quad$ Spark ignited (engines)
SOC: $\quad$ Start of combustion (SOC)
SOI $_{\mathbf{H}}$ : $\quad$ High temperature start of ignition (CA degrees)
SOI : $\quad$ Low temperature start of ignition (CA degrees)
T_SOI $\mathrm{H}_{\mathrm{H}}$ Gas mixture temperature corresponding to $\mathrm{SOI}_{\mathrm{H}}$
T_SOI $\mathrm{L}_{\mathrm{L}} \quad$ Gas mixture temperature corresponding to $\mathrm{SOI}_{\mathrm{L}}$
$\mathbf{T}_{\text {INT }}$ : Temperature at IVC (intake conditions)
WGSR: Water gas shift reaction 


\section{Abstract}

The key to overcome Low Temperature Combustion (LTC) load range limitations in reciprocating engines is based on proper control over the thermo-chemical properties of the incylinder charge. The studied alternative to achieve the required control of LTC is the use of two separate fuel streams to regulate timing and heat release at specific operational points, where the secondary fuel is a reformed product of the primary fuel in the tank. It is proposed in this report that the secondary fuel can be produced using exhaust heat and Thermo-Chemical Recuperation (TCR). TCR for reciprocating engines is a system that employs high efficiency recovery of sensible heat from engine exhaust gas and uses this energy to transform fuel composition. The recuperated sensible heat is returned to the engine as chemical energy. Chemical conversions are accomplished through catalytic and endothermic reactions in a specially designed reforming reactor. An equilibrium model developed by Gas Technology Institute (GTI) for heptane steam reforming was applied to estimate reformed fuel composition at different reforming temperatures. Laboratory results, at a steam/heptane mole ratio less than $2: 1$, confirm that low temperature reforming reactions, in the range of $550 \mathrm{~K}$ to $650 \mathrm{~K}$, can produce 10-30\% hydrogen (by volume, wet) in the product stream. Also, the effect of trading low mean effective pressure for displacement to achieve power output and energy efficiency has been explored by WVU. A zerodimensional model of LTC using heptane as fuel and a diesel Compression Ignition (Cl) combustion model were employed to estimate pressure, temperature and total heat release as inputs for a mechanical and thermal loss model. The model results show that the total cooling burden on an LTC engine with lower power density and higher displacement was $14.3 \%$ lower than the diesel engine for the same amount of energy addition in the case of high load $(43.57 \mathrm{mg}$ fuel/cycle). These preliminary modeling and experimental results suggest that the LTC-TCR combination may offer a high efficiency solution to engine operation. A single zone model using a detailed chemical kinetic mechanism was implemented in CHEMKIN and to study the effects of base fuel and steam-fuel reforming products on the ignition timing and heat release characteristics. The study was performed considering the reformed fuel species composition for total $n$-heptane conversion (ideal case) and also at the composition corresponding to a specific set of operational reforming temperatures (real case). The computational model confirmed that the reformed products have a strong influence on the low temperature heat release (LTHR) region, affecting the onset of the high temperature heat release (HTHR). The ignition timing was proportionally delayed with respect to the baseline fuel case when higher concentrations of reformed gas were used. For stoichiometric concentration of $R G$, it was found that by increasing the proportion of reformed fuel to total fuel $(\mathrm{RG})$, from $0 \%$ to $30 \%$, the amount of energy released during the LTHR regime, or $\mathrm{HR}_{\mathrm{L}}$, was reduced by $48 \%$ and the ignition timing was delayed 10.4 $\mathrm{CA}$ degrees with respect to the baseline fuel case. For $\mathrm{RG}$ composition corresponding to certain operational reforming temperatures, it was found that the most significant effects on the $\mathrm{HCCl}$ 
combustion, regarding $\mathrm{HR}_{\mathrm{L}}$ reduction and $\mathrm{CA} 50$ delay, was obtained by $\mathrm{RG}$ produced at a reforming temperature range of $675 \mathrm{~K}-725 \mathrm{~K}$. 


\section{Introduction}

The research presented in this report examined the feasibility of employing Low Temperature Combustion (LTC) with TCR for heavy-duty engine applications, and represented the first phase of a study funded by the US Department of Energy. Initial modeling was performed to determine the differences in mean effective pressure (MEP), efficiency, friction and cooling losses, and exhaust temperatures between a diesel $\mathrm{Cl}$ engine and an LTC engine. The results from LTC modeling were applied to TCR experimental results to determine the feasibility of combining the two systems to extend the operational range of LTC with respect to engine load. The modeling was also used to validate LTC as a possible method of increasing efficiency, prior to beginning an experimental phase. This report presents results from LTC modeling and TCR experimental work in order to show that the overall system is feasible and that it has the potential to increase engine efficiency and extend the operational range.

The report consists of four main sections. The first section is dedicated to obtaining values for energy losses in a LTC engine. These values were compared with values obtained from the model of a diesel engine with half the displacement of the LTC engine. Energy losses assessed in this report include friction, auxiliaries and heat transfer. Simple models for LTC and diesel engines were implemented to obtain the pressure and temperature data required for the evaluation of the energy losses. The second section is devoted to modeling and experimental work in steam reforming of $n$-heptane, used to represent the fuel. The reformed fuel is proposed to be used as a secondary fuel for control purposes in the LTC engine. The third section examines the interaction between LTC and TCR, based on temperature data from the previous LTC modeling results and the experimental results obtained from steam reforming of $n$-heptane. The fourth section is focused on studying the effects of reformed fuel. Experimental values of RG mixture composition were linearized as a function of reforming temperature to be used in the second part of this study. The stoichiometric case of steam $/ \mathrm{n}$-heptane reforming and the linearized experimental values of RG mixture composition were employed as inputs in the zerodimensional $\mathrm{HCCl}$ combustion model to analyze the ignition phasing and heat release trends as function of $R G$ substitution into the cylinder charge 


\section{Efficiency Modeling. Task 1.1}

The Recipient shall gather existing empirical and fundamental models to describe combustion, heat release, heat transfer, piston and ring friction, rod-and crank losses, and other frictional losses in heavy-duty engines and in light-duty diesel engines. Information will also be obtained for LTC and Homogeneous Charged Compression Ignition ( $\mathrm{HCCl}$ ) operation. These data will be processed to understand the limits of $L T C$ and $\mathrm{HCCl}$ under constraint of $0.02 \mathrm{~g} / \mathrm{bhp}-\mathrm{hr}$ NOX requirements. The effects on mechanical efficiency of changing displacement, imep and boost will be considered using well-established data and models. Results from a mechanical model and thermodynamic model will be merged to suggest the optimum range of variables that will enable LTC for study in Task 1.2 and later project phases. Response times and tools (variables) used for LTC control, and the limits of LTC imep will be evaluated with respect to transient operation. Existing data will be processed to determine transient requirements of typical engine operation as a target for control. An overall model will be used for computation of ignition, heat release, in-cylinder pressure and heat transfer.

During the development of Task 1.1 and prior to beginning an experimental phase of LTC research, an initial literature review was performed to obtain typical operational limits of experimental LTC engines and to compare those limits with a typical CIDI (Compression Ignition Direct Injection) operational range.

Modeling was performed to investigate effects of altering the main variables involved in the LTC process, identify an operational range during the experimental stage and to compare efficiency under different displacement volumes of the LTC engine. Additionally, the friction model was run for both the LTC and the CIDI engine and the results obtained were compared at different load cases. The model was separated into three main modules: a combustion model for LTC, a combustion model for CIDI combustion (which provide bulk temperature information to the heat transfer model and pressure and kinematics information to the friction/losses model), and a mechanical losses model. The total summation of energy losses was in Task 1.2 as an input to the cooling burden model for each type of engine.

\subsection{Literature Review on LTC}

LTC, also known as $\mathrm{HCCl}$ (Homogeneous Charge Compression Ignition) combustion, is a combustion technique investigated since the late 1970's to reduce emissions from a compression ignition engine while maintaining high efficiency, similar to that of a CIDI diesel engine [1-5]. There are still technical barriers involved in the development of the LTC engine, including 
extending its operational range to high power densities, gaining complete control over the ignition of the fuel/air mixture, and handling transients $[6,7,8,9]$.

LTC utilizes a homogeneous air/fuel mixture, similar to spark ignited systems, but the combustion is initiated by fuel auto-ignition due to the increase in temperature associated with the compression stroke. This process is characterized by the absence of flame propagation, the almost simultaneous reaction of the entire cylinder charge, rapid heat release rates and small values for Coefficient of Variation (COV) of combustion parameters [6,7,8,9]. Recent chemiluminescence imaging techniques applied by Dec et al. [10] under various fueling strategies showed that this premixed combustion mode is not totally homogeneous and its heterogeneity is caused by thermal stratification due to turbulent transport and heat transfer during compression. The elimination of highly heterogeneous zones, which are characteristic of conventional $\mathrm{Cl}$ combustion, leads to a reduction in pollutant formation, especially formation of particulate matter (PM). The quasi-homogeneous operation generates lower gas temperatures and therefore low NOx, as compared with both Spark Ignition (SI) and Compression Ignition (Cl) systems, and this has been widely demonstrated by researchers [7-11].

Although LTC has emerged as an alternative to $\mathrm{SI}$ and $\mathrm{Cl}$ combustion, there is an inherent difficulty in maintaining LTC combustion over the entire operational load range. For SI engines, the ignition timing is controlled by the spark timing, and for $\mathrm{Cl}$ this is done indirectly by the fuel injection timing. The rate of heat release is controlled in SI engines by finite flame propagation and in $\mathrm{Cl}$ engines by the rate of fuel injection [14]. In the case of LTC, the combustion process is controlled by chemical kinetics [15], which is function of the charge composition and temperaturepressure history. The control over ignition timing and the rate of heat release rely on the ability to control these parameters [2].

Using primary reference fuels with different octane numbers and molecular structures, Najt and Foster [2] found that the homogeneous autoignition (ignition timing) is highly dependent on the type of fuel. For paraffin (alkane) fuels, the literature divides the oxidation reactions into three main stages [2]. Below $750^{\circ} \mathrm{K}$ the reactions are dominated by chain propagating steps including oxygen molecules and the generation of partially oxidized species [16,17]. Between $800 \mathrm{~K}$ and $950 \mathrm{~K}$ the chain propagating steps yield conjugate alkenes and $\mathrm{HO}_{2}$ radicals [17]. Above $1000^{\circ} \mathrm{K}$ the main fuel radical reactions are thermal decomposition by $\mathrm{C}-\mathrm{C}$ bond breakage, forming alkenes and smaller radicals [18]. Based on the previous characterization, Najt and Foster [2] divided the oxidation process in two stages: the low temperature kinetics (ignition) where fuel radicals react with oxygen and the high temperature kinetics (heat release), where fuel radicals thermally decompose. 
Currently, LTC engines are limited to low to mid power applications. Two general directions have been investigated in an effort to extend the operational range of LTC and to provide the required control, namely modifying air/fuel mixture properties and modifying engine operation and design parameters [19]. The final purpose of each of these strategies was to modify the composition and/or temperature of the in-cylinder charge. Blending of fuels and the use of exhaust gases (EGR) are two of the most studied and successful approaches on improving LTC performance.

The autoignition capacity of fuels depends on composition, molecular size and structure [2]. Blending of fuels with different autoignition properties has been studied by several researchers as a method to improve control and expand the operational range of actual LTC systems. Olsson et al. [8] modified a 6 cylinder turbo-charged engine for dual fuel operation. The system was designed to operate with $n$-heptane and ethanol. The addition of ethanol, with its high octane rating, allowed for combustion using a compression ratio $(\mathrm{CR})$ of $18: 1$, which would be difficult to achieve under high load conditions. Using an engine with a variable compression ratio mechanism, Christensen and Johansson [6] achieved LTC operation with natural gas as the main fuel and iso-octane as the pilot fuel to improve the autoignition properties of the mixture. It should be noted that autoignition of natural gas without a pilot fuel requires compression ratios greater than 20. Experiments conducted with light naphtha, which is easily ignited, as well as with alcohols, non-alcohol oxygenates and benzene, all of which are not easily ignited, showed that ignition timing can be controlled and excessively rapid combustion (similar to knock) can be suppressed [20]. These experiments demonstrated the control of ignition timing and the suppression of excessive rapid combustion [20]. Intake injection was used for the light naphtha and direct injection was used for the compounds that ignited more slowly. Each case also utilized different injection timing. Zhong et al. [21] worked with diesel/gasoline blends at a compression ratio of $15: 1$. They found that as the percentage of diesel was increased, the intake temperature required for knock free LTC operation was lowered and the excess air ratio was extended.

The idea behind the use of trapped exhaust gases for control of LTC engines is based on the availability of an inert gas that can be used to change the thermo-chemical characteristics of the in-cylinder charge. The control over the temperature and amount of this gas has been based on two different technologies: a hot internal trapping of exhaust gases, or on a cooling charge of external EGR. The internal trapping of exhaust gases increases the initial temperature of the incylinder charge, advancing the ignition timing, and the High-Temperature Heat Release (HTHR) timing [31,32]. The external EGR will dilute the mixture, reducing the concentration of reacting species, delaying the ignition timing, and reducing the HTHR. Using methane as fuel, Olsson et al. [33] demonstrated the positive effects of cooled EGR on emissions and the extension of the 
load limit when combined with supercharging. The effect of EGR on the LTC of diesel fuels has been studied by Ryan et al. [34].

As in the approaches discussed above, the use of a TCR system allows the in-cylinder charge composition to be modified on a cycle-by-cycle basis, which improves the thermal efficiency of the engine by using energy from exhaust gases at relative low temperatures.

\subsection{LTC and CIDI modeling: combustion, heat transfer and cooling burden}

Section 1.2 presents all the mathematical formulation behind each one of the models employed during this task.

\subsubsection{LTC Combustion and Heat Transfer Model}

A simple model (without detailed chemistry) was selected to describe the in-cylinder LTC process. Simple models have demonstrated good performance for control purposes, which is a future thrust of the authors' program. It may also be used for relative efficiency estimation as parameters are varied.

Shaver et al. [22] developed a single-zone model taking some elements from simple modeling and adding a two-step mechanism for fuel-air mixture combustion. This model was developed for propane but can be adjusted for other fuels assuming a homogeneous charge. According to Shaver et al. the model is defined by the combustion chemistry mechanism used. The proposed model tracks the in-cylinder pressure, temperature and species concentration during a compression, combustion and expansion cycle. This model has been adapted for a closed system first law analysis.

The volume is function of the crank angle, compression ratio, bore, stroke and the rod length.

$$
V(\theta)=V_{c}+(\pi / 4) B^{2} S\left(0.5+\frac{R}{2}+\frac{1}{r c-1}-\frac{\cos (\theta)}{2}-\frac{1}{2} \sqrt{R^{2}-\sin ^{2}(\theta)}\right)
$$

Where $\theta$ is crank angle (deg), $c r$ is compression ratio, $B$ is bore $(\mathrm{m}), S$ is stroke $(\mathrm{m})$ and $R L$ is rod length $(m)$. For a constant rotational speed

$$
\theta=\omega t
$$

Where $\omega$ is the crankshaft rotational speed $(\mathrm{rad} / \mathrm{s})$ and $t$ is time (s). 
The energy balance for a closed system and the ideal gas law are combined in order to derive a differential equation for the temperature of the gas inside the cylinder.

$$
\frac{d U}{d t}=\frac{d Q_{w}}{d t}-\frac{d W}{d t}
$$

Where $d Q_{w} / d t$ is the rate of heat transferred to the wall $(\mathrm{kW}), d W / d t$ is the work done by the system by unit time $(\mathrm{kW})$, and $d U / d t$ is the rate of change of internal energy of the species involved in the combustion process $(\mathrm{kW})$.

The rate of change of total energy $U$ can be expressed as

$$
\frac{d U}{d t}=\frac{d(m h)}{d t}-p v \frac{d m}{d t}-V \frac{d p}{d t}-m p \frac{d v}{d t}
$$

Where the mass $m(\mathrm{~kg})$ is calculated from ideal gas state equation and $v\left(\mathrm{~m}^{3} / \mathrm{kg}\right)$ is the specific volume of gas in the cylinder.

The work is expressed as

$$
\frac{d W}{d t}=m p \frac{d v}{d t}
$$

The enthalpy term is expanded in terms of the contributions of the species in the cylinder as

$$
m h=H=\sum N_{i} \bar{h}_{i}
$$

Where $N_{i}$ is the number of moles of species $i$ in the cylinder (kmol), $H$ is the total enthalpy of species $(\mathrm{kJ})$ and $h_{i}$ is the enthalpy of species $i$ in a molar basis $(\mathrm{kJ} / \mathrm{kmol})$.

The rate of change of molar enthalpy is expressed in terms of the specific heat of species $C_{p, I}$ ( $\mathrm{kJ} / \mathrm{kmol}-\mathrm{K})$ at temperature $T(\mathrm{~K})$.

$$
\frac{d \bar{h}_{i}}{d t}=C_{p, i}(T) \cdot \frac{d T}{d t}
$$

Differentiating the ideal gas law, changes in pressure, $p(\mathrm{kPa})$, are related to temperature changes and molar concentration changes by, 


$$
\frac{1}{p} \frac{d p}{d t}=\frac{1}{\sum\left[X_{i}\right]} \frac{d}{d t}\left[\sum\left[X_{i}\right]+\frac{1}{T} \frac{d T}{d t}\right.
$$

Where $\left[X_{i}\right]$ is the concentration of species in the cylinder $\left(\mathrm{kmol} / \mathrm{m}^{3}\right)$, defined as

$$
\left[X_{i}\right]=\frac{N_{i}}{V}
$$

Where $N_{i}$ is the number of moles of species $i$ in the cylinder $(\mathrm{kmol})$. The rate of change of concentration of species is obtained differentiating with respect to time

$$
\frac{d\left[X_{i}\right]}{d t}=\frac{1}{V} \frac{d N_{i}}{d t}-\frac{\left[X_{i}\right]}{V} \frac{d V}{d t}
$$

The first term on the right side of equation 10, the rate of change of moles of species per unit volume, can be obtained from reaction rate and combustion mechanisms available in literature.

During this research program three different fuels were modeled: propane, decane and heptane. Propane was modeled first as a validating tool to compare the mathematical model developed in Simulink with the experimental results obtained by Shaver et al. Once the model was proven capable of reproducing the experimental results, the research fuel was modeled. $n$ decane was selected at first as the candidate for the research project, with the intent of moving to diesel fuel for subsequent work. However, GTI elected to conduct initial reforming work with nheptane primarily to assure that the fuel was evaporated and in a homogenous mixture. As a result, for modeling work, WVU elected to use n-heptane as well in the first phase of the program, as reported below.. The ultimate goal should be to employ diesel fuel.

Following the approach of Shaver et al., the combustion mechanism utilized is based on the two step global n-heptane reaction mechanism proposed by Westbrook and Dryer [23].

The global reaction for stoichiometric oxidation of $n$-heptane can be written as:

$$
\mathrm{C}_{7} \mathrm{H}_{16}+11 \mathrm{O}_{2} \rightarrow 7 \mathrm{CO}_{2}+8 \mathrm{H}_{2} \mathrm{O}
$$

In order to account for the effects of partial oxidation of the fuel and its influence over the adiabatic flame temperature, Dryer and Glassman [24] proposed a two step mechanism:

$$
\mathrm{C}_{7} \mathrm{H}_{16}+7.5 \mathrm{O}_{2} \rightarrow 7 \mathrm{CO}_{2}+8 \mathrm{H}_{2} \mathrm{O}
$$




$$
\mathrm{CO}+1 / 2 \mathrm{O}_{2} \leftrightarrow \mathrm{CO}_{2}
$$

The reaction rates of $\mathrm{n}$-heptane and $\mathrm{CO}$ reactions are expressed by Arrehenius type reactions,

$$
\begin{gathered}
\frac{d\left[C_{7} H_{16}\right]}{d t}=k_{R 1} \cdot \exp \left(-30 / R_{u} T\right)\left[C_{7} H_{16}\right]^{0.25}\left[O_{2}\right]^{1.5} \\
\frac{d[C O]}{d t}=k_{R 2} \cdot \exp \left(-40 / R_{u} T\right)[C O]\left[H_{2} O\right]^{0.5}\left[O_{2}\right]^{0.25}-5 \times 10^{8} \exp \left(-30 / R_{u} T\right)\left[C O_{2}\right]
\end{gathered}
$$

Where $k_{R 1}$ and $k_{R 2}$ are the reaction rate constants, $R u$ is the universal gas constant $(82.05$ $\mathrm{cm}^{3}$.atm/gmol.K) and $T$ is the temperature (K). For values of air/fuel ratio near to stoichiometric combustion $(0.8<\phi<1.2)$, the values used in the model were the same as those proposed by Westbrook and Dryer: $k_{R I}=6.3 \times 10^{11}$ and $k_{R 2}=10^{14.6}$. Values of equivalence ratio lower than 0.8 required that these constants be scaled, following author's recommendations [23], in order to match experimental data published on LTC (or $\mathrm{HCCl}$ ) using $\mathrm{n}$-heptane as fuel. The reaction rates of other species concentrations are derived from the two step mechanism.

This simple approach using two step mechanisms was also tested by Sun et al. [25] with ethanol as fuel, finding good agreement in the general trend of the LTC $(\mathrm{HCCl})$ process and in the ignition and combustion phasing with differences of 1-2 crank angle degrees.

The dominant heat transfer mechanism in the LTC engine is forced convection, while the radiation contribution is negligible due to the low-soot, low temperature combustion on the premixed lean mixture of a LTC engine [26].The literature regarding the convective heat transfer problem offers correlations for the instantaneous convective heat transfer coefficient based on dimensional analysis for turbulent flow. Based on the heat transfer work developed by Woschni [27], on diesel engines, Chang et al. [26] improved the correlation for application in LTC (or $\mathrm{HCCl})$. This spatially averaged correlation is used in this modeling work. The heat transfer to the walls can be expressed as,

$$
\frac{d Q_{w}}{d t}=h_{\text {avg }}\left(T-T_{\text {wall }}\right)
$$

Where $h_{\text {avg }}$ is the spatially averaged convective heat transfer coefficient $\left(\mathrm{kW} / \mathrm{m}^{2}-\mathrm{K}\right)$ and $T_{\text {wall }}$ is the average temperature of the cylinder inside walls $(\mathrm{K})$. The value of $T_{\text {wall }}$ is considered constant during the cycle. The proposed correlation for the averaged convective heat transfer coefficient is [26], 


$$
h_{\text {avg }}(t)=\alpha \cdot L(t)^{-0.2} \cdot p(t)^{0.8} \cdot T(t)^{-0.73} \cdot v(t)^{0.8}
$$

Where $L(t)$ is the instantaneous chamber height $(\mathrm{m})$, and $v(t)$ represents the average cylinder gas velocity $(\mathrm{m} / \mathrm{s})$

$$
v(t)=C_{1} \bar{S}_{p}+\frac{C_{2}}{6} \frac{V_{d} T_{r}}{p_{r} V_{r}}\left(p-p_{m o t}\right)
$$

Here $C_{1}$ and $C_{2}$ are constants, and $S_{p}$ is the mean piston speed $(\mathrm{m} / \mathrm{s}) . T_{r}, p_{r}$ and $V_{r}$ are the working fluid pressure $(\mathrm{kPa})$, volume $\left(\mathrm{m}^{3}\right)$ and temperature $(\mathrm{K})$ at some reference state (inlet valve closing or start of combustion), and $p_{m o t}$ is the motored cylinder pressure $(\mathrm{kPa})$ at the same angle as $p(\mathrm{kPa})$. The parameter $\alpha$ is a tuning factor that is varied to match the energy balance of the cycle.

\subsubsection{Advanced LTC Modeling: Single and Multi-zone models}

Modeling of LTC combustion has been accomplished mainly through three different approaches depending on the specific process to be modeled and on information required by the researcher. Single-zone models, multi-zone models and CFD models have been developed to study this combustion process [50,51]. It was proposed in this research work to proceed systematically from a simple closed volume model, i.e. the single-zone model, which allows the study of the combustion phasing under different operational conditions, and then move towards a multi-zone model where the thermal stratification can be reproduced. Heat release can be obtained more accurately with multi-zone models.

Single-zone and multi-zone combustion models are designed to calculate in-cylinder mixture properties from IVC to EVO, describing compression, combustion and expansion processes. In many cases the actual intake and exhaust events are omitted from the model, with properties the end of the intake process used as an initial condition. Linking the closed volume combustion model to a gas exchange model, able to capture information on residual mass fraction $\left(m_{R}\right)$, composition and temperature before IVO, provides defining conditions at IVC. In this research a gas exchange model was developed and integrated with the combustion model into a cycle model aiming to provide a good approximation for exhaust gas temperature and conditions at IVC. Once the first IVC conditions are provided, the steady state solution was reached after a few iterations of the cycle model. 
The exhaust gas temperature value provided by the model was later used in the TCR model to predict RG composition. The combustion model, gas exchange model and TCR model were later integrated into a $\mathrm{HCCl}-\mathrm{TCR}$ cycle model where the interaction between the models was studied.

\subsubsection{Single-Zone Modeling Description}

A single-zone (SZ) model was developed in Matlab-Cantera to simulate the $\mathrm{HCCl}$ combustion of $\mathrm{n}$-heptane. The major assumptions and initial conditions applied in the single-zone model were as follows.

1. Closed system analysis from IVC to EVO. Blowby is neglected.

2. In-cylinder mixture composition and temperature are considered homogeneous at any given time.

3. Temperature and pressure at IVC, and composition of mixture of residual gas and fresh intake charge, are considered as the initial conditions for solving the set of differential equations.

4. The homogeneous mixture is compressed and expanded following the slider-crank kinematics.

5. The compression of the in-cylinder charge provides the temperature conditions to initiate the autoignition process.

6. Convective heat transfer to walls is the only form of heat transfer considered. Constant walls temperature is assumed [44].

The chemical kinetic code that describes the oxidation of $n$-heptane in air was taken from the Lawrence Livermore National Laboratory ${ }^{1}$ (LLNL), based on the reaction rates for $\mathrm{n}$-heptane oxidation proposed by Curran et al. [53]. Heat transfer to the walls was calculated using the correlation for convection proposed by Chang et al. [26]. This is a modification of the traditional Woschni correlation for $\mathrm{SI}$ engines, while considering the combustion features of the $\mathrm{HCCl}$ engine. A constant wall temperature of $420 \mathrm{~K}$ was used for all cases in this simulation. The thermodynamic fundamentals of this model were previously described by the authors [43].

According to this approach, the rate of change of species concentration is $d[X i] / d t$ (equation 10 ) is obtained not from a global reaction, but from a LLNL chemical kinetic code. The rate of change of species concentration and the rate of change of moles are related by,

$$
w_{i}=\frac{\dot{N}_{i}}{V}
$$

where $w_{i}$ is the rate of change of species concentration obtained from chemical kinetics data.

\footnotetext{
${ }^{1}$ https://www-pls.llnl.gov/?url=science_and_technology-chemistry-combustion-nc7h16
} 
This oversimplified model does not account for the boundary layer mass, with lower temperature than the cylinder core. This overall higher in-cylinder temperature leads to faster combustion reactions, and higher peak pressure rise than the values reported by experiments. However, combustion phasing, or CA50, have been shown to be determined with good accuracy with this type of model [44].

The SZ model does not properly describe the pressure and temperature history, and cannot predict BL phenomena. A multi-zone (MZ) model was required to better predict engine performance and emissions. Steps on this direction were taken and a multi-zone model with heat and mass interaction between zones was developed.

\subsubsection{Multi-Zone Modeling Description}

The limitations of the SZ model in describing peak temperature and rate of pressure rise require the implementation of a multi-zone (MZ) model. The major assumptions made in the $M Z$ model were as follows.

1. Closed system analysis from IVC to EVO. Blowby is neglected.

2. In-cylinder mixture composition and temperature stratification are simulated by dividing the cylinder volume in $Z$ number of zones. The temperature and composition of each zone is the same around the zone at any given time [51].

3. Pressure across all zones is the same at any given time.

4. Every zone interacts with its neighboring zones by exchanging energy via heat conduction and mass (enthalpy). Mass exchange is required in order to keep pressure constant across all zones [51].

5. The cylinder volume is compressed and expanded following the slider-crank kinematics. Each zone has its own volume and there is no volume interaction between zones associated with work [51].

6. The crevice volume is considered as a fraction of the cylinder volume at TDC, and the temperature of the gas inside the crevice zone is always constant and equal to wall temperature $[50,51]$.

7. Convective heat transfer to walls is the only form of heat transfer considered. Constant wall temperature is assumed $[44,26]$.

Figure 1 shows a schematic of the multi-zone model. In this case, six zones are presented: four inner core zones, one boundary layer and a crevice volume. The number of zones was selected by adopting a shell thickness similar to the boundary layer, which is usually around 1-3 $\mathrm{mm}$ in $\mathrm{HCCl}$ engines according to Hulkvist et al. [53]. 


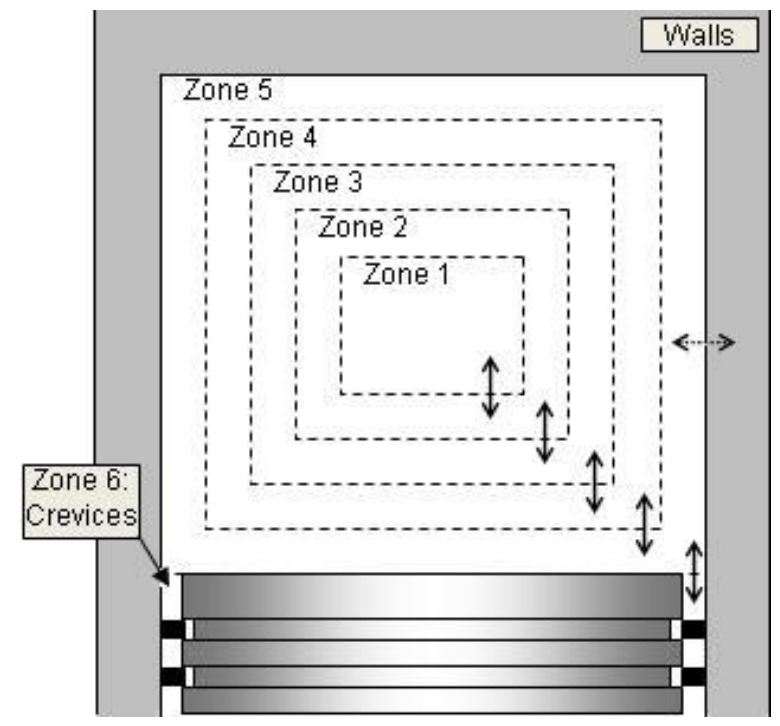

Figure 1. Multi-zone model representation

Each zone, but the inner core, is a cylindrical shell, with constant thickness in the radial and axial directions, and during the piston movement. The shell thickness is determined by the cylinder volume at TDC:

$$
2 \cdot(Z-2) \cdot t_{i}=f \cdot S_{T D C}
$$

where $Z$ is the number of zones, $t_{i}$ is the wall thickness, $S_{T D C}$ is the clearance volume height, and $f$ is the fraction of the $S_{\text {TDC }}$ devoted to the core zone at TDC.

This zone configuration is in agreement with experiments conducted in optical engines, where it was observed that the combustion is initiated at the core of the cylinder charge and it advances towards cylinder head and piston [53]. This thermal stratification is what differentiates the multizone model from previous single-zone models.

Heat transfer by conduction was assumed between neighboring zones,

$$
\dot{q}^{\prime \prime}=-k \frac{d T}{d x} \approx-k \frac{\Delta T_{i}}{t_{i}}
$$

where $\Delta T_{i}$ corresponds to the temperature difference between neighboring zones. The value of thermal conductivity, $k$, was calculated using the approach of Yang and Martin [54]. The thermal conductivity was calculated as composed of laminar and turbulent parts.

$$
k=k_{l}+k_{t}
$$

where $k_{l}$ and $k_{t}$ are the laminar and turbulent values respectively. The value of $k_{l}$ was calculated from gas conductivity, as function of temperature; $k_{t}$ was calculated as [54]: 


$$
\frac{k_{t}}{k_{l}}=\frac{\operatorname{Pr}_{l}}{\operatorname{Pr}_{t}} \frac{\mu_{t}}{\mu_{l}}
$$

This relationship holds for swirl dominated flows. Clearly the exact nature of the in-cylinder flow for a generic engine is unknown.

The viscosity ratio was calculated from the empirical expression fitting for incompressible turbulent flow [54]

$$
\frac{\mu_{t}}{\mu_{l}}=\kappa y^{+}\left[1-\exp \left(-2 a \kappa y^{+}\right)\right]
$$

where $a=0.06, k=0.41$ is the Von Karman constant, and $\mathrm{y}^{+}$was defined as [54]

$$
y^{+}=\frac{u^{*}}{\mu_{w}} \int_{0}^{y} \rho d y
$$

where $\mu_{w}$ was the viscosity at wall conditions, $u^{*}$ is the friction velocity, proportional to engine speed, $\rho$ is the gas density as it changes from the wall towards the core [54]. This integral is easily solved because the gas density is constant along the zone.

Mass exchange between zones to keep a constant pressure around the cylinder requires a pressure difference between zones. This suggests that the energy equation needs to be solved initially without mass exchange. The resultant zone thermodynamic conditions of each zone are adjusted by exchanging mass, with its corresponding enthalpy value, until pressures values are equal for each of the zones.

For each zone $Z$, the energy balance for an open system and the ideal gas law are combined in order to derive a differential equation for the temperature of the gas inside the cylinder,

$$
\left.\left.\frac{d U_{z}}{d t}=\dot{Q}_{z, H T}-\dot{W}_{z}+\dot{m} h\right]_{z, \text { in }}-\dot{m} h\right]_{z, \text { out }}
$$

where $Q_{z, H T}$ is the rate of heat transferred by conduction, $W_{z}$ is the work done by the zone per unit time, and $d U_{z} / d t$ is the rate of change of internal energy of the species involved in the combustion process inside zone $Z$.

Using the ideal gas law, and basic thermodynamic relationships, the energy equation becomes,

$$
\frac{d T_{z}}{d t}=\frac{\left.\left.\dot{Q}_{z, H T}+\dot{Q}_{Z, \text { react }}-\dot{W}_{z}+\dot{m} h\right]_{z, \text { in }}-\dot{m} h\right]_{z, \text { out }}}{\sum_{i=1}^{N} n_{i} c_{p},{ }_{i}-\sum_{i=1}^{N} n_{i} R_{u}}
$$


where $T_{z}$ is the zone temperature, $n_{i}$ is the molar composition of species $i$, and $R_{u}$ is the universal gas constant and

$$
\dot{Q}_{z, H T}=A_{z} \dot{q}^{\prime \prime}
$$

where $A_{z}$ is the zone $Z$ cylinder area. The rate of work developed by zone $Z$ is:

$$
\dot{W}_{z}=P_{z} \frac{d V_{z}}{d t}
$$

And the rate of heat addition due to species reaction is calculated as,

$$
\dot{Q}_{Z, \text { react }}=-\sum_{i=1}^{N} h_{i, Z} \frac{d n_{i, Z}}{d t}+R_{u} T_{z} \sum_{i=1}^{N} \frac{d n_{i, Z}}{d t}
$$

where $d n_{i, Z} / d t$ can be obtained from reaction rates defined by the chemical kinetics mechanism,

$$
\frac{d n_{i, z}}{d t}=\dot{n}_{i n, z}-\dot{n}_{o u t, z}+w_{i, z} \frac{d V_{z}}{d t}
$$

where $w_{i, Z}$ is the molar rate of production of species $i$ in the zone $Z$.

Solution of the set of equations Eq.27 and Eq.31 was performed for each crank angle, from inlet valve closing (IVC) to exhaust valve opening (EVO). Temperature, molar composition and volume of each zone define the state for each zone. A value of pressure for each zone $P_{z}$ can be calculated using ideal gas law. In order to equalize pressures for all zones a mass exchange is performed.

Solving the mass exchange part of the equation is done in two stages. First, based on the results from the energy equation for closed volume, the cylinder pressure at the end of each crank angle period was calculated for both the whole cylinder, $P_{c y l}$, and for each zone $Z, P_{Z}$ as:

$$
P_{c y l}=\frac{m_{c y l} R_{u}}{\sum_{j=1}^{Z} \frac{V_{j} M W_{j}}{T_{j}}}
$$

and

$$
P_{Z}=\frac{m_{Z} R_{Z} T_{Z}}{V_{Z}}
$$


where $m_{z}$ was the mass at zone $Z$, and $R_{z}$ is the gas constant for zone $R_{u} / M W_{z} . M W_{z}$ was calculated using the average molar mass of the mixture according to composition in zone $Z$. If the pressures in each zone were equal to in-cylinder pressure $P_{c y l}$, then the energy equation was solved, and the energy and mass conservation equation solutions are saved and the process repeats in the next CA step. If the pressure of any zone was different to the in-cylinder pressure then mass is transferred between zones until each zone and the in-cylinder pressure are equal.

The second part of the solution involves the mass exchange between zones to equalize pressure in all zones, rather than to expand or contract whole zones. The mass flow from zone $Z$ to its adjacent zones $Z-1$ and $Z+1$ is determined based on the pressure differences, from higher to lower pressure zones. This was performed iteratively. Because mass carries energy via enthalpy, the energy conservation equation was solved along with mass conservation.

The mass present in each zone at the end of the closed system solution $m_{Z}$ was temporary renamed here as $m_{z, 1}$, and was used as the initial condition to solve the mass exchange equation. The mass required at each zone to achieve $P_{z}=P_{c y l}$, at the end of the CA step, $m_{z, 2}$ was calculated as

$$
m_{j, 2}=P_{c y l} \frac{V_{j} M W_{j}}{R_{u} T_{j}}, \mathrm{j}=1 \ldots \mathrm{Z}
$$

Second, the change of mass required to equalize pressures is found by

$$
m_{z, 2}=m_{z, 1}-\Delta m_{z}
$$

where $\Delta m_{z}$ can be obtained from the pressure difference by

$$
\Delta m_{z}=\frac{V_{z}}{R_{z} T_{z}}\left(P_{z}-P_{c y l}\right)
$$

With mass exchange, species also are exchanged and relative zone composition must change. The energy and mass conservation equation require a mass flowrate value to be applied in Equations 32 and 36. The time differential comes from the duration of the CA step, $\Delta t_{C A}$. Mass flowrate or molar flowrate can be calculated for each zone. Conditions for mass (molar) exchange require that the core zone (Zone 1) only interacts with the adjacent Zone 2, and that the boundary layer zone interacts with the adjacent shell zone and with the crevice zone. The crevice zone only interacts with the BL zone. The mass exchange implies changes in the internal energy of the affected zone. The energy equation for the zone receiving mass during the mass and enthalpy exchange is,

$$
U_{z, 2}=U_{z, 1}+H_{z^{\prime}}
$$


where $U_{z, 1}$ is the internal energy of zone $Z$ at the end of closed volume analysis, $U_{z, 2}$ is the internal energy of zone $Z$ at the end of the mass and energy exchange, and $H_{z}$, is the enthalpy of the zone that provides the mass $\Delta m$. In a more convenient way, the temperature change due to the mass exchange can be derived from the energy equation and mass equation Eq. 35 as

$$
T_{z, 2}=\frac{T_{z, 1} m_{z, 1} c_{v_{z, 1}}+T_{z^{\prime}} \Delta m_{z^{\prime}} c_{p_{z^{\prime}}}}{\left(m_{z, 1}+\Delta m_{z}\right) c_{v_{z, 2}}}
$$

where $c p_{z, 1}$ and $c p_{Z}$, are the specific heat of the receiving zone at the start of the iteration and the specific heat evaluated at the temperature corresponding to the zone providing $\Delta m_{z} . C v_{z, 2}$ is adjusted during the iterative process. The iterative process that involves mass and enthalpy exchange between zones is performed until $P_{z, 2}=P_{c y l}$, where $P$ was calculated by ideal gas law using $T_{z, 2}$ and $m_{z, 2}$ and its molar composition. As a result of this iterative process, the mass flow rate and its direction (from $Z_{i}$ to $Z_{i-1}$ and $Z_{i+1}$ ) were calculated.

\subsubsection{CIDI Combustion Model and Heat Release Model}

Applying first law analysis to the cylinder as the control volume and assuming that it is a closed system, the change of an ideal gas state due to heat addition with negligible mass losses can be written as:

$$
\frac{d P}{d \theta}=-\gamma \frac{P}{V} \frac{d V}{d \theta}+(\gamma-1) \frac{1}{V}\left(\frac{d Q_{h}}{d \theta}-\frac{d Q_{w}}{d \theta}\right)
$$

Where $d V / d \theta$ is driven by equation (1), $d Q_{h} / d \theta$ is the rate of heat release per crank angle, $d Q_{w} d \theta$ is the rate of heat transfer to walls per crank angle and $\gamma$ is the specific heat ratio. The rate of heat release is modeled for conventional diesel combustion, calculating the delay time from the start of injection and the rate of change of fraction of fuel burnt as a function of crank angle after the ignition starts. Heat transfer to the walls is modeled using the instantaneous spatially averaged heat transfer coefficient proposed by Woschni [27]. The value of the specific heat ratio, as a function of temperature, was calculated using the polynomial approximation proposed by Brunt and Platts [28], which applies to CIDI diesel engines. Integration of equation 16 combined with the differential expression of the ideal gas law allows the calculation of the cylinder pressure and temperature variation throughout the combustion process [29].

Ignition is assumed to initiate a period of time $\boldsymbol{\tau}_{i}$ after the start of injection. Models for the delay can vary widely in their prediction and do not translate well between different engine, fuel and injection characteristics. According to the experimental work of Wolfer [30], the ignition delay time in CIDI engines can be determined by an empirical expression: 


$$
\tau_{i}=3.45 \exp \left(2100 / T_{m}\right) P_{m}^{-1.028}
$$

Where $\boldsymbol{\tau}_{i}$ is the delay time $(\mathrm{ms})$, and $T_{m}(\mathrm{~K})$ and $P_{m}(\mathrm{kPa})$ are the average temperature and pressure calculated from the start of injection to the actual time-step value. The onset of ignition is determined to occur when the calculated value of $\boldsymbol{\tau}_{i}$ is smaller than the amount of time after injection. The authors acknowledge that many other studies have used the form of equation (40) with different constants, and that the value of $\boldsymbol{\tau}_{i}$ is difficult to predict.

The burn rate is determined using a semi-empirical model proposed by Watson et al. [31] to represent the combustion process by an apparent heat release rate. It is based on expressions describing the fuel-burning rate as a function of the dominant parameters for control such as ignition delay and equivalence ratio.

Burning rates of premixed and diffusion phases have been calculated independently using Wiebe functions and the total burning rate is determined by the relative proportion of each one.

$$
x=\beta \cdot \mathrm{x}_{\mathrm{P}}+(1-\beta) \cdot x_{D}
$$

Where $x_{P}$ is the fraction of fuel burnt in the premixed phase, and $x_{D}$ is the fraction of fuel burnt in the diffusion phase. The variables $x, x_{P}, x_{D}$ vary from 0 to 1 during the combustion process. The weight of each function is calculated by the empirical factor $\beta$ :

$$
\beta=1-a \cdot \phi_{e}^{b} \cdot \tau_{i}^{-c}
$$

Where $\mathrm{a}, \mathrm{b}$ and $\mathrm{c}$ are empirical constants, and $\phi_{e}$ is the engine equivalence ratio.

A Weibe-like function is used during the pre-mixed burn phase and a standard Weibe function is used during the diffusion burn phase

$$
\begin{aligned}
& x_{D}=1-\exp \left(-A \Omega^{B}\right) \\
& x_{P}=1-\left(1-\Omega^{n}\right)^{5000}
\end{aligned}
$$

Where $A, B$ and $n$ are shape factors, as described in [31].

$$
\Omega=\left(\theta-\theta_{I}\right) / \theta_{D U R}
$$


$\Omega$ is the nondimensional crank angle, and $\theta_{1}$ is the crank angle at ignition and $\theta_{\mathrm{DUR}}$ is the burn duration.

With the fraction burnt, $x$, known at any instant, it is possible to approximate the heat release by

$$
Q_{h}=x M_{f} Q_{L H V}
$$

Where $M_{f}$ is the fuel charge $(\mathrm{kg})$ and $Q_{L H V}$ is the lower heating value of the fuel $(\mathrm{kJ} / \mathrm{kg})$.

Now, taking derivatives with respect to the crank angle $\theta$,

$$
\frac{d Q_{h}}{d \theta}=M_{f} Q_{L C V} \frac{d x}{d \theta}
$$

Where,

$$
\frac{d x}{d \theta}=\beta \cdot \frac{d x_{P}}{d \theta}+(1-\beta) \cdot \frac{d x_{D}}{d \theta}
$$

The term $d x / d \theta$ represents the rate of fraction burnt, $d x_{P} / d \theta$ corresponds to premixed combustion phase and $d x_{D} / d \theta$ corresponds to diffusion combustion phase.

Heat transfer to the walls is calculated from equation 16 with the same constant wall temperature as in the LTC model but using the correlation from the experimental work of Woschni [27] determined for a water cooled CIDI engine,

$$
h(t)=\alpha \cdot B^{-0.2} \cdot p(t)^{0.8} \cdot T(t)^{-0.53} \cdot v(t)^{0.8}
$$

In the original Woschni correlation the cylinder bore $B(\mathrm{~m})$ is the characteristic length $l$, the value of the temperature exponent is -0.53 and $v(t)$ the local average gas velocity is

$$
v(t)=C_{1} \bar{S}_{p}+C_{2} \frac{V_{d} T_{r}}{p_{r} V_{r}}\left(p-p_{m o t}\right)
$$

With different values of constants $C_{1}$ and $C_{2}$ for compression and combustion-expansion period. 
Now, with the pressure and temperature data from each combustion model and with the basic kinematics data from equations 1 and 2, the friction model can be solved for any geometric configuration.

The geometric parameters used in both models were based on a typical Cummins B-series 5.9 liter engine. Table 1 presents the main parameters.

\subsubsection{Friction Model}

A friction model developed by Bryzik et al. [32] was implemented to determine the total energy lost due to friction. This model was added to hypothetical engines employing the diesel and LTC combustion models to determine frictional losses for both cases and compare them, along with the cooling burden, between LTC and diesel operation.

The friction model, based on reference [32], predicts losses for four main components: engine bearings (crank and connecting rod), piston-ring assembly (two compression rings, one oil ring, and piston skirt), valve train, and engine auxiliaries. For the purpose of determining heat loss, the valve train portion of the friction model was not calculated since it is the smallest contributor to total friction in the model and the engine parameters required for the sub-model would prove difficult to define accurately for preliminary modeling. Instead, a finite 7\% [32] of the total friction was attributed to valve train losses.

\subsubsection{Piston-Ring Assembly}

Following [32], the piston-ring assembly model used a duty parameter approach, which was dependant on the piston velocity, normal force acting on the ring, and a length parameter. The following equation was used to determine the duty parameter, $S$. Where $\mu_{o i l}$ is the oil viscosity (kPa-s), $V_{p}$ is the instantaneous piston speed $(\mathrm{m} / \mathrm{s}), F_{N}$ is the ring normal force $(\mathrm{kN})$, and $L$ is the ring length parameter $(\mathrm{m})$.

$$
S=\frac{\mu_{o i l} \cdot\left|V_{p}\right|}{F_{N} / L}
$$

In the duty parameter equation, the normal force and length parameter of each ring were determined using the following relationships, which implemented ring geometry $\left(a_{1}, a_{2}, b\right)(m)$, diametric tensions of the rings $\left(T_{1}, T_{2}, T_{3}\right)(\mathrm{kN})$, cylinder geometry $(D, h)(\mathrm{m})$, and in-cylinder pressure $\left(p_{c y l}\right)(\mathrm{kPa})$. The top ring normal force includes a term involving the in-cylinder pressure, making it large for the case of a fired engine. 
- Compression ring 1: $\begin{aligned} & F_{N 1}=2 T_{1}+\pi D h p_{c y l} \\ & L_{1}=0.25 a_{1}\end{aligned}$

$F_{N 2}=2 T_{2}$

- Compression ring 2: $L_{2}=0.75 a_{2}$ (upstroke)

$L_{2}=a_{2}($ downstroke $)$

$\begin{array}{ll}-\quad & F_{N 3}=2 T_{3} \\ & L=2 b\end{array}$

The duty parameter then determined if the friction was acting in a purely hydrodynamic manner or if it is in a mixed lubrication regime [32]. By comparing the duty parameter, $S$ (dimensionless), to a critical duty parameter value, the type of lubrication is determined. If the $S$ value is greater than 1.1E-4, the lubrication is hydrodynamic, and the following logarithmic correlation is used to determine the friction factor, $f$ [32].

$$
f=C \times S^{m}
$$

If the $S$ value is less than $1.10 \mathrm{E}-4$, mixed lubrication is assumed and equation 34 is used to determine the friction factor [32]. Here the dry friction coefficient, $f_{o}$, is assumed to be 0.28 for cast iron on cast iron, based on data presented by Taraza, et al [32]. The critical friction coefficient, $F_{c r}$ is approximately 0.0225 [32].

$$
f=f_{0}\left(1-S / S_{c r}\right)+f_{c r}\left(S / S_{c r}\right)
$$

The ring geometries and diametral elastic tensions required for the model were approximated using a sample diesel engine compression ring.

The final component of the piston-ring assembly friction is the friction force of the skirt $(k N)$, which was determined directly using equation 35 . Where, $L_{s}$ is the skirt length $(\mathrm{m}), V_{p}$ is the instantaneous piston speed $(\mathrm{m} / \mathrm{s})$, and the normal force, $F_{N}(\mathrm{kN})$, is the piston thrust force determined from engine geometry and total piston force.

$$
F_{f_{s}}=2.5 \sqrt{L_{s} \eta_{o i l}\left|V_{p}\right| F_{N}}
$$




\subsubsection{Crank and Connecting Rod Bearings}

The bearings accounted for nearly as much of the total friction as the piston-ring assembly. The bearing geometries were found using online Cummins engine manuals and good engineering judgment was used for additional parameters not provided by Cummins. The bearings were assumed to be the same size for both the LTC and CIDI diesel engines. A constantly loaded bearing was assumed, simplifying the friction force equation to the short bearing theory [32]. The friction force acting at the bearing surface was determined by the following equation.

$$
F_{f}=\frac{2 \pi \eta_{o i l} R^{2} \omega L}{c \sqrt{1-\varepsilon^{2}}}+\frac{e W}{2 R} \sin \varphi
$$

Where $R$ was the bearing radius $(\mathrm{m}), \omega$ was engine speed $(\mathrm{rad} / \mathrm{s}), L$ was the bearing length $(\mathrm{m}), c$ was the bearing clearance $(\mathrm{m})$, and $W$ was the resultant force acting on the bearing $(\mathrm{kN})$, determined from a balance of forces and engine geometry.

The remaining two parameters, eccentricity ratio $(\varepsilon)$ and attitude angle $(\varphi)$ (rad) were determined by solving the following two equations. First, eccentricity ratio was determined by iteratively solving equation 37 using the Newton-Raphson method.

$$
\frac{W / L}{R \omega \eta_{\text {oil }}}\left(\frac{c}{R}\right)^{2}\left(\frac{2 R}{L}\right)^{2}=\frac{\pi \varepsilon}{\left(1-\varepsilon^{2}\right)^{2}} \sqrt{0.62 \varepsilon^{2}+1}
$$

Then the attitude angle was found directly using the eccentricity ratio determined above and the following equation.

$$
\varphi=\tan ^{-1}\left(\frac{\pi \sqrt{1-\varepsilon^{2}}}{4 \varepsilon}\right)
$$

The friction force of each bearing was translated to torque by multiplying it by the bearing radius as proposed by the bearing friction model. The connecting rod and crank bearing torque values were summed and then translated to power by multiplying by engine speed.

\subsubsection{Auxiliaries}

The model for losses associated with engine auxiliaries includes fuel injection, fuel circulation, oil pump, and coolant pump. These auxiliaries are commonly considered part of engine friction since they are essential to the engine operation. The engine auxiliary model is another section of the model that requires very specific engine parameters, so good engineering judgment and 
credible values were used to develop the model. In addition, because the engine is modeled at steady-state, the accessory load is mostly constant, other than for the period of fuel injection.

The torque required for fuel circulation was determined using the following equation.

$$
T_{\text {fuel }}=\frac{\pi d^{2}}{4} S \frac{N_{c y l}}{2} \frac{P}{\eta_{\text {fuel }}}
$$

Where $d$ is the injector diameter $(\mathrm{m}), s$ is the injector stroke $(\mathrm{m}), N_{c y l}$ is the number of cylinders, $P$ is the fuel pressure on the low side $(\mathrm{kPa})$ and $\eta_{\text {fuel }}$ is the volumetric efficiency of the fuel pump, assumed to be 0.85 .

The torque required for fuel injection was determined using the following equation set (62).

$$
\begin{aligned}
& \left|T_{i n j}\right|=\frac{360}{\Delta \theta} Q_{i n j} \frac{p_{i n j}}{\eta_{i n j}} \\
& T_{i n j}=\left|T_{i n j}\right| \sin \left(\frac{360}{\Delta \theta} \cdot \theta\right)
\end{aligned}
$$

Where $Q_{i n j}$ is the amount of fuel injected $(\mathrm{kg}), \Delta \theta$ is the injection duration ( $\left.\mathrm{rad}\right), p_{i n j}$ is the injection pressure $(\mathrm{kPa}), \theta$ is the instantaneous crank angle (rad), and $\eta_{i n j}$ is the volumetric efficiency of the injector. Injection torque is only calculated when the instantaneous crank angle falls within the period of injection.

The torque required by the oil pump was determined next. The typical oil flow rate $\left(Q_{o i l}\right)\left(\mathrm{m}^{3} / \mathrm{s}\right)$ of a 5.9L Cummins B-Series engine was estimated for Dodge Ram truck. Then the torque required by the oil pump was determined in $\mathrm{kN}$, directly using equation 41 .

$$
T_{o p}=\frac{\dot{Q}_{o i l} p_{o i l}}{\omega}
$$

Where $p_{\text {oil }}$ is the typical oil pressure $(\mathrm{kPa})$ and $\omega$ is the engine speed $(\mathrm{rad} / \mathrm{s})$. This equation assumes the ratio between the volumetric efficiency of the oil pump and the mechanical efficiency of the oil pump to be equal to 1.0, as proposed by Bryzik, et al. [32].

The final auxiliary component was the cooling system. The following equation is used to determine the torque required by the cooling system. Here, $\omega_{\max }$ and $P_{\max }$ are the maximum rated engine speed (rad/s) and power (kW). 


$$
T_{\text {cool }}=P_{\max } \frac{\omega^{2}}{\omega_{\max }^{3}}
$$

The torque values for each auxiliary component are summed and then converted to power by multiplying by engine speed.

\subsubsection{Cooling Burden Model}

As indicated in previous sections, proper heat transfer models were adapted from the literature on heat transfer to the cylinder walls specifically for LTC [26] and CIDI engines [27]. In addition, the energy losses associated with piston-ring assembly friction and the energy losses due to auxiliary mechanisms were calculated for each type of engine. The fraction of energy that is transformed in heat from the auxiliary mechanisms was determined by the mechanical efficiency of each mechanism, however in this model the only mechanical contributors to the cooling load were the piston-ring assembly friction losses and the bearing losses. The last element to complete the cooling burden evaluation was the energy consumed by the cooling (radiator) fan. It was the last element because the fan load model required the total amount of heat loss to be removed, or cooling burden, as an input. The output, the energy consumed by the fan, was added in a closed loop to the total cooling burden, completing the energy balance.

\subsubsection{Fan Load}

The power consumed by a fan in order to force a fluid from a stagnation state, $V_{1}=0$, and $P_{1}=P_{0}$ to certain velocity $V$ and pressure $P_{2}$ can be calculated as:

$$
\dot{W}_{\text {fan }}=A \cdot \rho_{\text {air }} \cdot V \cdot \Delta P
$$

Where $A$ is the frontal area, $\rho_{\text {air }}$ is the air density at certain temperature $\left(\mathrm{kg} / \mathrm{m}^{3}\right), V$ is the air velocity $(\mathrm{m} / \mathrm{s})$ and $\Delta P$ is the pressure drop along the fluid field $(\mathrm{kPa})$.

In the case of an automotive radiator, the value of $\Delta P$ corresponds to the pressure drop across the radiator matrix and depends on matrix geometry, velocity of the air and the density evaluated at the bulk temperature across the radiator. From fluid mechanics, the value of $\Delta P$ can be expressed as:

$$
\Delta P=f \frac{l}{4 R h} \rho \frac{V^{2}}{2}
$$


Where $f$ is the friction factor, which is function of Reynolds number $(\boldsymbol{R} \boldsymbol{e})$ and the surface roughness, $l$ is the length in the flow direction and $R h$ is the hydraulic radius which is a geometric property of the matrix.

The velocity of the air is function of the amount of heat that should be transferred from the water cooling system. According to Fraas and Ozisik [33] in order to minimize the radiator size it is desirable to operate the coolant system at as high temperature as possible to achieve the maximum temperature difference between the coolant and the air. The suggested temperature range, avoiding boiling and evaporation of the coolant, is $350 \mathrm{~K}$ to $360 \mathrm{~K}$. From equations 43 and 44 , it can be inferred that the density of air plays an important role in determining fan power consumption, which is assessed in the model results section.

The literature available on radiator design offers a limited number of matrix configurations to calculate the convective heat transfer coefficient $h$ and the friction factor $f$. In this model, the radiator matrix configuration corresponding to the surface 11.36-0737-S from reference [34] was selected as a typical configuration, similar to the radiator of a Dodge Ram (with a 5.9L Cummins ISB engine) (36" x 20" x 21/4") with 14 fins/inch.

In real use, average fan loads are difficult to predict, because they are highly dependent on ambient conditions. As a result, differences in fan loads represent fuel economy differences that vary by region and season.

\subsection{Model Analysis and Results}

The LTC model was first run as a stand-alone module to demonstrate the effects of varying parameters such as equivalence ratio, intake temperature, EGR and boost. Then the LTC and diesel $\mathrm{Cl}$ combustion models were joined with the friction and cooling models to compare LTC and diesel $\mathrm{Cl}$ combustion for several operating conditions (summarized in Table 1). Model verification for the LTC model was also accomplished.

\subsubsection{LTC Model Results: Combustion and Heat Transfer Trends}

The zero-dimensional LTC model was run at constant engine speed under different conditions of intake temperature, equivalence ratio and EGR. The compression ratio was kept constant and the manifold pressure was set to $95 \mathrm{kPa}$ for all cases.

In order to demonstrate the effect of intake temperature on the model, the inlet manifold temperature was varied between $360 \mathrm{~K}$ and $380 \mathrm{~K}$, and the effect on ignition onset was studied. 
Temperatures lower than $360 \mathrm{~K}$ delayed the onset of combustion, generating pressure trends without physical meaning. As shown in Figure 2, when the intake temperature was increased, it advanced the onset of ignition due to increased reaction rates, which are strongly dependant on temperature. It should be noted that increasing intake temperature reduces volumetric efficiency and the advance of ignition timing affects the mechanical efficiency due to the negative work on the compression stroke. The temperature range needed to keep the combustion ignition at the desired crank angle is narrow.

Figure 3 shows the pressure curves at three different equivalence ratios. All plots share the same intake temperature, $375 \mathrm{~K}$, and have no EGR. The initial charge of the air/fuel mixture determines the first part of the temperature history due to the specific heat of the in-cylinder mix. At low equivalence ratios, the specific heat of the mixture is lower and hence the temperature is higher at every point before ignition. The ignition timing on LTC is governed by the temperature, and this temperature was high enough for low equivalence ratios to advance the ignition timing of the mix in the simplified one-dimensional model. In order to keep control on the ignition timing at different equivalence ratios it is required to increase the intake temperature along with the increase in amount of fuel in the mixture.

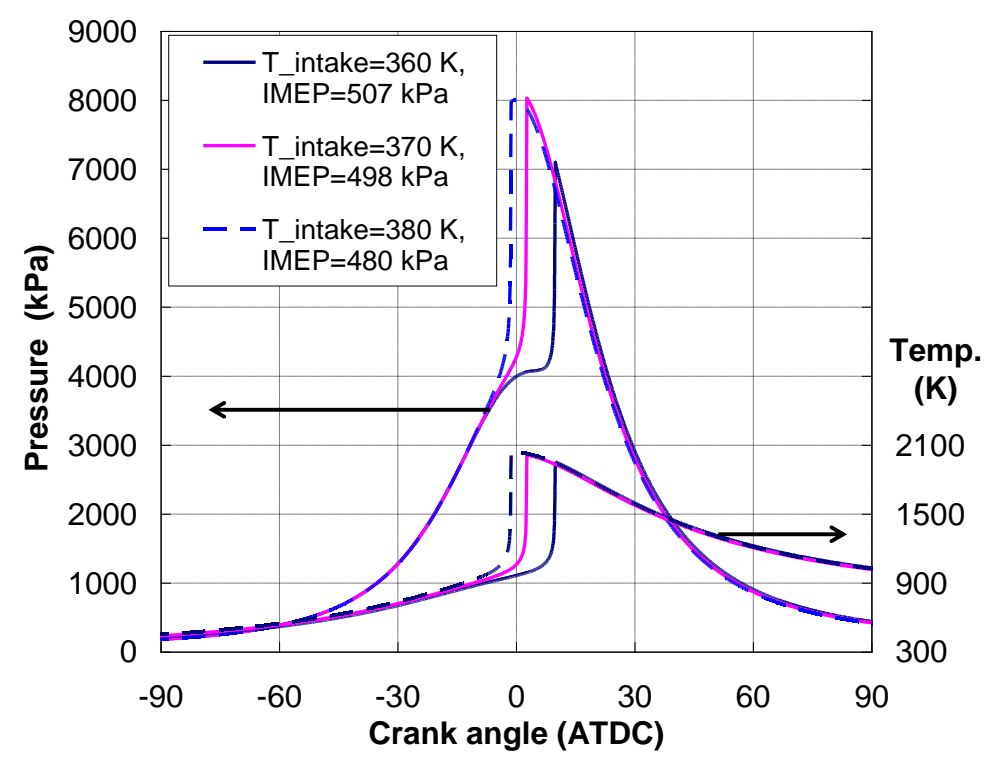

Figure 2: LTC Model Results of In-Cylinder Pressure and Temperature Variations at Different Intake Temperatures 


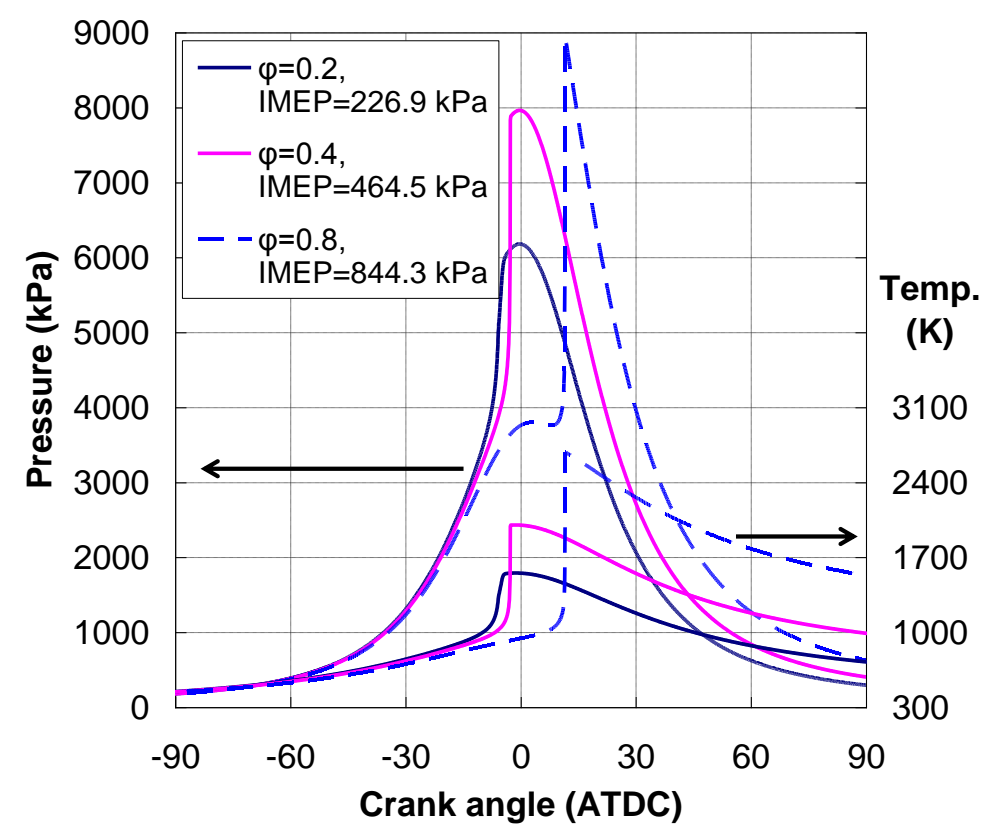

Figure 3: LTC Model Results of In-Cylinder Pressure and Temperature Variations at Different Equivalence Ratios for a Fixed Intake Temperature

The effects of EGR on the model for LTC operation are presented in Figure 4 at the same equivalence ratio $(\phi=0.5)$. The values of EGR were varied according within percentage limits reported in the literature for LTC, which are in the range of 0 to $30 \%$ for LTC utilizing diesel-like fuels [7]. In order to isolate the effects of the EGR percentage on the pressure and temperature histories, the value of the intake temperature was held constant at $360 \mathrm{~K}$, for the air/fuel mixture and the introduced amount of EGR.

The effect of EGR on ignition timing and the impact on IMEP was evident and has been suggested or used by several researchers as a tool to achieve the desired cycle-by-cycle control. This is accomplished by changing the composition of the charge, whether by hot residual EGR using variable valve strategies, or by external cooled EGR. The plot shows that in order to keep the ignition timing at a specific crank angle, which is desired in terms of thermal efficiency, the combined effect of the intake temperature and the amount of EGR should be evaluated. Higher levels of EGR reduced the peak temperature and pressure values and retarded the combustion event. This retarding effect could be counteracted with higher EGR temperature.

The effects of boost on pressure, temperature and heat release histories were studied in the LTC model. Intake temperatures were varied in order to achieve the same ignition timing for each case. Figure 5 shows the results obtained at different manifold pressures. The amount of fuel 
used in each case was kept at $26.4 \mathrm{mg}$ fuel per cycle. The value of equivalence ratio varied in inverse proportion to the boost according to the amount of air that is fed into the cylinder. The calculated values of IMEP for each case were: $556.2 \mathrm{kPa}$ without boost ( $P$ _intake=95 kPa), 579.5 $\mathrm{kPa}$ at intake pressure of $142.5 \mathrm{kPa}$ and $635.7 \mathrm{kPa}$ at intake pressure of $190 \mathrm{kPa}$. Consequently, thermodynamic efficiency values increased from 0.469 without boost to 0.532 at $190 \mathrm{kPa}$ (approximately $1 \mathrm{~atm}$ boost).

The heat transfer model for the LTC engine was evaluated at different equivalence ratios and at the same intake temperature, $T_{\text {intake }}=375 \mathrm{~K}$, and amount of $E G R(E G R=10 \%)$. The amount of fuel per cycle for each case was $11.04 \mathrm{mg}, 21.98 \mathrm{mg}$ and $40.68 \mathrm{mg}$ of $\mathrm{n}$-heptane. The model shows good agreement with values reported in the paper published by Chang et al. [26]. The temperature of the walls was kept constant at $400 \mathrm{~K}$ throughout the runs. This value was obtained by averaging the coolant temperature at different load conditions, from heat release data recorded by West Virginia University (WVU) researchers at the WVU Engine Research Center $(E R C)$. This value is in agreement with those reported in the literature on LTC heat release. Figure 6 shows the instantaneous value of heat transfer to walls and Figure 7 shows the values obtained for cumulative heat transferred to the walls at the three different equivalence ratio cases. These figures are related to the results of Figure 3, for different equivalence ratios. The heat transfer during the compression stroke was higher at lower equivalence ratios because of the differences in specific heat capacities of each mixture, which generate higher compression temperatures, as was explained in previous sections.

Although the cumulative heat transfer cases

for $\phi=0.2$ and $\phi=0.4$ yield higher values of energy losses before TDC, the final value at the end of the simulation (EVO), is higher for $\phi=0.8$ as is expected from a higher energy input. The cumulative heat transfer to the walls shows a strong inflection point that is not found in published data. This sharp inflection point is a consequence of the fast heat release observed in the twostep combustion model.

The influence of boost on heat release trends is shown in Figure 8. Although peak temperature and the general trend of temperature values are lower in the case without boost (Fig. 4 ), the calculated heat transfer is higher in the case with the highest boost and lowest temperature trend. This result is due to the dependence of the averaged heat transfer coefficient on the pressure term in eq. 17. 


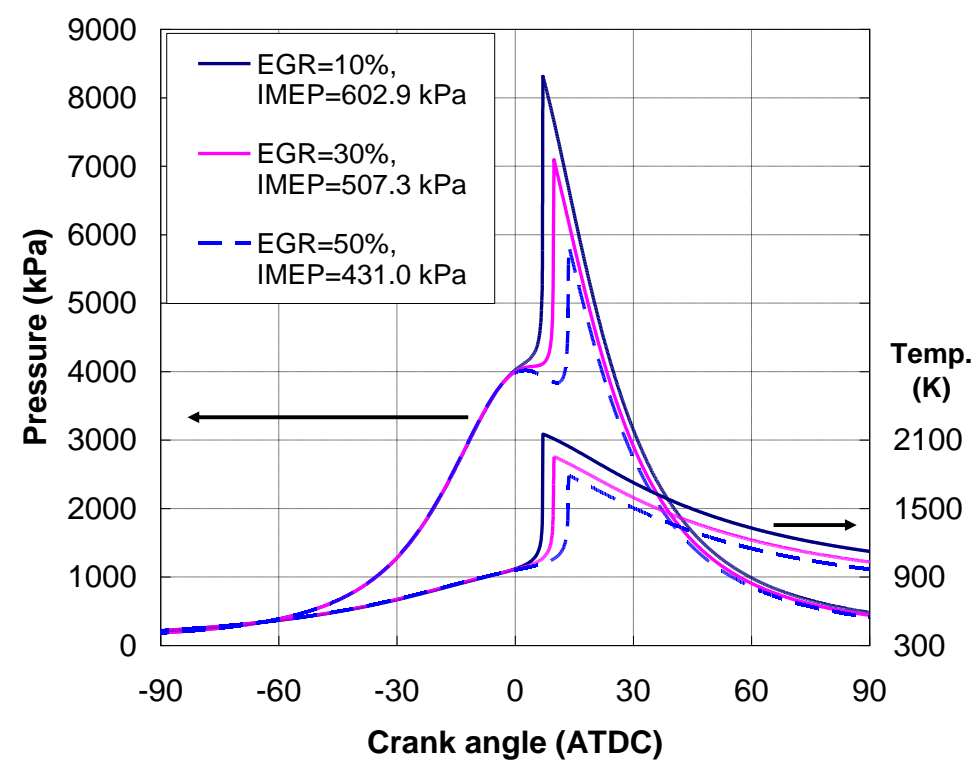

Figure 4: Influence of EGR on In-Cylinder Pressure and Temperature Histories

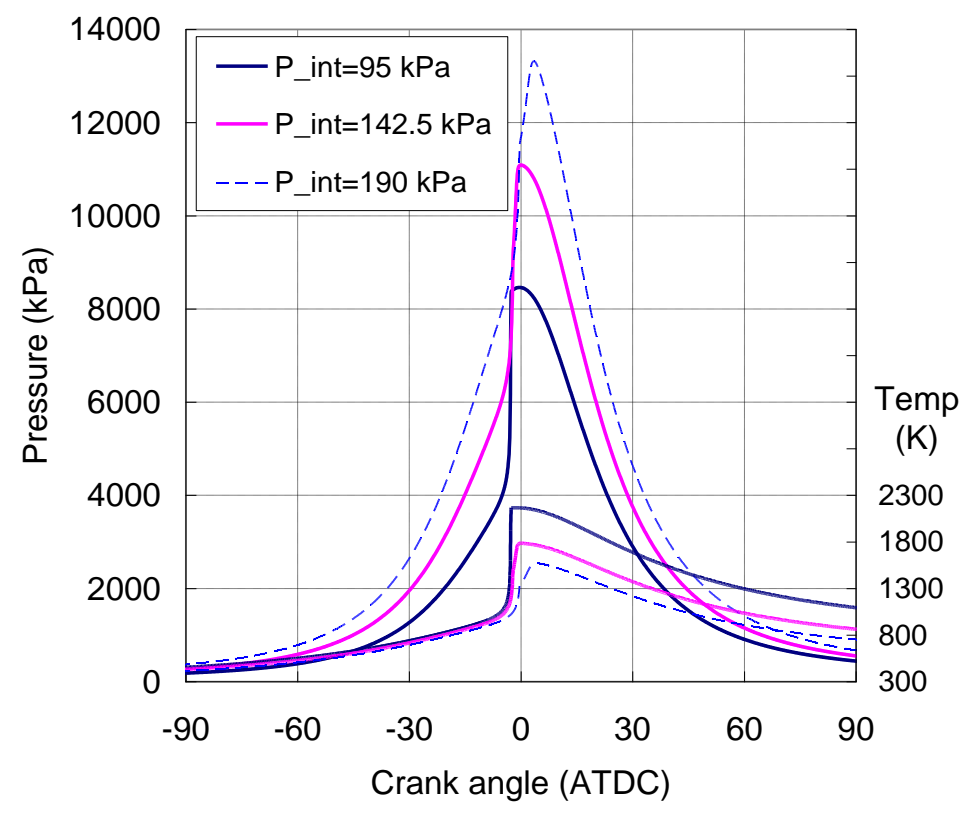

Figure 5: Influence of boost on In-Cylinder Pressure and Temperature Histories. The pressure values correspond to intake manifold pressures. 


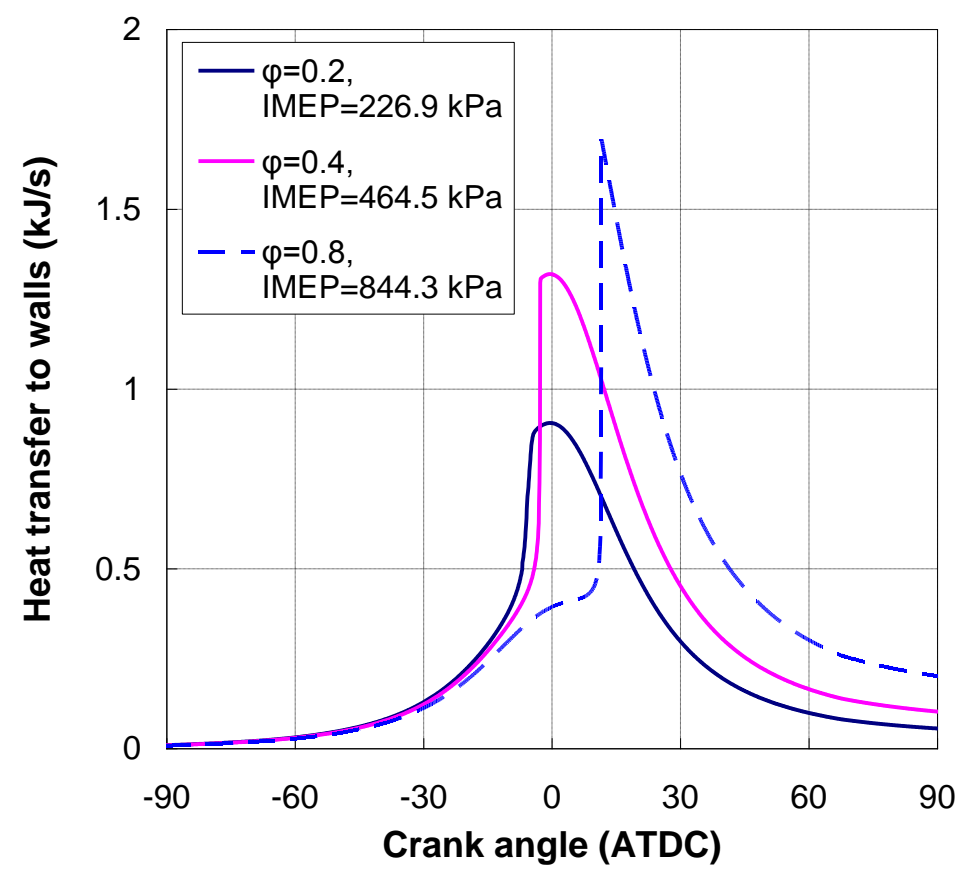

Figure 6: LTC Heat Transfer to Walls

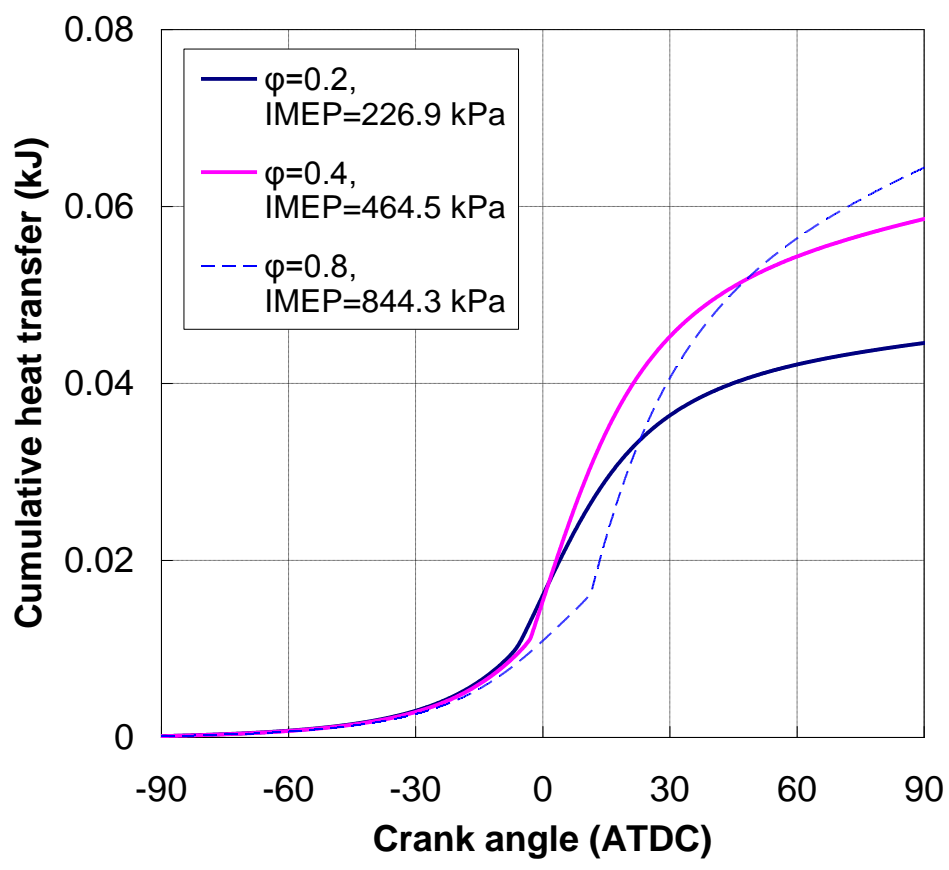

Figure 7: LTC Cumulative Heat Transfer to Walls 


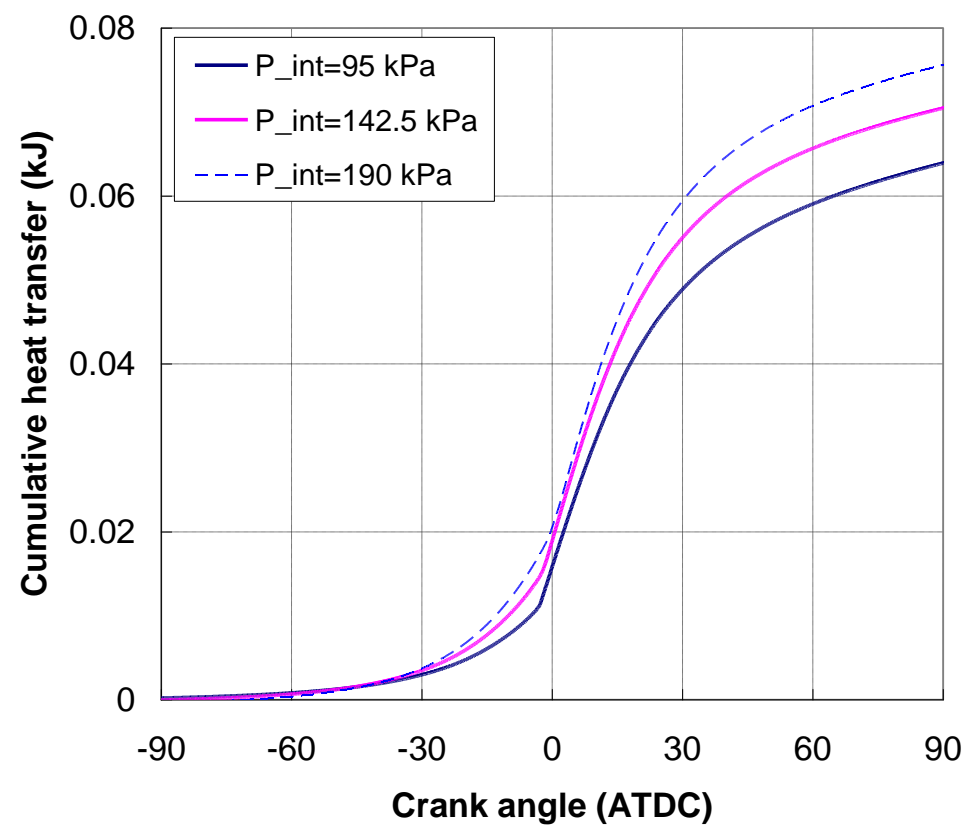

Figure 8: Influence of boost on heat transfer to walls. The amount of fuel is the same in each case: $\mathbf{2 6 . 4} \mathbf{~ m g}$ fuel per cycle.

\subsubsection{MZ Model Temperature Stratification and Mass Exchange}

Figure 9 shows the temperature (a) and mass distribution (b) considering a cylinder divided in six zones. An average calculated in-cylinder bulk temperature is also presented. Before the NTC zone, the temperature of each zone is very similar, about $5-8 \mathrm{~K}$ difference between zones 1-4 depending on load conditions. At higher load the difference is higher. The behaviors of zones 5 and 6, the boundary layer $(\mathrm{BL})$ zone and crevices zone, are different. The calculated temperature history of the BL zone was $40-50 \mathrm{~K}$ below the core temperature (zone 1) due to convective heat transfer to the walls. This difference between zone behavior is reduced at lower loads. Wall temperature was kept at $400 \mathrm{~K}$ for all the cases studied in this research work.

The definition of the MZ model specified that the crevices were kept at wall temperature along the whole process. The implications of having a zone that does not ignite gives the MZ model the ability to predict $\mathrm{CO}, \mathrm{HC}$ and unburned fuel better than a SZ model. The LTHR stage starts at about the same temperature in each zone, with earlier combustion in core zones and later combustion in the BL zone. Once the LTHR starts, the temperature difference between zones increases. The temperature stratification during the LTHR stage is extended along the HTHR stage, allowing for longer combustion duration. The sequential heat release is responsible for this 
extended combustion duration, which is a significant benefit of $M Z$ models. It should be noted that by increasing the number of zones the heat release sequence would be smoother, resembling the experimental one.

Peak temperatures reached by each zone varied significantly and were highly dependent on load (AF). Difference between core and $\mathrm{BL}$ zones varied from $170 \mathrm{~K}$, at $\mathrm{AF}=43$, up to $600 \mathrm{~K}$ at $A F=55$. In the later case the $B L$ zone was close to misfire. During the expansion process the temperature stratification accentuates, with differences between core and $B L$ zone varying from $400 \mathrm{~K}$ up to $600 \mathrm{~K}$. For a given number of zones, the thermal stratification during the compression and combustion stages is dominated by the initial temperature at IVC, chemical kinetics and the mass exchange between zones; the stratification during expansion is dominated by heat transfer between zones and by the convective heat transfer at the $B L$ zone.

Chemical kinetics is defined with the SZ model, which provides consistence with CA10 and CA50 values in all cases previously tested and explained. The mass exchange is required for the model to adjust pressure and is not suited to empirical adjustments. The convective heat transfer can be adjusted during the MZ model tuning but was left constant in all cases. The temperature at IVC and the heat transfer between zones are the only parameters that cannot be fully defined without more sophisticated temperature-sensing tools. Specifying initial temperature at IVC can be circumvented by forcing a gradient temperature at IVC, based on CFD calculations or available literature. In this model the zone temperature distribution at IVC was based on CFD based calculations performed by Aceves et al. [44] while studying modeling of $\mathrm{HCCl}$ combustion of methane. 

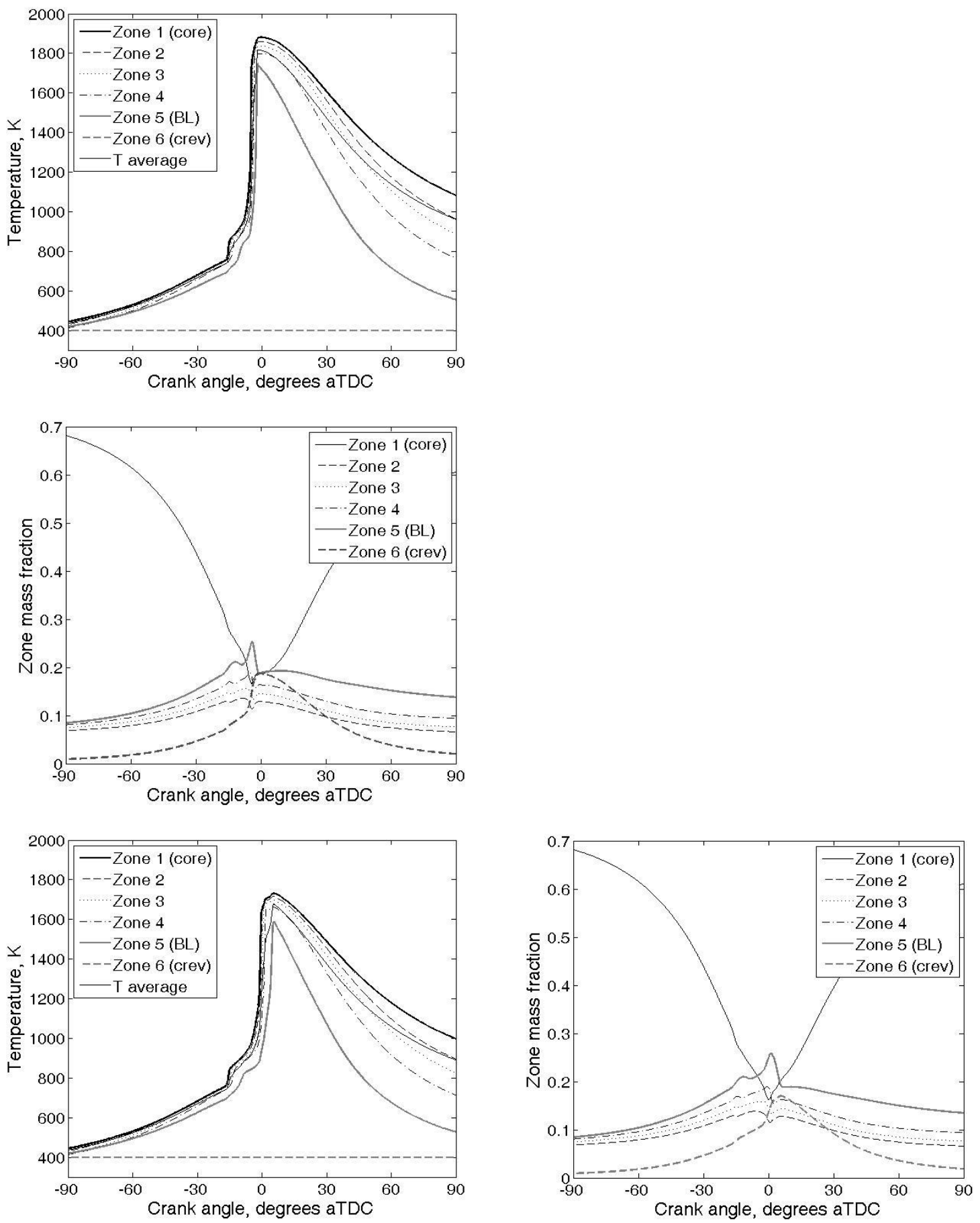


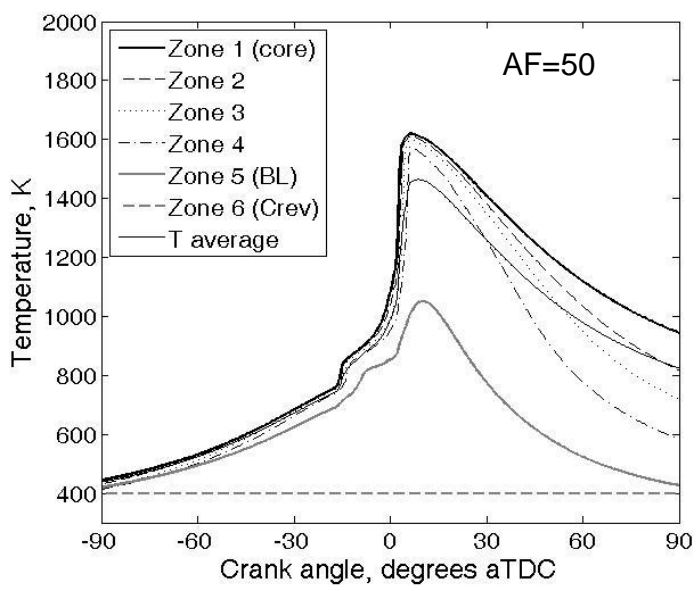

$\mathrm{AF}=50$

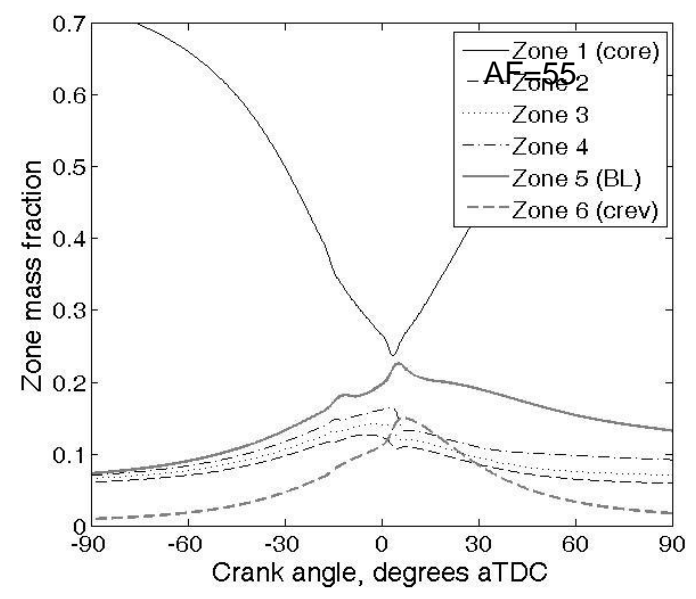

$\mathrm{AF}=55$

Figure 9. Calculated temperature and zone mass (as fraction of total mass) for three different $A / F$ values, $A F=43, A F=50$ and $A F=55 . P_{\text {int }}=95 \mathrm{kPa}, T_{\text {int }}=310 \mathrm{~K}, C R=10, P_{\text {exh }}=104$ $\mathrm{kPa}, 900 \mathrm{rpm}$.

The heat transfer between zones was studied during the model development. It was noted that changes in order of magnitude of thermal conductivity, $k$, did not affect the compressioncombustion part, but they changed the temperature history of the expansion stroke. Although the difference was significant between zones, the average value was very similar and its effect on pressure history was negligible.

The calculated mass distribution for each zone, presented in Figure 9 as zone mass fraction, shows the interaction between adjacent zones. During the compression stroke the core zone reduces its fraction of in-cylinder mass to compensate for a reduction in volume and increase in temperature. During the LTHR and HTHR stages, the mass is quickly exchanged between zones, resulting in a significant mass increase for the crevices. Around TDC the crevice zone contains around $15 \%$ of the total in-cylinder mass. Although it seems excessive, it should be noted that around TDC, zones 1 through 5 have much higher temperature than the crevice (3-4 times more), 
which reduces their density. The calculated mass in the BL zone was the second largest after the core zone, which is due to its low temperature compared to zones 1 through 4 . It should be noted that the exchange of mass between zones also conveys enthalpy, and that affects significantly the temperature history of each zone, because the vtemperature is averaged within each zone.

\subsubsection{Comparisons between Diesel Engine and LTC Engine: Heat Transfer, Friction and Auxiliary Losses}

The authors have argued that the lower power density of LTC might be acceptable, by increasing displacement without altering the engine lower end design. A comparison was considered for an LTC engine that has twice the displacement of the diesel engine, but approximately half of the MEP. In this way, the output of the engines could be similar, and the two engines could employ mechanical components (such as the crankshaft) that would be of similar size, because the connecting rod forces on the two engines would be similar. Therefore the CIDI engine was modeled using a 1 liter displacement per cylinder and the LTC was modeled at double (2 liter) displacement. In one case the LTC engine bore diameter was increased and for the second case the bore/stroke ratio was held equal to one while displacement was doubled. The bore/stroke variation was performed for several equivalence ratios, corresponding to two amounts of fuel and for two cases of manifold intake pressure (or boost). The simulation conditions for each run can be seen in Table 1.

Table 1: Simulation Conditions

\begin{tabular}{|c|c|c|c|c|c|c|c|c|c|c|}
\hline & & \multicolumn{3}{|c|}{ Diesel Cl } & \multicolumn{6}{|c|}{ LTC } \\
\hline $\begin{array}{r}\text { Equivalence } \\
\text { Ratio } \\
\end{array}$ & --- & 0.4 & 0.8 & 0.4 & 0.2 & 0.4 & 0.2 & 0.4 & 0.2 & 0.2 \\
\hline Bore & [m] & 0.102 & 0.102 & 0.102 & 0.1442 & 0.1442 & 0.1358 & 0.1358 & 0.1442 & 0.1358 \\
\hline Stroke & [m] & 0.12 & 0.12 & 0.12 & 0.12 & 0.12 & 0.1358 & 0.1358 & 0.12 & 0.1358 \\
\hline Fuel & [mg] & 21.89 & 43.57 & 43.57 & 21.89 & 43.57 & 21.89 & 43.57 & 43.57 & 43.57 \\
\hline Displacement & {$[\mathrm{L}]$} & 0.98 & 0.98 & 0.98 & 1.96 & 1.96 & 1.96 & 1.96 & 1.96 & 1.96 \\
\hline Boost & [kPa] & 0 & 0 & 95 & 0 & 0 & 0 & 0 & 95 & 95 \\
\hline $\begin{array}{r}\text { Compression } \\
\text { Ratio } \\
\end{array}$ & --- & $16.5: 1$ & $16.5: 1$ & $16.5: 1$ & $16.5: 1$ & $16.5: 1$ & $16.5: 1$ & $16.5: 1$ & $16.5: 1$ & $16.5: 1$ \\
\hline Engine Speed & [RPM] & 1500 & 1500 & 1500 & 1500 & 1500 & 1500 & 1500 & 1500 & 1500 \\
\hline $\begin{array}{r}\text { Intake Valve } \\
\text { Close (ATDC) }\end{array}$ & [deg] & -150 & -150 & -150 & -150 & -150 & -150 & -150 & -150 & -150 \\
\hline $\begin{array}{r}\text { Exhaust Valve } \\
\text { Open (ATDC) }\end{array}$ & [deg] & 120 & 120 & 120 & 120 & 120 & 120 & 120 & 120 & 120 \\
\hline
\end{tabular}

Results from energy losses derived from friction and auxiliaries loads, were summed along with the energy lost by heat transfer to evaluate the total cooling burden for each type of engine. 


\subsubsection{Heat Transfer Losses}

The cumulative heat loss was compared for two different engines, a LTC engine and a CIDI engine, operating with the same amount of fuel consumed per cycle. The $\mathrm{Cl}$ engine was modeled as a naturally aspirated 0.98 liter cylinder, with injection of fuel at 14CA BTDC (Crank Angle before Top Dead Center) and a compression ratio of 16.5. The bore and stroke were $102 \mathrm{~mm}$ and $120 \mathrm{~mm}$ according to the Cummins B Series 5.9 liter specifications. Intake pressure was set to be $95 \mathrm{kPa}$, and the intake manifold temperature was set to be $390 \mathrm{~K}$. The LTC engine was modeled at the same initial conditions of pressure and temperature in order to keep the same initial conditions for the differential equations in both modes. The bore and stroke were varied in two different ways to represent a 2 liter displacement engine. In the first case the face of the piston was doubled and the stroke was kept the same. In a second case the volume was doubled but the aspect ratio of the cylinder was kept the same $(B / S=1)$. Two different load cases were applied: a low load of $21.89 \mathrm{mg}$ of fuel per cycle and a high load of $43.57 \mathrm{mg}$ of fuel per cycle. At $21.89 \mathrm{mg}$ of fuel per cycle and a doubled volume for the LTC engine the equivalence ratio for the LTC and CIDI were 0.2 and 0.4 respectively. At $43.59 \mathrm{mg}$ of fuel the equivalence ratios were 0.4 for the LTC engine and 0.8 for CIDI engine.

Figures 10a and 10b show the cumulative heat loss in both cases. The resultant IMEP values in the low load case (Figure 10a) were $457.0 \mathrm{kPa}$ for the CIDI engine and $262.3 \mathrm{kPa}$ and 259.8 $\mathrm{kPa}$ for each bore/stroke combination for the LTC engine model outputs. In both cases the total amount of energy lost by heat transfer was higher for the CIDI engine, which speaks to the advantage of the LTC engine compared to the CIDI engine. At low load the total amount of heat loss was slightly higher (3.2\%) for the CIDI engine because the larger surface area associated with the LTC engine compensates for the higher heat release produced by the CIDI combustion. This produced higher temperatures during combustion and introduced a radiation heat transfer component. At higher load represented by $43.57 \mathrm{mg}$ of fuel per cycle, the results were more favorable for LTC. The resultant IMEP values in this case were $826.4 \mathrm{kPa}$ for the CIDI engine and 477.0 and $449.9 \mathrm{kPa}$ for each of the bores/stroke combinations for the LTC engines. The amount of heat loss was $41.1 \%$ higher for the CIDI compared to the LTC engine. The amount of heat loss was almost the same in all engines before the start of ignition. After the ignition event, the rate of heat loss was higher for the LTC engine but due to the longer duration of combustion for the $\mathrm{Cl}$ engine, the cumulative heat became markedly higher for the $\mathrm{Cl}$ engine after 20 degrees ATDC (After Top Dead Center). The rate of heat release in the LTC model was larger than the values reported from non-perfectly homogeneous real LTC engines, which indicated that the cumulative heat loss may be consequently lower for LTC engines. 

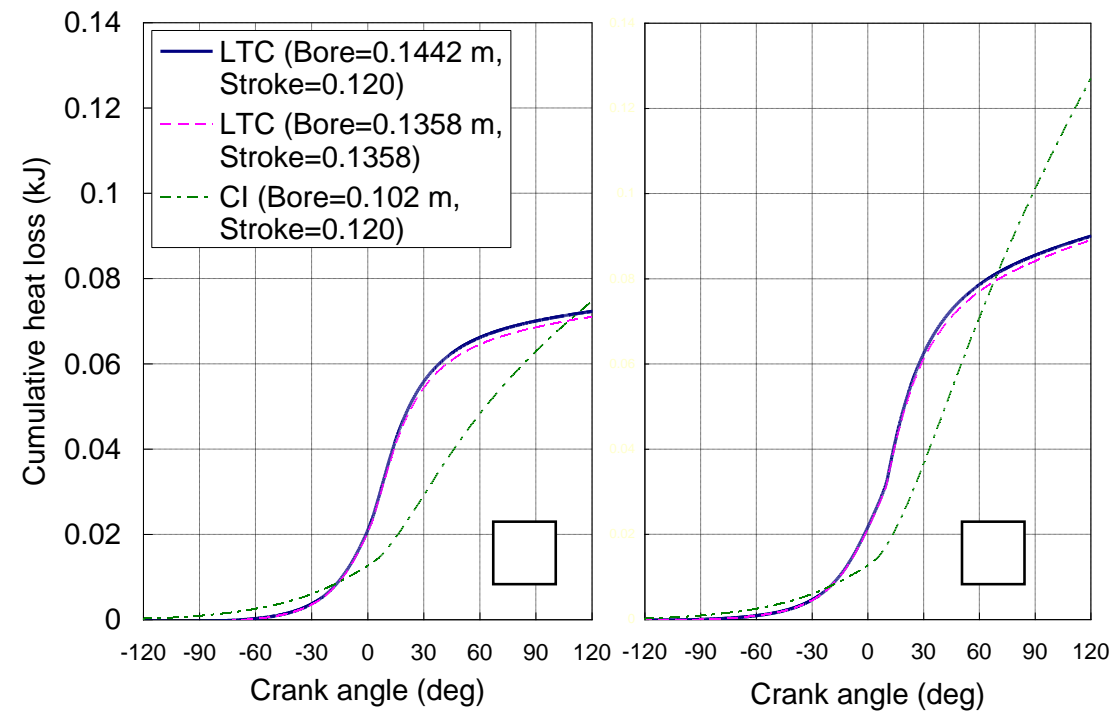

Figure 10: (a) LTC and CIDI Cumulative Heat Transfer to Walls, Low Load Case: 21.89 mg of Fuel per Cycle (b) LTC and CIDI Cumulative Heat Transfer to Walls, High Load Case: $41.79 \mathrm{mg}$ of Fuel per Cycle

The effect of boost on heat transfer was also studied. Figure 11 shows the cumulative heat loss for both engines, the LTC $(B / S=1)$ and the CIDI engine in two different cases: naturally aspirated and with 1 atmosphere boost (190 kpa). The amount of fuel per cycle was kept approximately the same in all cases at $41.57 \mathrm{mg}$ fuel per cycle. The resultant IMEP value in the naturally aspirated case was $448.0 \mathrm{kPa}$ for the LTC engine and $856.3 \mathrm{kPa}$ for the CIDI engine, while in the case with 1 atmosphere boost the values were 503.3 for the LTC engine and 948.1 for the CIDI engine. In the case without boost the total amount of energy lost by heat transfer was higher for the CIDI engine, as was presented in figure 10a and 10b. However, in the case with boost, the heat transferred to walls was higher for the LTC engine than for the CIDI engine. These results should be interpreted carefully. The spatially averaged heat transfer correlations used in both models were adjusted to reproduce results published under different geometries and specific conditions. Changes in geometry and boost were not specifically studied by the authors of those correlations, hence, predicted values without experimental validation are assumed as valid for comparative purposes, but they do not reflex with accuracy the final product of this research project. 


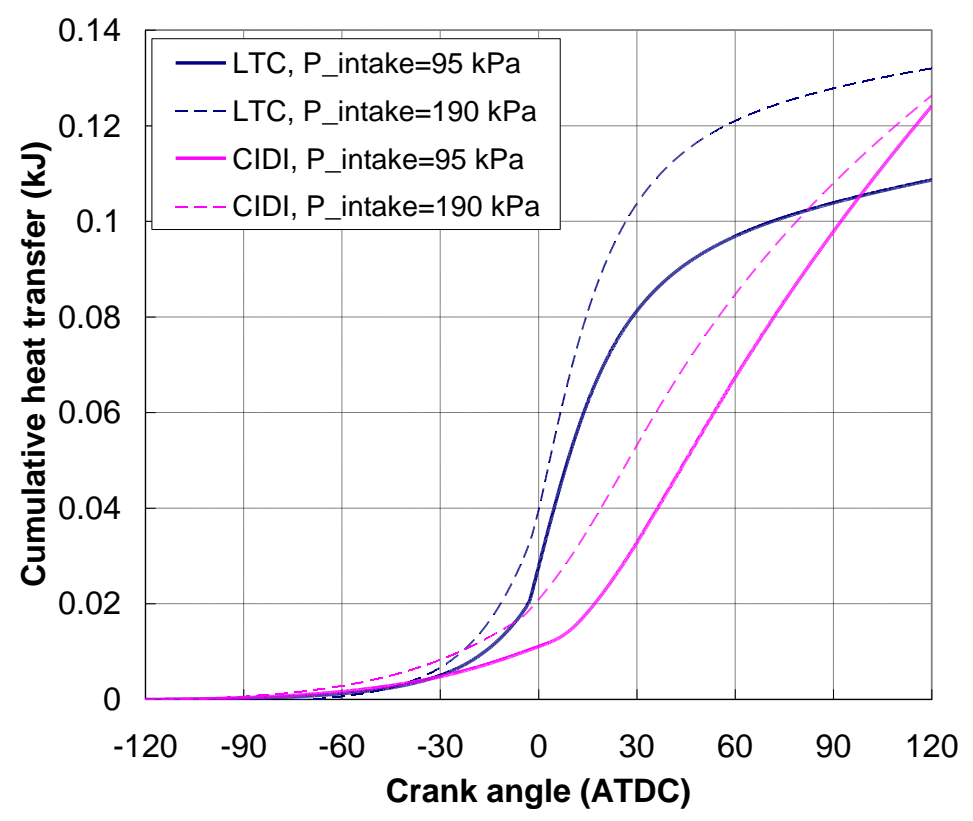

Figure 11: LTC and CIDI Cumulative Heat Transfer to Walls, for naturally aspirated $(95 \mathrm{kPa})$ and with boost (190 kPa). Amount of fuel per cycle: $41.57 \mathrm{mg}$ of Fuel per Cycle

\subsubsection{Friction and Auxiliary Losses}

The friction model produced results showing lower frictional losses for the LTC cases compared to the diesel $\mathrm{Cl}$ cases for a given amount of fuel. The piston-ring assembly in particular was most sensitive to changes in parameters, since the in-cylinder pressure largely determines the frictional losses for the piston-ring assembly section of the model. Figure 11 shows the pistonring assembly friction force for the two LTC and one diesel $\mathrm{Cl}$ bore/stroke combinations. The comparison was performed for a constant $43.57 \mathrm{mg}$ of fuel.

The bearing model showed some differences, but the differences were small compared to that of the piston-ring assembly. The bearing friction losses can be seen in Figure 12, plotted as a function of crank angle for a constant $43.57 \mathrm{mg}$ of fuel. It can be seen that the rapid pressure increase of the LTC cases produces large bearing friction forces for a very short period of time. Despite this, the overall integrated work was lower for both LTC cases.

The auxiliary losses were constant for all diesel Cl and LTC cases since they are only dependant on physical engine parameters, engine speed, and instantaneous crank angle. In reality, if LTC engine heat losses are lower, this might imply that the coolant pump could be reduced in power demand, further emphasizing LTC benefit. Since engine speed was held 
constant, there were no changes. Figure 13 shows the contribution of each friction component (PRA, bearings, valvetrain, auxiliaries) for the two LTC and one diesel $\mathrm{Cl}$ bore/stroke combinations. The results are shown in terms of MEP, defined as total friction or auxiliary work done between the time when the intake valve closes and the exhaust valve opens divided by the total displacement volume of the cylinder.

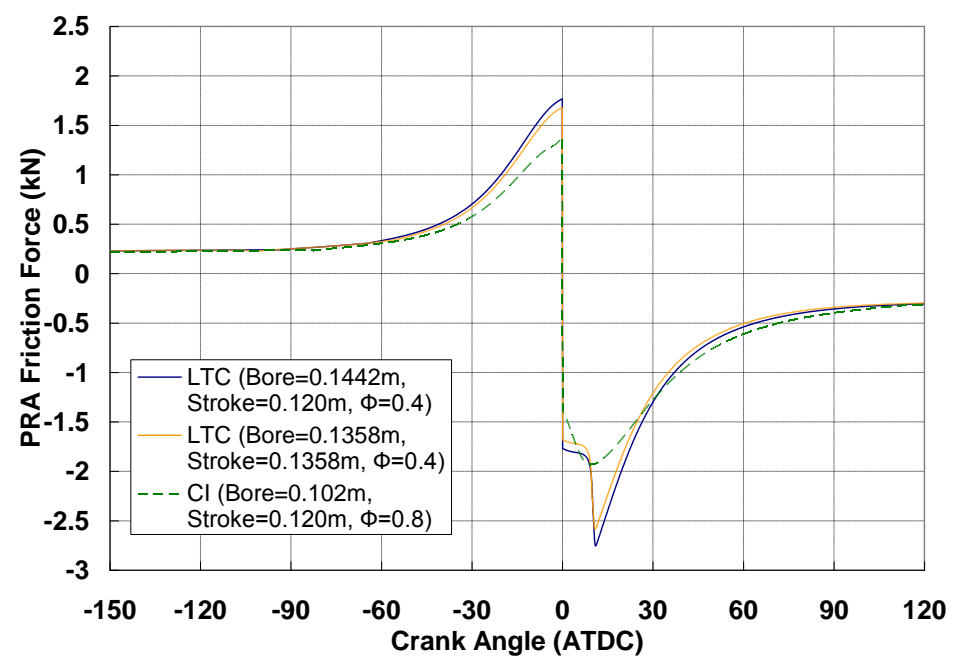

Figure 12: Piston-Ring Assembly Friction Force (43.57 $\mathrm{mg}$ of fuel)

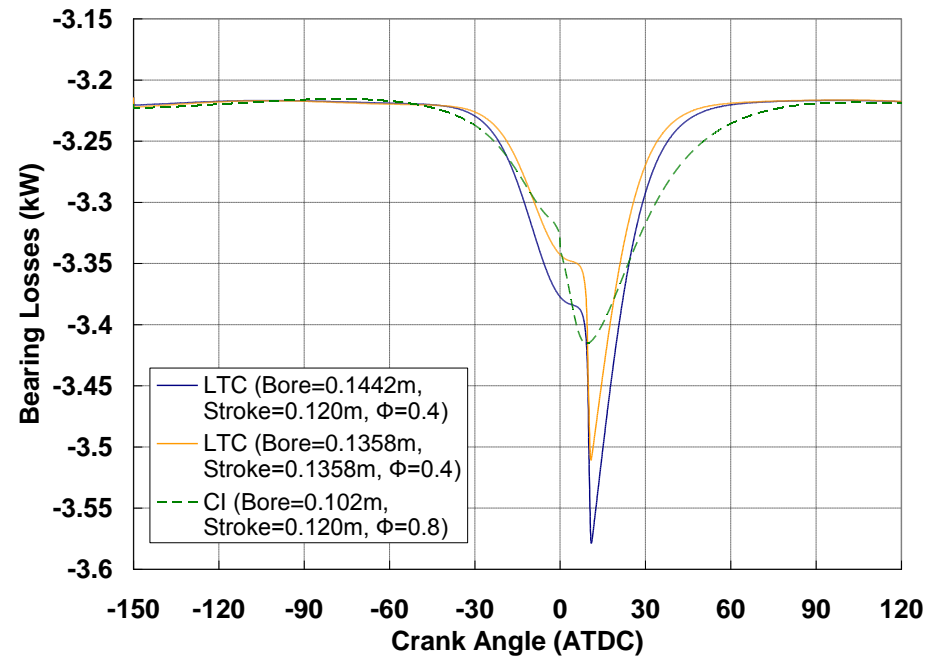

Figure 13: Bearing Friction Losses (43.57 $\mathrm{mg}$ of fuel) 


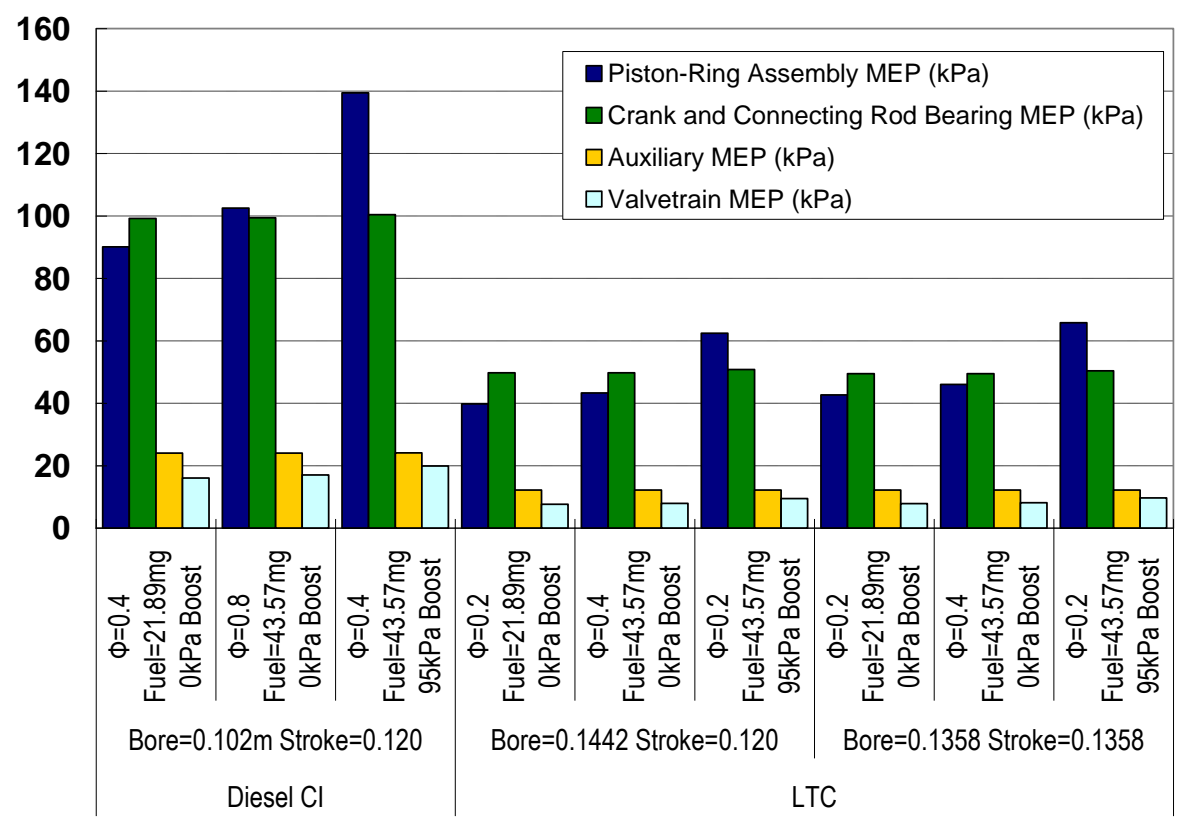

Figure 14: Friction MEP Comparison

In addition, Table 2 (below) shows a complete summary of the friction results in terms of total friction energy lost and mechanical efficiency. By examining the total friction work for a given amount of fuel, it can be seen that the LTC case had lower friction work for both bore/stroke combinations.

\subsubsection{Fan Loss Results}

Using the available radiator geometric information and the temperature limits suggested, a model was developed using Matlab to calculate the power required by the fan to generate the heat transfer desired by the coolant system. Calculated values of power consumed by the fan were based on a one square foot face area. This is a critical value because if larger areas were employed, the velocity would be reduced proportionally and the reduction factor to calculate the new value of power $(\mathrm{kW})$ would be elevated to the $3^{\text {rd }}$ power. The model used the temperature limits established and a velocity of $15 \mathrm{mph}$, which was the minimum velocity that the fan should guarantee to maintain the desired heat transfer without the additional effect of the ram air flow. Figure 15 shows the power consumed per unit area, assuming a fan efficiency of $50 \%$. The effect of the ambient temperature on the power consumed by the fan (per feet square area) is illustrated in this figure. Results obtained from this model were merged with the energy losses from pistonring assembly and bearings and the energy loss from heat transfer to obtain the total cooling burden of each engine. 


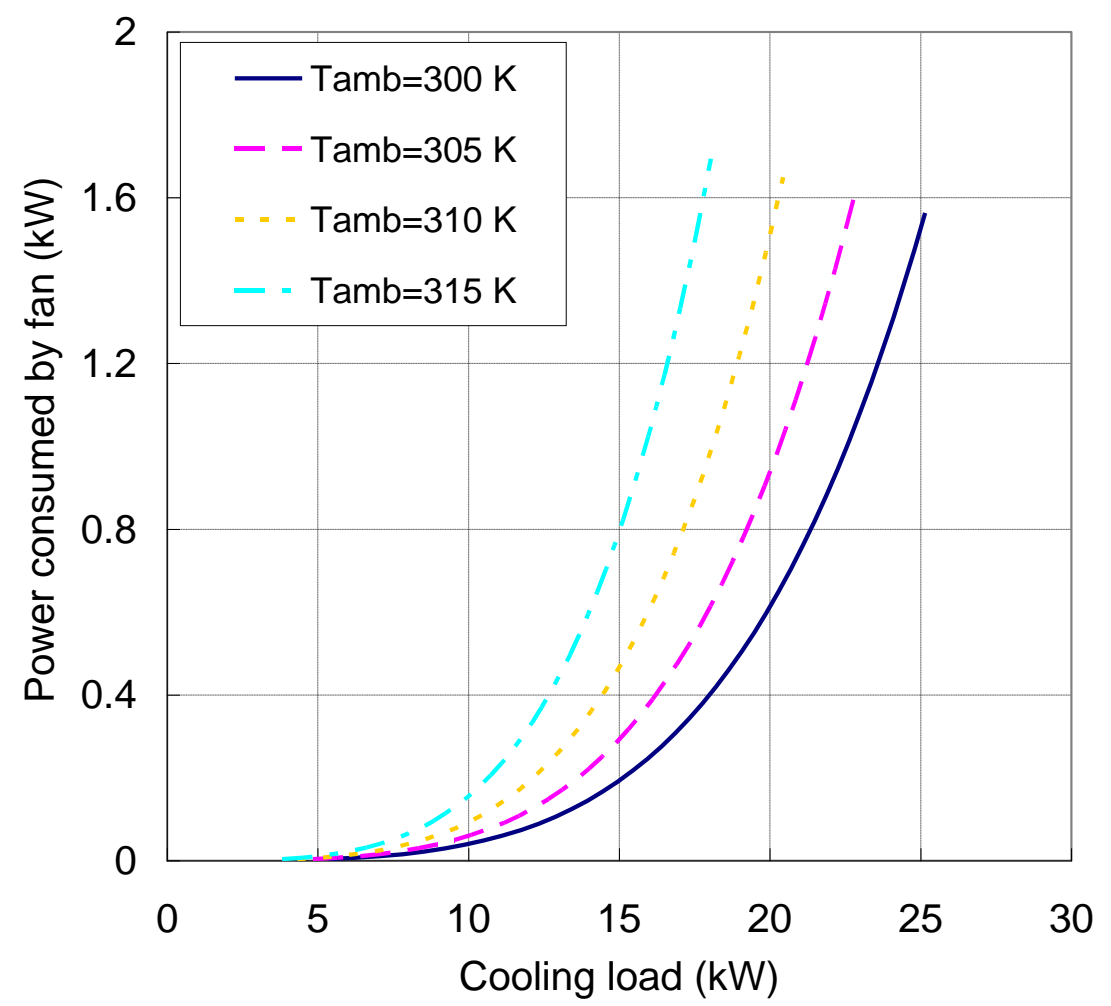

Figure 15: Power Consumed by the Engine Cooling Fan at Different Ambient Temperatures 


\section{Cooling Burden Modeling.(Program Task 1.2)}

The Recipient shall extend modeling and analysis from Task 1.1 to include the shaft work needed for adequate engine cooling. Analysis will include fan and coolant pump losses, as well as the effect of cylinder wall temperature. Data used in the analysis will include non-proprietary data developed by the Recipient, and regional and seasonal temperatures. The impact of substantial exhaust gas cooling (for a variety of EGR strategies) on fan load will also be examined. The conclusions developed under Task 1.1 will be re-evaluated to include the impact of these additional engine loads.

\subsection{Comparisons between Diesel Engine and LTC Engine: Total Cooling Burden}

One of the strategies proposed in this project was to reduce the in-cylinder power density extending the operational range of LTC operation, which is limited by knock phenomena. By increasing the volume of the cylinder, lower IMEP was achieved and the amount of work obtained was found to be similar compared to an engine working with the same amount of fuel in the cylinder. Lower power density generated lower friction losses as is demonstrated in the results summarized in Table 2.

Table 2: Summary of friction losses, heat transfer and work during one cycle for the CIDI and the LTC engine

\begin{tabular}{|c|c|c|c|c|c|c|c|c|c|c|}
\hline & & \multicolumn{3}{|c|}{ CIDI } & \multicolumn{6}{|c|}{ LTC } \\
\hline \multicolumn{11}{|c|}{ Simulation Parameters. 1500rpm } \\
\hline Equivalence Ratio & $\overline{---}$ & 0.4 & 0.8 & 0.4 & 0.2 & 0.4 & 0.2 & 0.2 & 0.4 & 0.2 \\
\hline Bore & $\mathrm{m}$ & 0.102 & 0.102 & 0.102 & 0.144 & 0.144 & 0.144 & 0.136 & 0.136 & 0.136 \\
\hline Stroke & $\mathrm{m}$ & 0.120 & 0.120 & 0.120 & 0.120 & 0.120 & 0.120 & 0.136 & 0.136 & 0.136 \\
\hline Fuel per cycle & $\mathrm{mg}$ & 21.89 & 43.57 & 43.47 & 21.89 & 43.57 & 43.57 & 21.87 & 43.59 & 43.59 \\
\hline Boost & $\mathrm{kPa}$ & 0 & 0 & 95 & 0 & 0 & 95 & 0 & 0 & 95 \\
\hline Displacement & Titer & \multicolumn{3}{|c|}{0.980} & \multicolumn{3}{|c|}{1.96} & \multicolumn{3}{|c|}{1.96} \\
\hline $\begin{array}{r}\text { Friction energy } \\
\text { losses }\end{array}$ & $\mathrm{kJ}$ & 0.225 & 0.238 & 0.278 & 0.214 & 0.222 & 0.264 & 0.220 & 0.228 & 0.271 \\
\hline $\begin{array}{r}\text { Heat transfer to } \\
\text { walls }\end{array}$ & $\mathrm{kJ}$ & 0.074 & 0.124 & 0.126 & 0.072 & 0.090 & 0.132 & 0.071 & 0.089 & 0.130 \\
\hline Fan load & $\mathrm{kJ}$ & 0.0012 & 0.0026 & 0.0040 & 0.0010 & 0.0014 & 0.0035 & 0.0011 & 0.0015 & 0.0037 \\
\hline $\begin{array}{r}\text { Total cooling } \\
\text { burden }\end{array}$ & kJ & 0.300 & 0.365 & 0.408 & 0.287 & 0.313 & 0.400 & 0.292 & 0.318 & 0.405 \\
\hline $\begin{array}{r}\text { Work developed } \\
\text { per cycle }\end{array}$ & $\mathrm{kJ}$ & 0.492 & 0.836 & 0.967 & 0.509 & 0.896 & 1.037 & 0.517 & 0.886 & 1.049 \\
\hline $\begin{array}{l}\text { Mechanical } \\
\text { effieciency }\end{array}$ & --- & 0.541 & 0.712 & 0.708 & 0.577 & 0.751 & 0.742 & 0.571 & 0.741 & 0.738 \\
\hline
\end{tabular}

A comparative evaluation of the fan load shows that although the absolute values were not representative, the relative values were highly favorable for the LTC engine. At light loads the benefit was $14.3 \%$ and at higher loads the benefit was more substantial, reaching $44.23 \%$. The total cooling burden balance values obtained for LTC were approximately the same at lower loads 
compared with the CIDI engine. At higher loads the benefit was more noticeable, with $14.26 \%$ lower cooling burden for the LTC engine compared to the CIDI engine. 


\section{Thermo-Chemical Recuperation. (Program Task 1.3)}

\subsubsection{TCR Test Rig Construction}

The Recipient shall design, fabricate, and construct a TCR test rig to reform ultra-low sulfur diesel fuel to hydrogen-enriched gaseous fuel. The rig will consist of a liquid fuel evaporating system, steam generator, TCR reformer, and afterburner. A cylinder gas fuel train will be constructed to simulate engine exhaust recirculation (EGR) in the TCR lab testing. Heating will be supplied to simulate the thermal energy recovered from engine exhaust waste heat.

\subsubsection{TCR Performance Measurement}

The Recipient shall measure the performance of the TCR reformer. The major operating parameters will include, but are not limited to steam to liquid fuel ratio, TCR reformer exhaust gas temperature, reformer fuel side pressure, and EGR ratio (for EGR reforming only). HYSYS modeling of the TCR reformer will also be performed in conjunction with the laboratory experiment. The laboratory results will include conversion efficiency, reformate compositions (such as $\mathrm{H}_{2}, \mathrm{CO}, \mathrm{H}_{2} \mathrm{O}$ and major hydrocarbon species), and an energy balance.

In the program discussed in this paper, LTC operation was predicted on the availability of two fuel streams, to expand the LTC operating envelope. The second fuel stream was a reformate of the first fuel. Two main techniques for onboard reforming of automotive fuels were proposed and studied, namely exhaust-gas reforming and steam reforming. In the exhaust gas reforming case, the fuel enters in direct contact with available water molecules in the exhaust gas stream after the combustion process [35]. Similarly, steam reforming is based on the interaction between fuel and water molecules, but in this case the water is provided by an independent source (on-board tank or exhaust gas condensate) and the exhaust gas stream can be used as a heat source without being in direct contact with the fuel.

\subsection{Exhaust Gas Reforming}

The first approach proposed was exhaust gas reforming. Discussions between WVU and GTI were centered on the issue of exhaust oxygen content. This oxygen could react with reforming fuel in the reformer, leading to a loss of efficiency but a gain in reformer temperature. Reducing excess air to the engine would reduce exhaust oxygen content and amount of reforming fuel that is oxidized. The ideal case would be the stoichiometric combustion air to fuel ratio when exhaust oxygen content is very low or equal zero. GTI, in conjunction with WVU, worked toward resolving the question of residual oxygen in the exhaust and its impact on reforming. 
Technical definitions and nomenclature for each stream were required to establish a common language between the WVU and GTI engineers. Based on a diagram of the engine and the TCR system (Figure 16), nomenclature was set for flow streams and compositions.

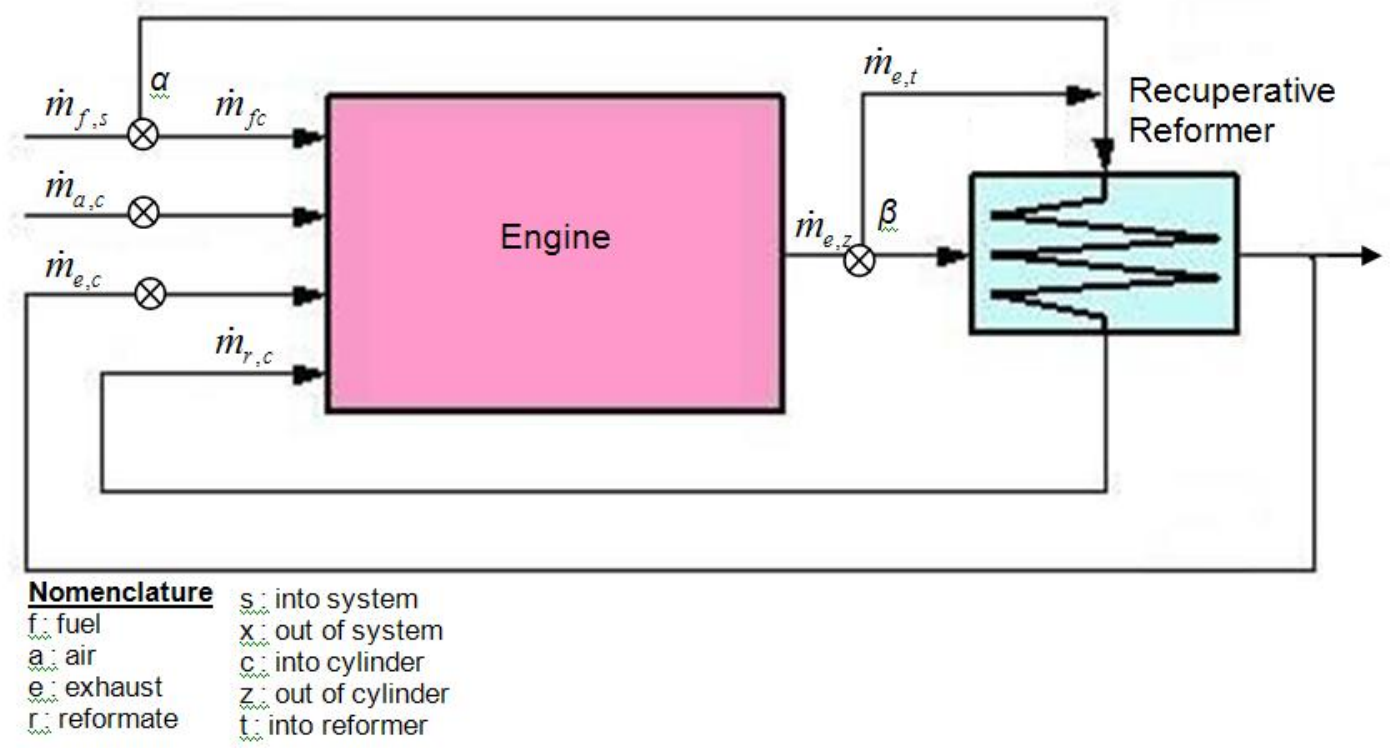

Figure 16 : System Engine and TCR Exhaust Reforming

Additionally, A/F ratio, EGR and rate of reformed gas (RR) were defined according to requirements of this specific system.

For actual air fuel ratio, the whole system was considered,

$$
A /\left.F\right|_{s y s t}=\frac{\dot{m}_{a c}}{\dot{m}_{f s}}(\% \text { mass })
$$

For EGR,

$$
E G R=\frac{\dot{m}_{e c}}{\dot{m}_{a c}+\dot{m}_{f c}+\dot{m}_{e c}+\dot{m}_{r c}}=\varepsilon
$$

For the Reformer,

$$
(R R)=\frac{\dot{m}_{e t}}{\dot{m}_{f r}}
$$

Where $R R$ represents the ratio of mass of exhaust gases into the reforming process to mass of fuel into the reforming process. 
The amount of fuel sent to the reformer was:

$$
\alpha=\frac{\dot{m}_{f r}}{\dot{m}_{f s}}
$$

The amount of exhaust gas sent to the TCR was:

$$
\beta=\frac{\dot{m}_{e t}}{\dot{m}_{e x}}
$$

Using the amount of EGR, $\varepsilon$, the ratio exhaust/fuel sent to the reformer was:

$$
R R=\frac{\beta}{\alpha}\left(1+A F_{s}\right)=\frac{\beta}{\alpha}\left(1+A F_{c y l}(1-\alpha)\right)
$$

The equations could be expressed for the engine and the TCR exhaust reforming as:

$$
\begin{aligned}
& (1-\alpha) \mathrm{C}_{10} \mathrm{H}_{22}+\mathrm{XsO}_{2}+3.76 \mathrm{XsN}_{2}+\varepsilon a C \mathrm{O}_{2}+\varepsilon b \mathrm{H}_{2} \mathrm{O}+\varepsilon d \mathrm{O}_{2}+\varepsilon e \mathrm{~N}_{2}+f \mathrm{CO}_{2}+g \mathrm{H}_{2} \mathrm{O}+j \mathrm{O}_{2}+k \mathrm{~N}_{2} \\
\rightarrow & (1+\varepsilon) a \mathrm{CO}_{2}+(1+\varepsilon) b \mathrm{H}_{2} \mathrm{O}+(1+\varepsilon) d \mathrm{O}_{2}+(1+\varepsilon) e \mathrm{~N}_{2}
\end{aligned}
$$

For the engine, and for the TCR

$$
\begin{aligned}
& \alpha C_{10} H_{22}+\beta(1+\varepsilon) a C O_{2}+\beta(1+\varepsilon) b H_{2} O+\beta(1+\varepsilon) d O_{2}+\beta(1+\varepsilon) e N_{2} \\
& \rightarrow f C O_{2}+g H_{2} O+j O_{2}+k N_{2}
\end{aligned}
$$

Using these equations and merging them into a matrix in Matlab, it was possible to quantify on a stoichiometric basis, the effect of variations in A/F ratio, EGR, and the ratio of exhaust gases to fuel into the reformer (RR). This approach was developed for the lean case. This lean case was calculated for values of equivalence ratio where the combustion reaction in the engine allows some amount of $\mathrm{O}_{2}$ to not be consumed. This available $\mathrm{O}_{2}$ at the engine exhaust $\left(\dot{m}_{e z}\right)$ would consume some amount of $\mathrm{C}_{10} \mathrm{H}_{22}$ in the reformer if exhaust gases were used in the process of fuel reforming. 
The model was focused on identifying the amount of exhaust gases for the case when $\mathrm{O}_{2}$ would consume the fuel added to the TCR. In this case, the amount of exhaust gas fed into the reformer $(\beta)$ was plotted against the amount of fuel sent to the reformer $(\alpha)$. This was only done for the case where the value of the coefficient $j$ in Equation 44 was zero, which meant no $\mathrm{O}_{2}$ was left after the reforming process because it had been consumed by oxidizing the fuel. The range of calculations for $\alpha$ and $\beta$ was 0.01-0.5 for each one. Figure 17 shows the fuel penalty associated with exhaust reforming. The penalty increased at higher $A / F$ ratios because of the remaining $\mathrm{O}_{2}$ at the exhaust stream.

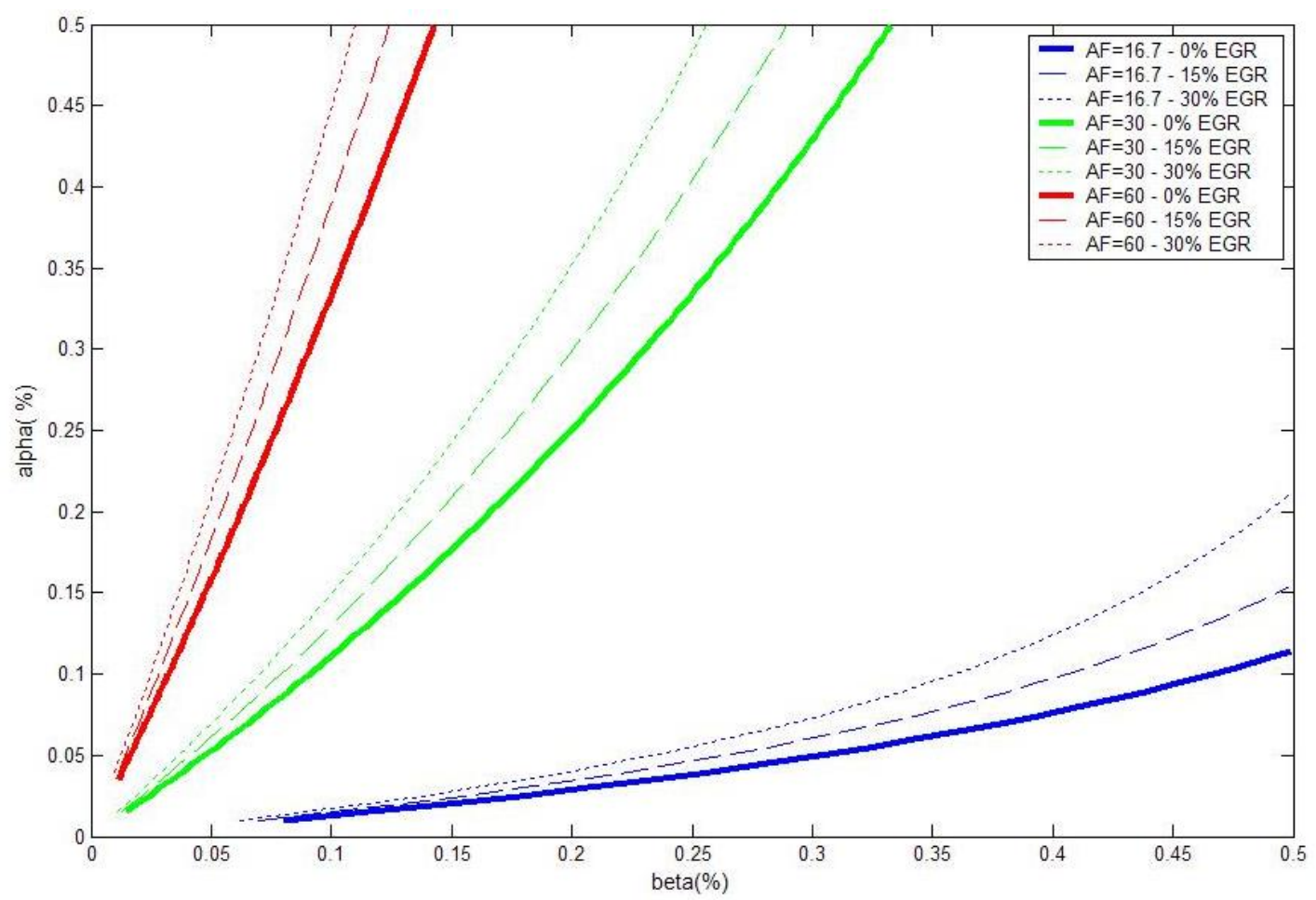

Figure 17: Alpha vs. Beta plots for Oxidation of Fuel at TCR-Exhaust Reforming

As an example, $2 \%$ of the fuel would be consumed if $10 \%$ of the exhaust gas were used at the TCR at an air-to-fuel ratio of 16.7 and no EGR. If the conditions were changed to an air-to-fuel ratio of 30 , almost $9 \%$ of the fuel would be consumed by the remaining $\mathrm{O}_{2}$. Figure 17 also shows the contribution of the EGR to the fuel consumption in the reformer.

It is clear that the fuel penalty could be harmful to the main efficiency objective of this program, which means that the evaluation of a second approach was required in the process of developing the TCR. The difficulty in applying the exhaust gas reforming system is based on the remaining $\mathrm{O}_{2}$ in the exhaust stream, which reacts with the fuel, oxidizing it into $\mathrm{CO}_{2}$ and releasing 
some amount of heat. Therefore, the applicability of this type of fuel reforming is limited to stoichiometric operational conditions.

\subsection{Steam Reforming}

Hydrocarbon fuel/steam reforming is a process in which steam is used to extract hydrogen from a hydrocarbon feedstock fuel [36]. Currently, the majority of the world's hydrogen is produced by steam reforming of fossil-fuels such as natural gas. For general hydrocarbon fuels, the following equation determines the amount of hydrogen produced from the fuel.

$$
\mathrm{C}_{n} \mathrm{H}_{2 n+2}+n \mathrm{H}_{2} \mathrm{O} \leftrightarrow n \mathrm{CO}+(2 n+2) \mathrm{H}_{2}
$$

The water-gas shift reaction then completes the formation of hydrogen in high-temperature and low-temperature stages [37].

$$
\mathrm{CO}+\mathrm{H}_{2} \mathrm{O} \leftrightarrow \mathrm{CO}_{2}+\mathrm{H}_{2}
$$

All reactions are carried out by catalytic processes. The steam reforming reaction is endothermic, and the required amount of energy depends on the stability of the substrate to be reformed and the ability of the catalyst to activate and transform the substrate into the products [36]. The water-gas shift reaction is slightly exothermic and if excess heat is generated, the reaction will be eventually driven toward the reactant side [37]. In order to minimize this, multiple stages with interstage cooling can be used [37]. The process also frequently requires the use of different catalysts, which operate under different conditions in separate reactors [36]. The process can be applied to many hydrocarbon fuels, requiring different catalyst materials and reforming temperatures. Methanol, for example, is reformed between $470 \mathrm{~K}$ and $570 \mathrm{~K}$, while methane is reformed between $1000 \mathrm{~K}$ and $1300 \mathrm{~K}$ [37]. Methanol reforming uses a copper catalyst supported by zinc oxide [37]. The best catalyst for the high-temperature water-gas shift reaction is a mixture of iron and chromium oxides, while the low-temperature reaction implements a copper catalyst supported by zinc oxide [37]. Methane reforming is usually catalyzed by nickel [37].

TCR for reciprocating IC engines is a system employing high efficiency heat exchangers to recover sensible heat from engine exhaust gases (and even engine oil) and convert it to chemical (fuel) energy. This conversion is accomplished by steam reforming through catalytic and endothermic reactions in a specially designed reforming reactor.

The reforming process uses waste exhaust heat as the energy input to drive the endothermic reaction. The reformer gas, which mainly consists of $\mathrm{H}_{2}, \mathrm{CO}$, and hydrocarbons, can be introduced into the engine through port injection or other methods. The hydrogen-rich fuel can be 
used as an additional control over the combustion process to alter the ignition properties of the mixture and extend the operational range of LTC.

\subsection{1 n-Heptane Steam Reforming Model Results}

Two models were considered to predict the reformer gas composition as a function of reformer temperature. The first model used was a Gibbs equilibrium model, implemented through HYSYS software. It predicted that the main components of the reformer gas were $\mathrm{CH}_{4}, \mathrm{H}_{2} \mathrm{O}, \mathrm{CO}_{2}, \mathrm{H}_{2}$, and CO. In addition, it predicted complete heptane conversion at any temperature in the range of 380 $\mathrm{K}-1140 \mathrm{~K}$. These results differed from those obtained through experimental work. This is particularly true for the amount of heptane reformed at low reforming temperatures. Experimental work showed less than $10 \%$ heptane was converted for temperatures below $600 \mathrm{~K}$. In addition, higher $\mathrm{CO}$ and $\mathrm{H}_{2}$ and lower $\mathrm{CH}_{4}$ were measured experimentally than what the equilibrium by Gibbs reaction model predicted.

A second equilibrium approach was used as well, determining the reformer gas composition as a function of reformer temperature using one or two reactions. The following reactions were considered

$$
\begin{aligned}
& \mathrm{C}_{7} \mathrm{H}_{16}+7 \mathrm{H}_{2} \mathrm{O} \leftrightarrow 7 \mathrm{CO}+15 \mathrm{H}_{2} \\
& \mathrm{CO}+\mathrm{H}_{2} \mathrm{O} \leftrightarrow \mathrm{CO}_{2}+\mathrm{H}_{2}
\end{aligned}
$$

This model better described the real process than the equilibrium approach implemented in HYSYS software. It showed a lower heptane conversion for temperatures below $600 \mathrm{~K}$, and regardless of whether one or two reactions were used the heptane conversion results were similar. Reformed fuel composition as a function of reforming temperature for steam/carbon mole ratio $1: 1$ is shown in Figure 19. Data in Figure 19 were obtained with the assumption of equilibrium by one reaction, $\mathrm{C}_{7} \mathrm{H}_{16}+7 \mathrm{H}_{2} \mathrm{O}=7 \mathrm{CO}+15 \mathrm{H}_{2}$. 


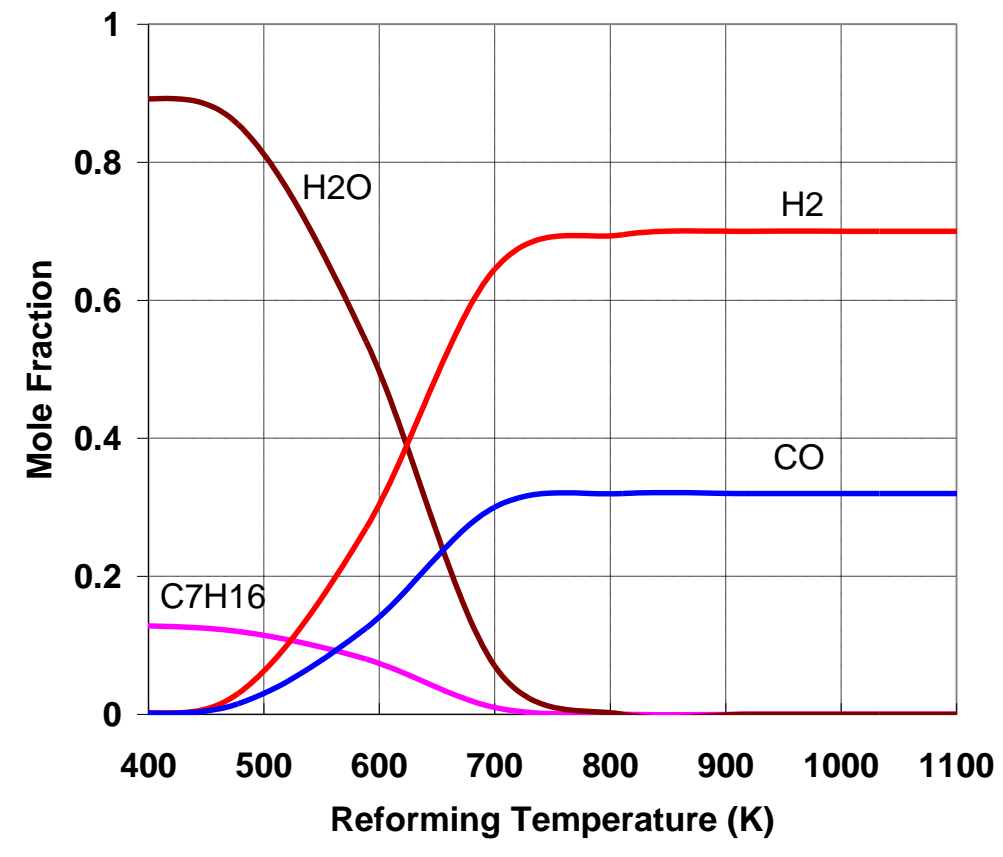

Figure 18: Reformer Gas Composition, Equilibrium by One Reaction

Figure 19 shows that there is a high level of $\mathrm{H}_{2}(25 \%-65 \%)$ and $\mathrm{CO}(10 \%-30 \%)$ content in the reformed fuel at relatively low reforming temperature $(600 \mathrm{~K}-700 \mathrm{~K})$ which was also confirmed experimentally.

The reformed fuel low heating value was estimated based on the two equilibrium approaches and using a steam/carbon molar ratio of 1:1. The results of the calculations are shown in Figure 19 , which assumed a heptane lower heating value of $44.93 \mathrm{MJ} / \mathrm{kg}$. Shown in the figure and according to the HYSYS model, thermo-chemical recuperation is not efficient at reforming temperatures below $700 \mathrm{~K}$, as the fuel heating value is decreased. According to these results, it was more efficient if the reforming process followed the reaction $\mathrm{C}_{7} \mathrm{H}_{16}+7 \mathrm{H}_{2} \mathrm{O}=7 \mathrm{CO}+15 \mathrm{H}_{2}$ than if it followed the HYSYS model. This result should be taken into account for appropriate catalyst selection when the catalyst is favorable for the reaction $\mathrm{C}_{7} \mathrm{H}_{16}+7 \mathrm{H}_{2} \mathrm{O}=7 \mathrm{CO}+15 \mathrm{H}_{2}$. 


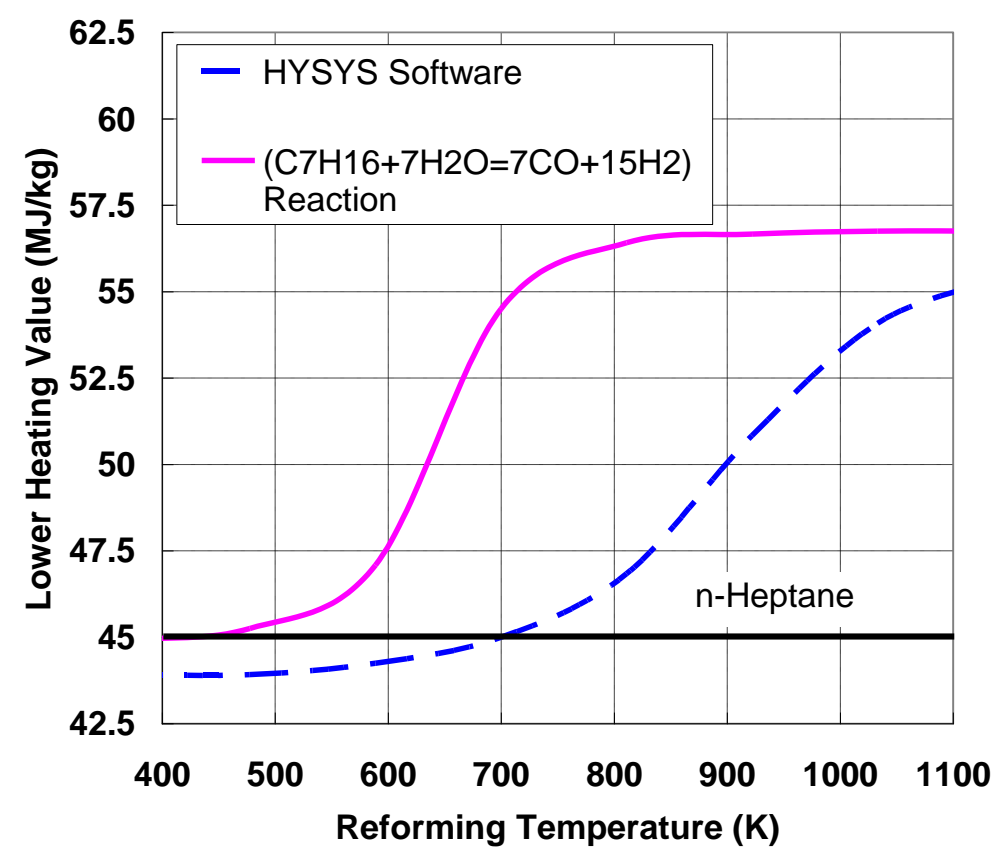

Figure 19: Reformed Fuel Low Heating Value at Equilibrium

\subsubsection{Experimental Set-Up for n-Heptane Steam Reforming}

The purpose of the experiment was to provide data for validation of theoretical modeling of the TCR system and to evaluate the liquid fuel/steam reforming process as applied to expected conditions of the LTC engine. The reformer was tested in order to estimate the reforming rate and process efficiency for non-catalytic and catalyzed reforming.

Figure 18 shows the bench-scale system that was designed and integrated with the TCR for conducting the laboratory tests. The system implemented a GTI natural gas-fired heat treating furnace equipped with two radiant $U$-tube burners. One of the burners was used as a high temperature exhaust gas energy source and the second burner was operated with the reformed fuel. The existing furnace set-up was modified in such a way that another recuperator was installed in series with the reformer. A preheater was installed to compensate for heat losses in the heptane/steam. The pipe connecting the preheater and reformer as well as the outlet pipe from the reformer to the second combustor were heat taped and insulated. The thermostatically controlled heat tapes were used to reduce heat losses in the pipes.

Fuel gas samples were taken from the reformer inlet and outlet through sample ports \#3 and \#9 respectively (Figure 20). Gas samples were passed through a specially designed water-cooled condenser to extract unprocessed water and heptane vapors. Condenser water temperature was at the level of $286 \mathrm{~K}$. All collected hydrocarbons were assumed to be heptane. The volume of dry 
gas and corresponding volumes of water and heptane were measured by dry gas meter DTM200A-3 and graduated glass cylinder.

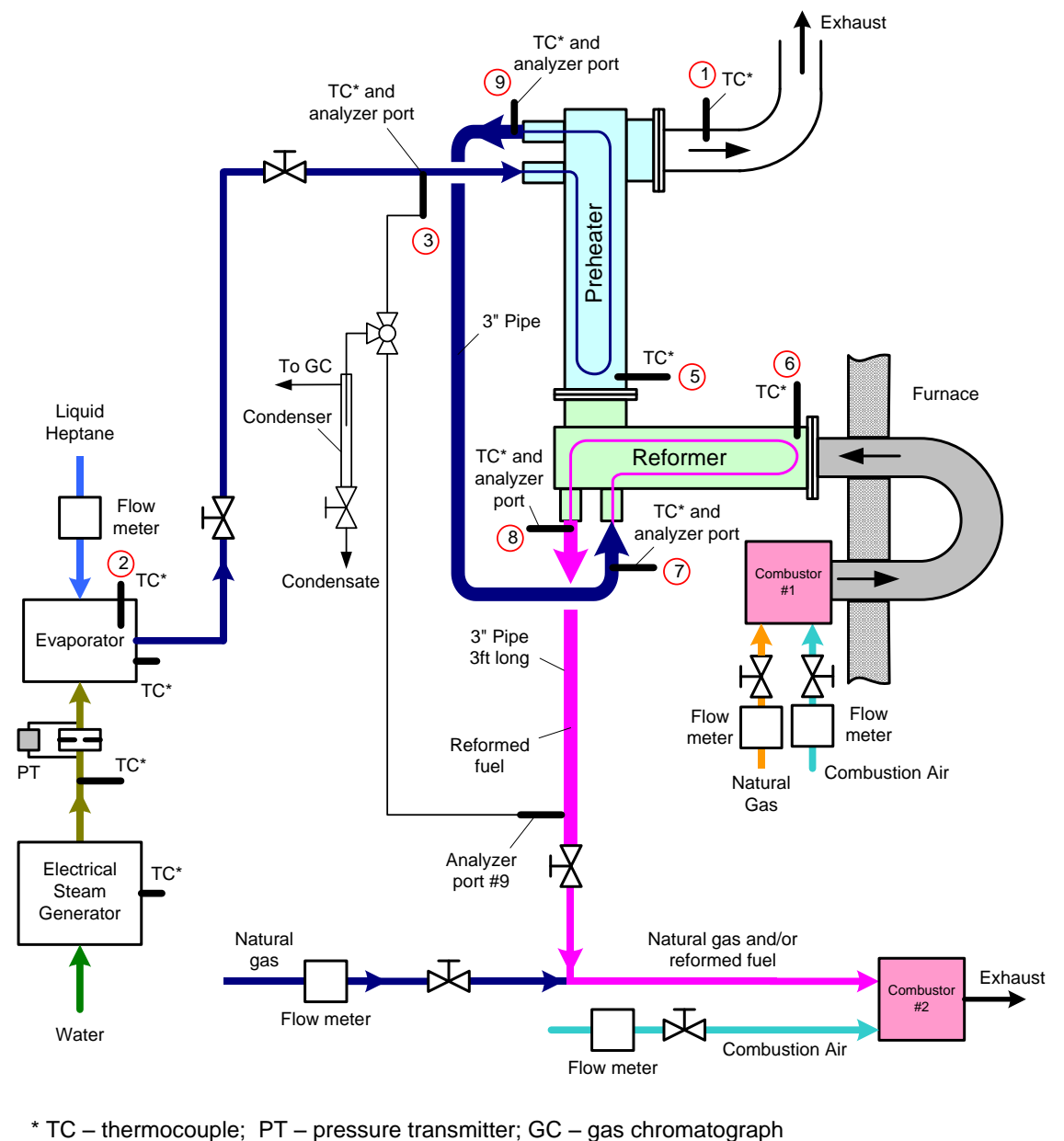

Figure 20: Experimental Setup for n-Heptane/Steam Reforming

\subsubsection{Measuring Equipment and Data Processing}

The following data were used in order to estimate the reforming process of heptane:

- $\quad$ properties of $n$-heptane (shown in Table 3)

- measured dry gas and condensate composition before and after the reformer

- volumetric flows of heptane and steam to the reformer

- temperature before and after the reformer 
Table 3: Properties of $\mathbf{n}$-Heptane

\begin{tabular}{|l|c|c|}
\hline Molecular formula & - & $\mathrm{C}_{7} \mathrm{H}_{16}$ \\
\hline Molecular weight & $\mathrm{g} / \mathrm{mol}$ & 100.20 \\
\hline Specific weight @ 295K, liquid & $\mathrm{kg} / \mathrm{m}^{3}$ & 683.74 \\
\hline Specific weight @ 295K, gas & $\mathrm{kg} / \mathrm{m}^{3}$ & 4.15 \\
\hline Gross Heating Value (HHV), liquid & $\mathrm{kJ} / \mathrm{kg}$ & 48085.00 \\
\hline Net Heating Value (LHV), liquid & $\mathrm{kJ} / \mathrm{kg}$ & 44538.00 \\
\hline Gross Heating Value (HHV), gas & $\mathrm{kJ} / \mathrm{kg}$ & 48448.00 \\
\hline Net Heating Value (LHV), gas & $\mathrm{kJ} / \mathrm{kg}$ & 44903.00 \\
\hline
\end{tabular}

Fuel gas was analyzed using a Varian CP 4900 gas chromatograph (GC). At least two samples were taken for each test. The GC was calibrated to measure the following components: $\mathrm{H}_{2}, \mathrm{O}_{2}, \mathrm{~N}_{2}, \mathrm{CH}_{4}, \mathrm{CO}, \mathrm{CO}_{2}, \mathrm{C}_{2} \mathrm{H}_{4}, \mathrm{C}_{2} \mathrm{H}_{6}, \mathrm{C}_{3} \mathrm{H}_{8}$, iso- $\mathrm{C}_{4} \mathrm{H}_{10}, \mathrm{n}-\mathrm{C}_{4} \mathrm{H}_{10}$, and $\mathrm{C}_{2} \mathrm{H}_{2}$. Heptane concentration was assumed to be equal to the saturated heptane vapor concentration at the condenser temperature if a non-zero volume of liquid heptane was collected. If no heptane was condensed, the heptane concentration was assumed to be equal to one half of the saturated heptane concentration at the condenser temperature. This assumption was checked for the second test by analyzing the gas sample in a GTI chemical laboratory and comparing the analysis results with the GC measurements. This comparison can be seen in Table 4 .

As seen in Table 4, the most uncertainty arose from the assumption of heptane and higher olefin content in the sample gas. For large volumes of sample gas (corresponding to the tests with heptane conversion rates close to $100 \%$ ) these uncertainties could lead to uncertainties in the definition of heptane conversion rate and reformer energy output.

Table 4: Comparison of GC and GTI Chemical Laboratory Analysis Results

\begin{tabular}{|c|c|c|c|}
\hline Component & UOM & GC & $\begin{array}{c}\text { Chemical } \\
\text { Lab }\end{array}$ \\
\hline $\mathrm{H}_{2}$ & vol \% & 58.60 & 58.40 \\
\hline $\mathrm{O}_{2}$ & vol \% & 0.20 & 0.04 \\
\hline $\mathrm{N}_{2}$ & vol \% & 0.80 & 0.20 \\
\hline $\mathrm{CH}_{4}$ & vol \% & 3.00 & 3.86 \\
\hline $\mathrm{CO}$ & vol \% & 18.30 & 17.00 \\
\hline $\mathrm{CO}_{2}$ & vol \% & 6.30 & 5.95 \\
\hline $\mathrm{C}_{2} \mathrm{H}_{4}$ & vol \% & 1.00 & 6.17 \\
\hline $\mathrm{C}_{2} \mathrm{H}_{6}$ & vol \% & 1.20 & 1.73 \\
\hline $\mathrm{C}_{3} \mathrm{H}_{8}$ & vol \% & 0.10 & 0.11 \\
\hline $\mathrm{i}-\mathrm{C}_{4} \mathrm{H}_{10}$ & vol \% & 0.00 & 0.00 \\
\hline $\mathrm{n}-\mathrm{C}_{4} \mathrm{H}_{10}$ & vol \% & 0.00 & 0.05 \\
\hline $\mathrm{C}_{2} \mathrm{H}_{2}$ & vol \% & 3.30 & 0.00 \\
\hline $\mathrm{C}_{7} \mathrm{H}_{16}$ & vol \% & 3.20 & 2.28 \\
\hline Olefins $\left(\mathrm{C}_{3}+\right)$ & vol \% & 4.00 & 3.86 \\
\hline
\end{tabular}


The heptane volumetric flow was measured using a rotameter with relative accuracy of $\pm 4 \%$. The fuel feed rate was constant due to the use of a special pressure regulator, making the total accuracy of fuel flow measurement $\pm 4 \%$. The steam flow rate was measured using an orifice plate with $\pm 0.8 \%$ relative error for typical flow rates. Flow instability was approximately $\pm 6 \%$. The resulting accuracy of steam flow measurements was approximately $\pm 6 \%$. The steam/heptane ratio was also determined at the reformer inlet by condensing the mixture and measuring the ratio of heptane to water volume. The accuracy of these methods was on the order of $\pm 15 \%$, compared to the $\pm 7 \%$ accuracy for the value derived from flow measurements. Because of this, condensation was used only for a coarse check of test conditions.

\subsubsection{Experimental Results}

Experimental data, including reformer gas composition and hydrogen yield, was produced for a range of reformer temperatures. In addition, a comparison to modeling results was performed to validate the model. Measured heptane conversion, as well as the calculated equilibrium values based on two reactions, as a function of reforming temperature, is shown in Figure 21.

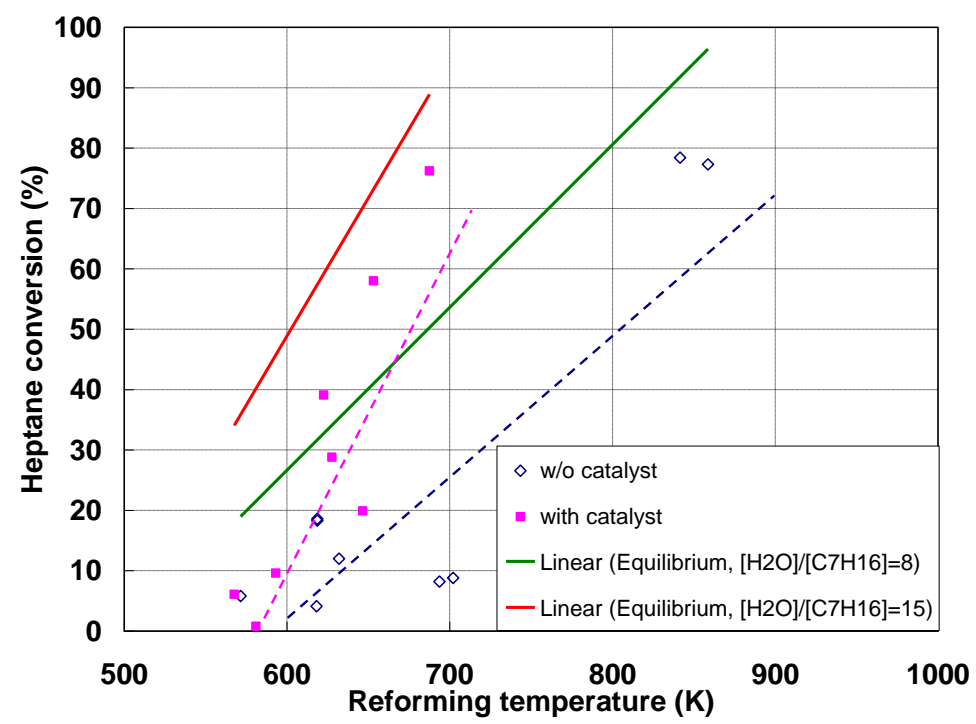

Figure 21: Heptane Conversion Rate Compared to Equilibrium Values

Figure 22 shows the main components of the reformed fuel composition (measured wet) for a steam/carbon molar ratio of $2: 1$ with catalyst. There was up to $45 \% \mathrm{H}_{2}$ and $18 \% \mathrm{CO}$ (by volume, wet) in the reformed fuel at a relatively low reforming temperature $(\approx 700 \mathrm{~K})$. 


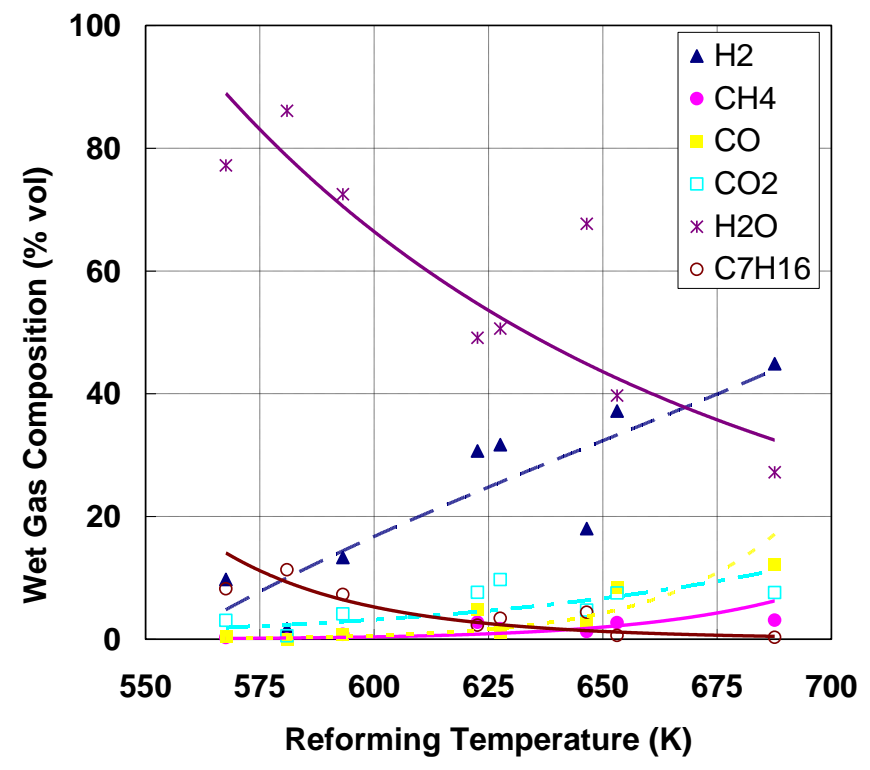

Figure 22: Reformed Gas Composition with Catalyst

To characterize the process efficiency for hydrogen production, hydrogen yield was estimated as the weight ratio of hydrogen produced to heptane fed into the reformer. Results from this estimation can be seen in Figure 23 for a steam/carbon mole ratio of 2:1.

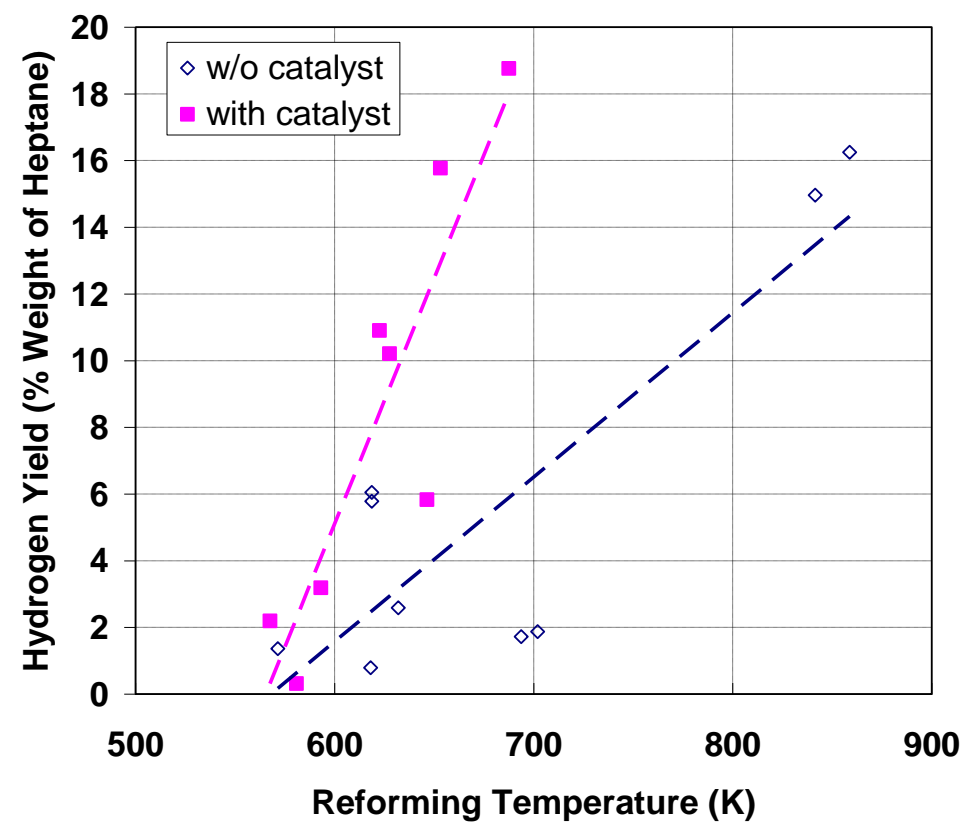

Figure 23: Reformer Hydrogen Production 
Process completeness was used as a parameter to describe the reforming process, defined by actual conversion amount as a percentage of theoretical equilibrium conversion amount.

As seen in Figure 24, the experimental reformer could provide close to $100 \%$ process completeness at $690 \mathrm{~K}$ for catalytic reforming and $860 \mathrm{~K}$ for non-catalytic reforming. Approximately the same process completeness was achieved for catalytic and non-catalytic reforming at temperatures between $550 \mathrm{~K}$ and $650 \mathrm{~K}$, suggesting that those temperatures are too low for the catalyst. All data shown in Figure 24 is for a steam/carbon molar ratio of 2:1.

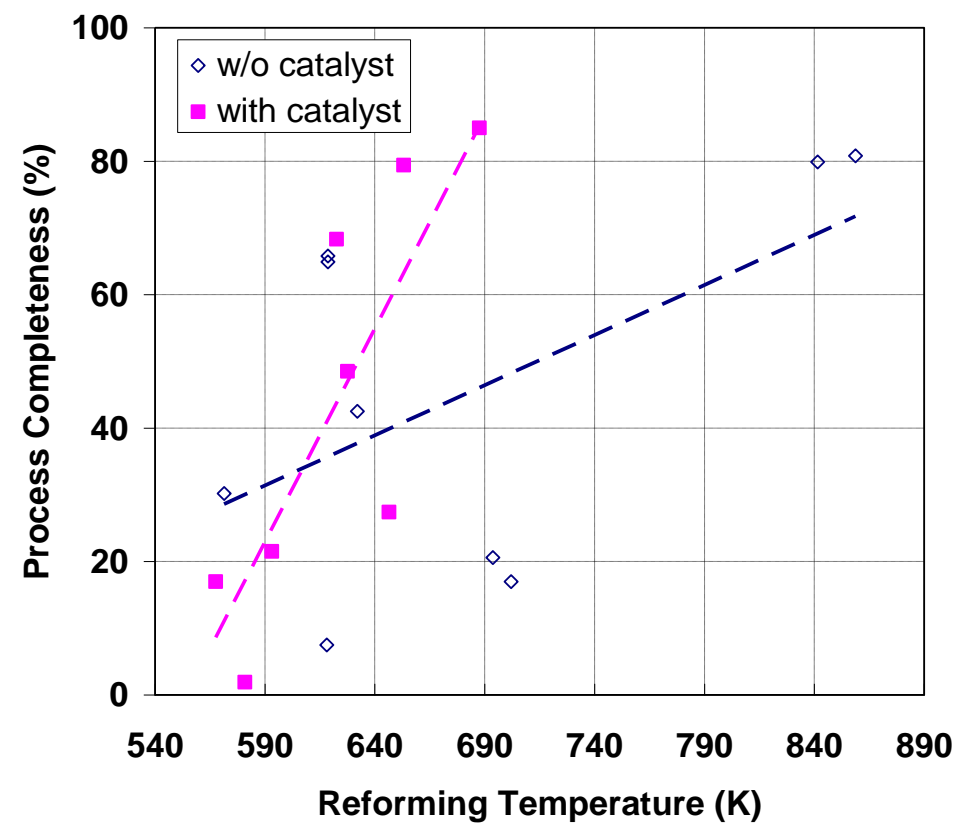

Figure 24: Reformer Process Completeness 


\section{Synergy between LTC and TCR}

The well known sensitivity of the LTC mode to temperature and charge composition has been demonstrated with a simple two-step chemical kinetics model. The strong influence of intake temperature, equivalence ratio and EGR on the ignition event suggests that the LTC engine requires an additional means of control to obtain the desired benefits regarding emissions and thermal efficiency of this technology.

The proposed method for LTC initiation (ignition) point control is to introduce two different fuels, with different combustion properties, into the cylinder. If one fuel is more ignition resistant than the other, the blend can be tailored to meet the immediate ignition requirements, on a cycleby-cycle basis. By producing a second, hydrogen-rich, fuel stream with TCR, and using two injection systems (possibly port injection for TCR products), subtle and rapid LTC control may be possible, and efficient combustion may be enabled for transient use.

Based on the results obtained from the LTC model, values of exhaust temperature were calculated to examine the operational range of the TCR system. Table 5 shows the resulting values of exhaust temperatures based on a model of adiabatic expansion of ideal gas mixture. The final pressure at exhaust conditions was considered to be $100 \mathrm{kPa}$.

These temperatures, which are higher than $650 \mathrm{~K}$ (according to Figure 23) match the operational range where the catalyst is acceptably effective and where the reaction completion is higher than $60 \%$. Moreover, based on the literature, the LTC mode has demonstrated good behavior in the low power demand range where the TCR is not required and where the available reforming temperature from exhaust gases is low and therefore low reforming process completeness would be obtained. It should be noted that the temperature of the gases obtained from the adiabatic expansion model may be lower than those obtained from a real prototype where heat transfer losses are involved in the process, but the exhaust area can be configured to minimize heat loss if the intent is to optimize waste heat recovery.

Table 5: Exhaust Gas Temperatures Calculated from Adiabatic Expansion from Exhaust Valve Open (EVO) Conditions at Different Equivalence Ratios 


\begin{tabular}{|c|c|c|c|}
\hline \multirow{2}{*}{$\phi$} & \multicolumn{2}{|c|}{$\begin{array}{c}\text { Exhaust Valve Open } \\
\text { Conditions }\end{array}$} & $\begin{array}{c}\text { Exhaust Gas } \\
\text { Temperature }\end{array}$ \\
\cline { 2 - 4 } & $\mathrm{T}(\mathrm{K})$ & $\mathrm{P}(\mathrm{kPa})$ & $\mathrm{T}(\mathrm{K})$ \\
\hline 0.2 & 650.4 & 194.9 & 547.1 \\
\hline 0.4 & 862.0 & 261.7 & 671.7 \\
\hline 0.6 & 1145.0 & 341.9 & 832.5 \\
\hline 0.8 & 1396.0 & 419.0 & 962.9 \\
\hline 1.0 & 1575.0 & 457.6 & 1061.8 \\
\hline
\end{tabular}

The argument for the novel approach is informed by the work of Hosseini and Checkel [38], who used low octane fuels (PRF0 and PRF20) and showed evidence that the addition of a second hydrogen-rich fuel stream extended the LTC operational range towards richer mixtures, and hence higher peak IMEP was obtained. In other words, they were able to alter the LTC operating envelope. The simulated reformed gas consisted of a prepared mixture of $75 \% \mathrm{H}_{2}$ and $25 \% \mathrm{CO}$. As an example, a $20 \%$ increase in reformed fuel delayed the start of combustion in their experiment by approximately 14 crank angle degrees, and increased the combustion duration by $50 \%$. A better combustion phasing compared with the short combustion duration for n-heptane generated a higher indicated power. A $17 \%$ increase in indicated power was achieved and as a result, the thermal efficiency was increased by $12 \%$. No significative changes in $\mathrm{NO}_{\mathrm{x}}$ emissions were observed when increasing the amount of $\mathrm{H}_{2}$ compared with the baseline LTC engine [38]. 


\section{Experimental Plans. (Program Task 1.4)}

The Phase 1 experimental and modeling data had suggested that TCR is feasible using exhaust waste heat, and that LTC with reduced power density and increased displacement offers efficiency advantages. This supports continued research according to the Phase 2 experimental test plan presented in the original proposal. WVU had identified the Cummins common rail Bseries engine as being well-suited to the Phase 2 LTC work, and had already acquired an engine through donation from Cummins. The engine was equipped with mounting hardware. It was the intent of the researchers to use one cylinder of this engine for the LTC research.

The researchers at WVU, with support from Atkinson LLC, had identified sensors and hardware needed for the experimental work, and proposed how these might be used in subsequent experimental control applications. It would be necessary to employ a small suite of sensors for control purposes, but it was the intent of the researchers to instrument the LTC cylinder more substantially. Also, the researchers considered integration options for the TCR and LTC, and the instrumentation that will be needed for the TCR.

The anticipated Phase 2 tasks, as presented in the original proposal, were not performed due to changes in funding availability. Instead, further modeling work was performed. The second phase modeling work included modeling the effect of reforming products in the LTC combustion phasing.

\section{Modeling the Effects of Reformer Products on HCCI}

The influence of $\mathrm{H} 2$ and $\mathrm{CO}$ on $\mathrm{n}$-heptane homogeneous charge compression ignition, a member of the LTC family, has been studied by other research groups, and experimental data demonstrating the effects of substituting the base fuel by different amounts of $\mathrm{H} 2$ and $\mathrm{CO}$ are available at certain load and engine speed conditions. It was the objective of this research period to develop a model able to match the trends of $\mathrm{H} 2$ and $\mathrm{CO}$ substitution on LTC of $n$-heptane.

The amounts of $\mathrm{H} 2$ and $\mathrm{CO}$ that were modeled on those initial runs were calculated based on theoretical yield, which means stoichiometric values of $n$-heptane steam reforming process. The equilibrium approach used to quantify the maximum yield is based on the reaction,

$$
\mathrm{C}_{7} \mathrm{H}_{16}+7 \mathrm{H}_{2} \mathrm{O} \leftrightarrow 7 \mathrm{CO}+15 \mathrm{H}_{2}
$$




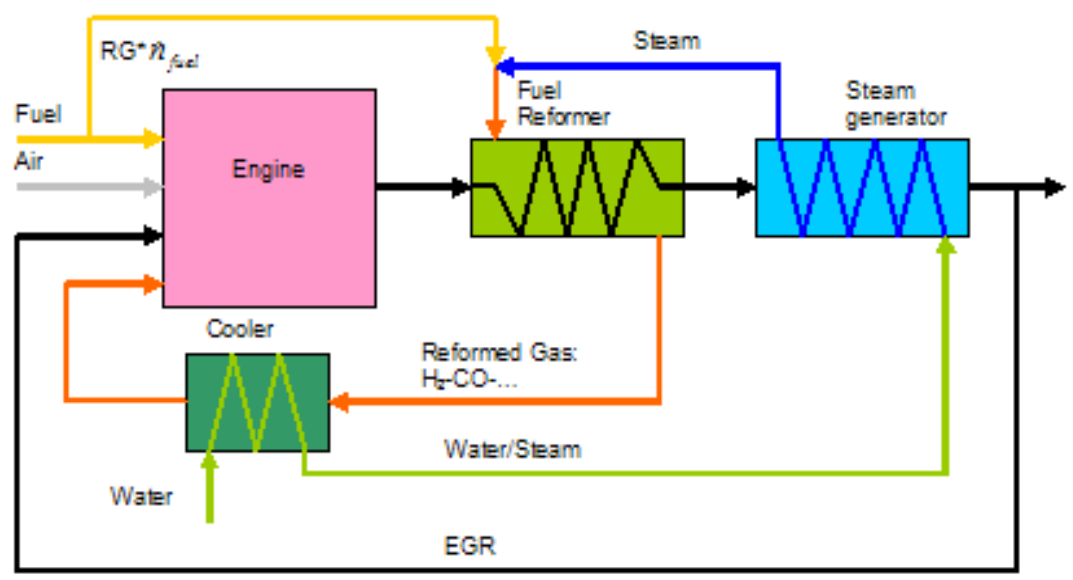

Figure 25 : n-Heptane recuperation system based on steam reforming

The concept of reformed gases $(R G)$, as the product of steam-n-heptane reforming was employed to quantify the initial reactants to be input in the model. Figure 25 describes the system approach to formulate the initial amounts of gas into the cylinder.

The ratio of fuel that is feed to the reformer to the total fuel into the system, RG, was defined as:

$$
R G=\frac{\dot{n}_{\text {reffuel }}}{\dot{n}_{\text {fuel }}}
$$

Another definition used was the steam:carbon ratio (S/C). This ratio quantifies the amount of steam that is added to the fuel being reformed in the steam reforming process. The stoichiometric amount is $\mathrm{S} / \mathrm{C}=1$, as can be observed from Equation 78 .

Base on these definitions, the formulation of the equilibrium equation (Eq.78) can be pre Figure 26: n-heptane recuperation system based on steam reforming

$$
R G \cdot\left(C_{7} H_{16}+(S / C) 7 H_{2} \mathrm{O}\right) \leftrightarrow R G \cdot 7 C O+R G \cdot 15 H_{2}+R G \cdot(1-(S / C)) 7 \mathrm{H}_{2} \mathrm{O}
$$

The ideal case for $n$-heptane steam reforming was defined as $S / C=1$, and the products resulting form this case correspond to those on the right side of Eq. 78,

$$
\text { Ideal case: } \quad R G \cdot\left(\mathrm{C}_{7} \mathrm{H}_{16}+7 \mathrm{H}_{2} \mathrm{O}\right) \leftrightarrow R G \cdot 7 \mathrm{CO}+R G \cdot 15 \mathrm{H}_{2}
$$


Experimental results published in the literature on addition of $\mathrm{H} 2$ and $\mathrm{CO}$ for control of $\mathrm{n}$ heptane $\mathrm{HCCl}$ were found mainly assuming a close to Ideal case of steam reforming. Hosseini and Checkel [38] studied the effect of different blending levels of reformed fuel $(0 \%-40 \%$ by mass) was studied for $\mathrm{HCCl}$ of $\mathrm{n}$-heptane (low octane base fuel). The reformed gas considered in that study was an arbitrary mixture of $75 \% \mathrm{H} 2$ and $25 \% \mathrm{CO}$ with a corresponding amount of diluents proportional to the residual exhaust gas. As an example, a $20 \%$ increase in reformed fuel delayed the start of combustion by approximately 14 crank angle degrees, and increased the combustion duration by $50 \%$. Experiments showed that the high temperature heat release (HTHR) was retarded even after TDC with increased values of fuel reformed and the combustion duration became longer.

Based on the promising evidence of the benefits of $\mathrm{H} 2$ and $\mathrm{CO}$ addition, a series of runs on CHEMKIN using the $\mathrm{HCCl}$ model were planned at different values of RG (0-40\% by volume) and at one condition of load $(\varphi=0.8)$ and speed (1200 rpm). Cylinder geometry was kept at the same values as in previous models, see table 1 , but the compression ratio was adjusted to match values reported in literature regarding combustion of $n$-heptane under $\mathrm{HCCl}$ conditions.

Table 6: Cylinder geometry and simulation conditions

\begin{tabular}{|l|l|}
\hline Bore, $\mathrm{cm}$ & 10.2 \\
\hline Stroke, $\mathrm{cm}$ & 12 \\
\hline Displacement, cm3 & 980 \\
\hline CR & 12 \\
\hline IVC (aTDC), CA & -140 \\
\hline EVC (aTDC), CA & 95 \\
\hline
\end{tabular}

Temperature and gas composition, the main factors that govern the LTC process were carefully selected on this model run. The value of intake temperature, which greatly affects the history of the combustion process, was set to $370 \mathrm{~K}$. This temperature allow for all the ignition events (at mixture composition) to occur just before TDC, which facilitates the analysis of the individual effects of gas composition.

Gas composition values that were selected to feed the model correspond to molar fractions of fuel, air and reformed fuel, where the total fuel and air was kept constant and the value of RG was changed from $0 \%$ to $40 \%$. The details from the reformed gas composition are presented in next section.

\subsection{Reformed gas composition}


During the first phase of the project performed by GTI on n-heptane steam reforming, experimental data (including reformer gas composition and hydrogen yield) were produced for a range of reformer operational temperatures at a fix value of steam/carbon ratio $S: C=2: 1$.

Figure 27 shows the main components of the reformed fuel composition (measured wet) for a steam/carbon molar ratio of $2: 1$ with catalyst. There was up to $45 \% \mathrm{H} 2$ and $18 \% \mathrm{CO}$ (by volume, wet) in the reformed fuel at a relatively low reforming temperature ( $T \leq 700 \mathrm{~K})$.

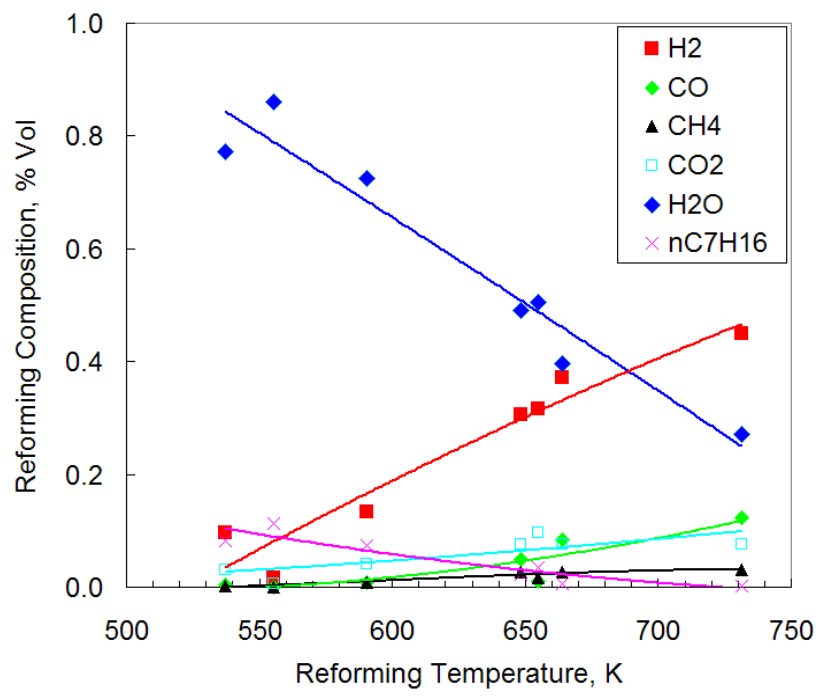

Figure 27 : Reformed Gas Composition with Catalyst

Based on the experimental data, a relation for $R G$ species composition as function of temperature was developed for the main species inventoried during the reforming test. Table 7 presents the polynomial fit $\mathrm{C}_{x}(T)$ corresponding to the steam/n-heptane composition for $\mathrm{S}: \mathrm{C}=2: 1$ and a temperature range of $540 \mathrm{~K}$ to $730 \mathrm{~K}$ at $1 \mathrm{~atm}$ pressure. In the set of polynomials presented below the temperature domain $T$, corresponds to the reforming temperature, $\mathrm{T}_{\text {ref, }}$, in $\mathrm{K}$, divided by 1000: $T=\mathrm{T}_{\text {ref }}[\mathrm{K}] / 1000$.

$$
C_{x}(T)=a_{n} T^{n}+a_{n-1} T^{n-1}+a_{n-2} T^{n-2}+\ldots a_{1} T+a_{0}
$$

Notice that the domain was changed by dividing the temperature by $1000(\mathrm{~K} / 1000)$.

The information provided by the polynomial representation was corrected to keep the elemental conservation balance. In this study, molar fractions of unreformed $\mathrm{nC}_{7} \mathrm{H}_{16}$ and excess $\mathrm{H}_{2} \mathrm{O}$ were adjusted to keep the elemental balance. 


\section{Table 7 : Polynomial coefficients used to calculate molar fraction composition at} different reforming temperatures. Based on Fig.25 data

\begin{tabular}{|c|c|c|}
\hline Species, $x$ & $\begin{array}{c}\text { Polynomial Coefficients, } \\
{\left[a_{n} a_{n-1} a_{n-2} \ldots a_{l} a_{0}\right]}\end{array}$ & $R^{2}$ \\
\hline $\mathrm{H}_{2}$ & {$[-1.7099 \quad 4.3928-1.8314]$} & 0.9269 \\
\hline $\mathrm{CO}$ & {$\left[\begin{array}{llll}1.8435 & -0.1955 & -1.356 & 0.50\end{array}\right]$} & 0.83 \\
\hline $\mathrm{H}_{2} \mathrm{O}$ & {$\left[\begin{array}{lll}-0.5114 & -2.4075 & 2.2844\end{array}\right]$} & 0.9385 \\
\hline & $\left.\begin{array}{llll}-2.7173 & 3.8047 & -1.2486\end{array}\right]$ & 0.7914 \\
\hline & {$\left[\begin{array}{lllll}-12.695 & 23.960 & -14.803 & 3.01\end{array}\right]$} & 0.9143 \\
\hline $\mathrm{nC}_{7} \mathrm{H}_{16}$ & {$\left[\begin{array}{lll}1.3549 & -2.2674 & 0.9307\end{array}\right]$} & 0.8563 \\
\hline
\end{tabular}

Due to the presence of excess water, there are significant additional species in the reformer output stream, mainly $\mathrm{H}_{2} \mathrm{O}$ and $\mathrm{CO}_{2}$. The effect of each of this species were studied with the CHEMKIN model, although the expected effect was the same as the effect produced by EGR, widely studied by research on $\mathrm{HCCl}$ [39].

The use of species composition based on polynomial fit as function of temperature allows predicting the composition of the reforming gas according to real operational temperatures that are function of exhaust temperature. The set of species composition is referred to in this model as the real case composition.

The amount of reformed gas going to the cylinder that was tested in this modeling exercise was then selected at constant equivalence ratio $(\varphi=0.8)$ and under two variable conditions: the amount of fuel to the reformer, expressed by RG, and the calculated reformed gas composition at certain reformer temperature. In mathematical terms,

$$
\left[X_{i}\right]_{\text {int ake }}=f\left(R G,\left[X_{i}\right]_{\text {reform }}\right)
$$

where

$$
[X i]_{\text {reform }}=f\left(T_{\text {ref }}\right)
$$

Table 8 presents the values of molar composition $\mathrm{Ni}$ at different temperature conditions according to expected range of reforming temperatures. This set of data that was called real case composition. 
Table 8 : Real case molar composition at different reforming temperatures and values of RG

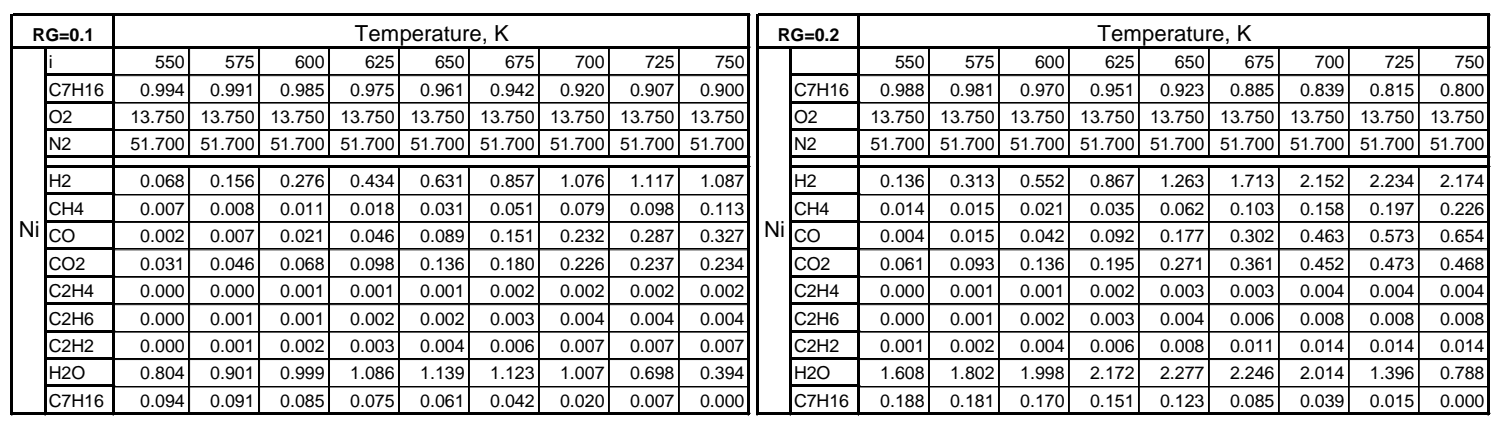

\begin{tabular}{|c|c|c|c|c|c|c|c|c|c|c|c|c|c|c|c|c|c|c|c|c|c|}
\hline \multicolumn{2}{|c|}{$R G=0.3$} & \multicolumn{9}{|c|}{ Temperature, $\mathrm{K}$} & \multicolumn{2}{|c|}{$\mathrm{RG}=0.4$} & \multicolumn{9}{|c|}{ Temperature, $\mathrm{K}$} \\
\hline & & 550 & 575 & 600 & 625 & 650 & 675 & 700 & 725 & 750 & & & 550 & 575 & 600 & 625 & 650 & 675 & 700 & 725 & 750 \\
\hline & $\mathrm{C} 7 \mathrm{H} 16$ & 0.982 & $\begin{array}{ll}0.972 \\
\end{array}$ & 0.955 & 0.926 & 0.884 & 0.827 & $\begin{array}{l}0.759 \\
\end{array}$ & 0.722 & 0.700 & & $\mathrm{C} 7 \mathrm{H} 16$ & 0.976 & 0.963 & 0.939 & 0.902 & 0.846 & 0.769 & $\begin{array}{l}0.679 \\
\end{array}$ & 0.629 & 0.600 \\
\hline & $\mathrm{O} 2$ & 13.750 & 13.750 & 13.750 & 13.750 & 13.750 & 13.750 & \begin{tabular}{|c|}
13.750 \\
\end{tabular} & 13.750 & 13.750 & & $\mathrm{O} 2$ & 13.750 & 13.750 & \begin{tabular}{l|l|}
13.750 \\
\end{tabular} & 13.750 & 13.750 & 13.750 & \begin{tabular}{l|l|}
13.750 \\
\end{tabular} & 13.750 & 13.750 \\
\hline & N2 & 51.700 & 51.700 & 51.700 & \begin{tabular}{|l|l|}
51.700 \\
\end{tabular} & 51.700 & 51.700 & 51.700 & 51.700 & 51.700 & & N2 & 51.700 & 51.700 & 51.700 & 51.700 & 51.700 & \begin{tabular}{|l|l}
51.700 \\
\end{tabular} & 51.700 & 51.700 & 51.700 \\
\hline & $\mathrm{H} 2$ & 0.204 & 0.469 & 0.828 & 1.301 & 1.894 & 2.570 & 3.228 & 3.352 & 3.261 & & $\mathrm{H} 2$ & 0.271 & 0.625 & 1.104 & 1.735 & 2.525 & 3.427 & 4.304 & 4.469 & 4.349 \\
\hline & $\mathrm{CH} 4$ & 0.022 & 0.023 & 0.032 & 0.053 & 0.092 & 0.154 & 0.237 & 0.295 & 0.340 & & $\mathrm{CH} 4$ & 0.029 & 0.030 & 0.042 & 0.071 & 0.123 & 0.206 & 0.315 & 0.394 & 0.453 \\
\hline $\mathrm{Ni}$ & $\mathrm{CO}$ & 0.005 & 0.022 & 0.062 & 0.139 & 0.266 & 0.454 & 0.695 & 0.860 & 0.981 & $\mathrm{Ni}$ & $\mathrm{CO}$ & 0.007 & 0.030 & 0.083 & 0.185 & 0.354 & 0.605 & 0.926 & 1.147 & 1.308 \\
\hline & $\mathrm{CO} 2$ & 0.092 & 0.139 & 0.204 & 0.293 & 0.407 & 0.541 & 0.678 & 0.710 & 0.702 & & $\mathrm{CO} 2$ & 0.123 & 0.185 & 0.272 & 0.390 & 0.542 & 0.722 & 0.904 & 0.946 & 0.936 \\
\hline & $\mathrm{C} 2 \mathrm{H} 4$ & 0.000 & 0.001 & 0.002 & 0.003 & 0.004 & 0.005 & 0.006 & 0.007 & 0.007 & & $\mathrm{C} 2 \mathrm{H} 4$ & 0.001 & 0.001 & 0.002 & 0.003 & 0.005 & 0.007 & 0.009 & 0.009 & 0.009 \\
\hline & $\mathrm{C} 2 \mathrm{H} 6$ & 0.001 & 0.002 & 0.003 & 0.005 & 0.007 & 0.009 & 0.011 & 0.012 & 0.011 & & $\mathrm{C} 2 \mathrm{H} 6$ & 0.001 & 0.002 & 0.004 & 0.006 & 0.009 & 0.012 & 0.015 & 0.016 & 0.015 \\
\hline & $\mathrm{C} 2 \mathrm{H} 2$ & 0.001 & 0.003 & 0.005 & 0.008 & 0.012 & 0.017 & 0.021 & 0.022 & 0.021 & & $\mathrm{C} 2 \mathrm{H} 2$ & 0.002 & 0.004 & 0.007 & 0.011 & 0.016 & 0.022 & 0.028 & 0.029 & 0.028 \\
\hline & $\mathrm{H} 2 \mathrm{O}$ & 2.413 & 2.702 & 2.997 & 3.258 & 3.416 & 3.369 & 3.022 & 2.094 & 1.182 & & $\mathrm{H} 2 \mathrm{O}$ & 3.217 & 3.603 & 3.996 & 4.344 & 4.555 & 4.493 & 4.029 & 2.792 & 1.577 \\
\hline & $\mathrm{C} 7 \mathrm{H} 16$ & 0.282 & 0.272 & 0.255 & 0.226 & 0.184 & 0.127 & 0.059 & 0.022 & 0.000 & & $\mathrm{C} 7 \mathrm{H} 16$ & 0.376 & 0.363 & 0.339 & 0.302 & 0.246 & 0.169 & 0.079 & 0.029 & 0.000 \\
\hline
\end{tabular}

To validate the reaction mechanism and the assumptions taken in this model it is required to compare the model used with data published on this topic. However, none of the published information which was available accounts for the effect of the whole spectrum of species that has been found in this study, which besides $\mathrm{H}_{2}$ and $\mathrm{CO}$ also includes $\mathrm{H}_{2} \mathrm{O}, \mathrm{CH}_{4}, \mathrm{C}_{2} \mathrm{H}_{2}, \mathrm{C}_{2} \mathrm{H}_{4}, \mathrm{C}_{2} \mathrm{H}_{6}$ and $\mathrm{CO}_{2}$. Thus, a more reduced set of species, similar to those used during experimental work $\left(\mathrm{H}_{2}\right.$ and $\mathrm{CO}$ ) was used during the validation stage of this model. Also the independent effect of $\mathrm{H}_{2} \mathrm{O}$ and $C O$ was analyzed in similarity with $E G R$, and the Individual effects of $\mathrm{C}_{2} \mathrm{H}_{2}, \mathrm{C}_{2} \mathrm{H}_{4}$ and $\mathrm{C}_{2} \mathrm{H}_{6}$ was modeled.

Table 9 presents values of ideal case composition of $\mathrm{H}_{2}$ and $\mathrm{CO}$ that were studied via CHEMKIN model and compared with experimental trends. This table represents $100 \%$ heptane conversion and no water.

Table 9 : Ideal case molar composition at different values of RG, $\varphi=0.8$

\begin{tabular}{|l|c|c|c|c|c|c|c|c|}
\hline & \multicolumn{2}{|c|}{$\mathbf{R G}=\mathbf{1 0} \%$} & \multicolumn{2}{c|}{$\mathbf{R G}=\mathbf{2 0} \%$} & \multicolumn{2}{c|}{$\mathbf{R G}=\mathbf{3 0} \%$} & \multicolumn{2}{c|}{$\mathbf{R G}=\mathbf{4 0} \%$} \\
\hline Species & $\mathrm{N}_{\mathrm{i}}$ & $\mathrm{X}_{\mathrm{i}}$ & $\mathrm{N}_{\mathrm{i}}$ & $\mathrm{X}_{\mathrm{i}}$ & $\mathrm{N}_{\mathrm{i}}$ & $\mathrm{X}_{\mathrm{i}}$ & $\mathrm{N}_{\mathrm{i}}$ & $\mathrm{X}_{\mathrm{i}}$ \\
\hline $\mathrm{nC}_{7} \mathrm{H}_{16}$ & 0.90 & 0.01 & 0.80 & 0.01 & 0.70 & 0.01 & 0.60 & 0.01 \\
\hline $\mathrm{O}_{2}$ & 13.75 & 0.20 & 13.75 & 0.19 & 13.75 & 0.18 & 13.75 & 0.18 \\
\hline $\mathrm{N}_{2}$ & 51.70 & 0.75 & 51.70 & 0.72 & 51.70 & 0.69 & 51.70 & 0.67 \\
\hline $\mathbf{H}_{\mathbf{2}}$ & 2.10 & 0.03 & 4.20 & 0.06 & 6.30 & 0.08 & 8.40 & 0.11 \\
\hline $\mathbf{C O}$ & 0.70 & 0.01 & 1.40 & 0.02 & 2.10 & 0.03 & 2.80 & 0.04 \\
\hline
\end{tabular}




\begin{tabular}{|l|l|l|l|l|l|l|l|l|}
\hline Total $\mathrm{N}_{\mathrm{i}}$ & 69.15 & 1.00 & 71.85 & 1.00 & 74.55 & 1.00 & 77.25 & 1.00 \\
\hline
\end{tabular}

Initial runs based on the reduced reaction mechanism (29 species and 52 reactions) developed at the Engine Research Center at the University of Wisconsin at Madison [40,41] were unable to represent experimental results on $\mathrm{H}_{2}$ and $\mathrm{CO}$ effects on homogeneous charge compression ignition combustion of low octane fuels. A second reaction mechanism from LLNL was studied: a 561 species and 2539 reactions developed and used to study the oxidation of $n-$ heptane in flow reactors, shock tubes and rapid compression machines. This reaction mechanism was validated by the researchers over a range of pressures from 1 bar to 42 bar, temperatures covering the $550 \mathrm{~K}$ to $1700 \mathrm{~K}$ range and equivalence ratios from 0.3 to 1.5 . [42]. Results and its analysis are presented in the next section.

\subsection{Model analysis and results}

A zero-dimensional, closed, perfectly mixed model was developed in CHEMKIN to simulate the $\mathrm{HCCl}$ combustion. At intake valve closing (IVC), the in-cylinder mixture composition is considered homogeneous. The manifold temperature and pressure at IVC are considered as the initial conditions for the differential equations. The homogeneous mixture is compressed and expanded following the slider-crank kinematics. The compression of the in-cylinder charge provides the temperature conditions to trigger the autoignition process. The chemical kinetic code that describes the combustion of $n$-heptane in air was taken from the Lawrence Livermore National Laboratory [42]. Heat transfer to the walls was calculated using the Woschni's correlation, with a constant wall temperature of $420 \mathrm{~K}$. The thermodynamic fundamentals of this model were previously described by the authors in reference [43]. This oversimplified model does not account for the boundary layer mass, with lower temperature than the cylinder core. This overall higher in-cylinder temperature leads to faster combustion reactions, and higher peak pressures than the values reported by experiments. However, combustion phasing, or CA50 have been shown to be determined with good accuracy [44].

The engine in-cylinder charge at IVC, was defined as a mixture of gases where the total amount of fuel to the system (defined by engine and reformer) was fixed, as well as the total amount of air, in order to obtain a constant system equivalence ratio $(\varphi=0.8)$. The amount of fuel that was taken from the total fuel to feed the reformer was denominated as RG. Water was added to match the amount of $n$-heptane to keep the ratio $S: C=2: 1$. The output gases concentration from the steam/n-heptane reforming system, or RG species concentration, was defined by the adjusted polynomial fit as function of reforming temperature $\left(T_{\text {ref }}\right)$. 
Initial conditions defined by the species concentration of fuel, air and RG were then used in the numerical model to study the effects of $R G$ under different reforming temperatures in the $\mathrm{HCCl}$ process.

The combustion parameters employed in this paper to analyze the combustion process are defined as follows. The LTHR regime was characterized using the low temperature start of ignition $\left(\mathrm{SOI}_{\mathrm{L}}\right)$, expressed as $\mathrm{CA}$ degrees, and the maximum heat release rate magnitude $\left(L_{T H R_{\max }}\right)$. The HTHR regime was similarly characterized by the high temperature start of ignition $\left(\mathrm{SOI}_{\mathrm{H}}\right)$ and its corresponding maximum heat release rate magnitude $\left(\mathrm{HTHR}_{\max }\right)$. T_SOI $\mathrm{L}$ and $\mathrm{T}_{-} \mathrm{SOI}_{\mathrm{H}}$ are the gas mixture temperature values corresponding to $\mathrm{SOI}_{\mathrm{L}}$ and $\mathrm{SOI}_{\mathrm{H}}$ respectively. The crank angle for $50 \%$ energy release (CA50) was also calculated.

\subsubsection{Combustion parameters}

Figure 28 presents the main combustion parameters employed in this analysis. LTHR and $H T H R$ are clearly identified, with corresponding maximum values $L_{T H R_{\max }}$ and $\mathrm{HTHR}_{\max }$ respectively. The crank angle degree corresponding to $50 \%$ of the total heat release is marked as CA50. SOI $\mathrm{L}_{\mathrm{L}}$ is defined as the start of ignition for the LTHR regime. It was calculated as the crank angle at $10 \%$ of the value corresponding to maximum dT/dCA. The start of ignition for HTHR $\left(\mathrm{SOI}_{H}\right)$, in crank angles degrees corresponds to the local minimum between $\mathrm{LTHR}_{\max }$ and $H_{T H R}$ max. The magnitude of the energy released during the LTHR regime, identified here as $H R_{L}$, is calculated as the accumulated value from $\mathrm{SOI}_{\mathrm{L}}$ up to $\mathrm{SOI}_{\mathrm{H}}$. No heat transfer is considered in this calculation. T_SOI and $\mathrm{T}_{-} \mathrm{SOI}_{\mathrm{H}}$ are the gas mixture temperature values corresponding to $\mathrm{SOI}_{\mathrm{L}}$ and $\mathrm{SOI}_{\mathrm{H}}$ respectively. 


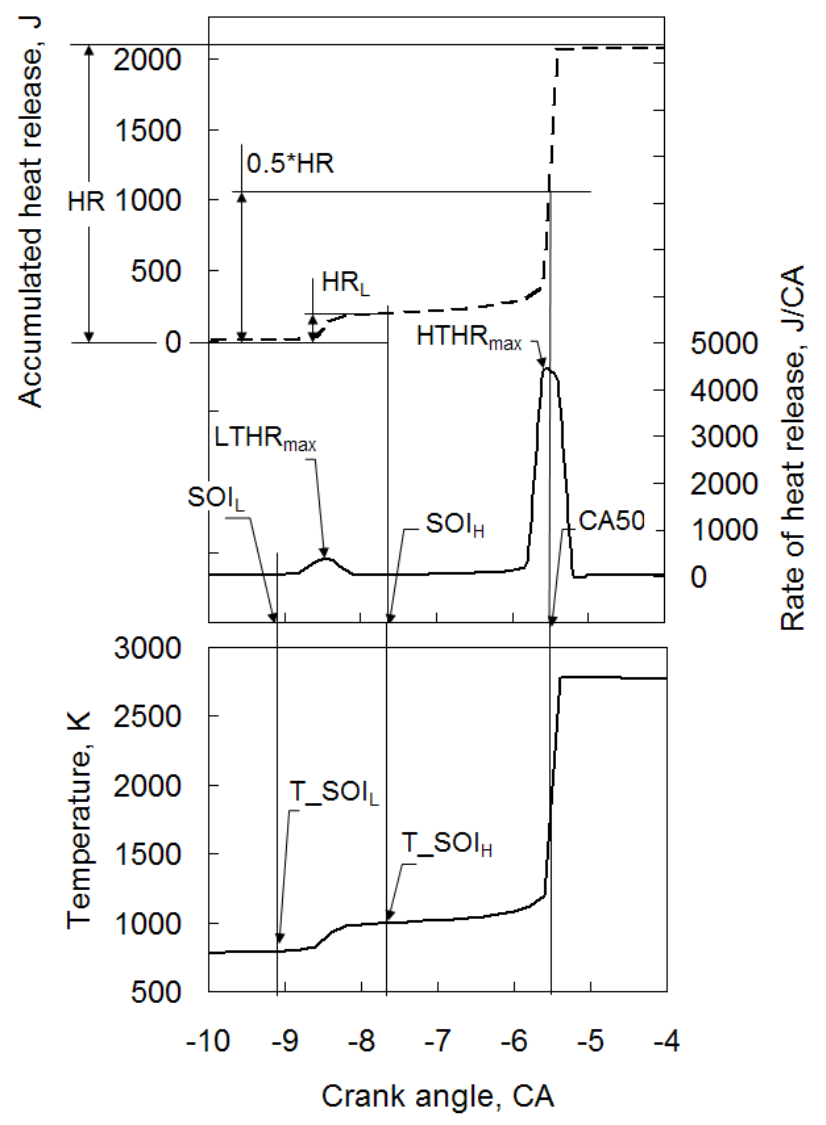

Figure 28 : Definition of combustion parameters and its nomenclature

\subsubsection{Model Verification}

The model verification was performed against experimental results from Hosseini and Checkel [38], at $700 \mathrm{rpm}$ and using a $\mathrm{RG}$ composed of $\mathrm{H}_{2}-75 \%$ and $\mathrm{CO}-25 \%$. Figure 29 shows that the zero-dimensional model predicts the general trend of the effect of $R G$ addition on the start of combustion (SOC). The values of SOC reported by Dr. Checkel's team were defined as $10 \%$ of the total heat release, and this definition was employed to calculate the numeric values of SOC to tune the zero-dimensional model. The difference between model and experimental SOC values was attributed to the model rapid combustion reactions. 


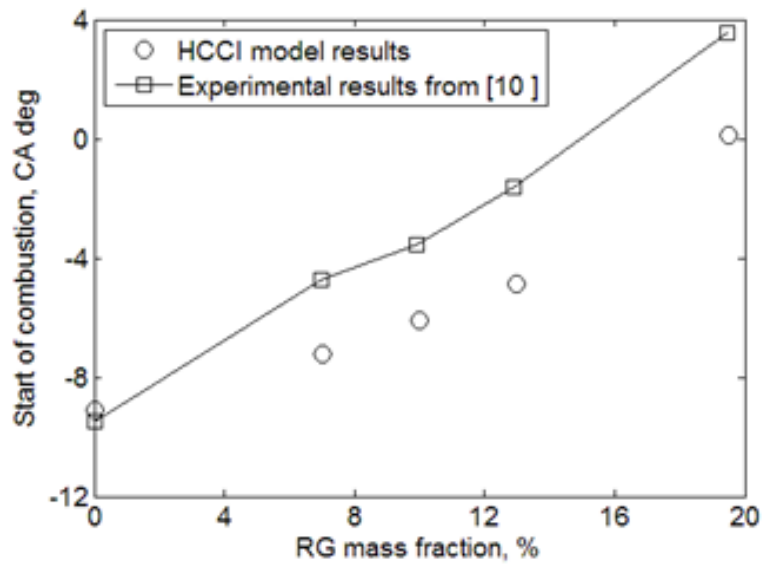

Figure 29 Effect of RG addition on SOC for $n$-heptane. Experimental data from reference [38]. $\mathrm{T}_{\mathrm{INT}}=373 \mathrm{~K}, 700 \mathrm{rpm}, \varphi=0.806, \mathrm{EGR}=40 \%$

For this study, one single case of engine speed (1200 rpm) intake temperature (370 K), system equivalence ratio $(\varphi=0.8)$ and no $E G R$ was studied. The compression ratio was set at 12 , and the intake manifold pressure was modeled as a naturally aspirated engine (100 kPa).

\subsubsection{Model results: ideal case composition}

The effect of increasing the amount of RG into the cylinder was studied first at the ideal case scenario. Figure 30 shows the change in timing of the onset of ignition as a result of variations in $R G$. It is evident that by increasing the amount of $\mathrm{H} 2+\mathrm{CO}$ the ignition event is delayed, in agreement with experimental results published by Hosseini and Checkel [38]. The temperature history before the LTHR regime increases in direct proportion to RG. The replacement of fuel molecules by smaller gas molecules reduces the average mixture specific heat. This results in higher mixture temperature during the compression process before the LTHR stage.

The LTHR region, corresponding to the magnified area in Figure 31, shows that the thermal effect (higher temperature) advances the $\mathrm{SOI}_{\mathrm{L}}$ by a few CA degrees. However, after this sharp increase in temperature due to heat released during the LTHR regime, the temperature increase was proportionally reduced with increasing amount of RG. Misfire was predicted at $40 \% R G$. This inversion in temperature profile can be only explained by kinetics effects due to the addition of RG. 


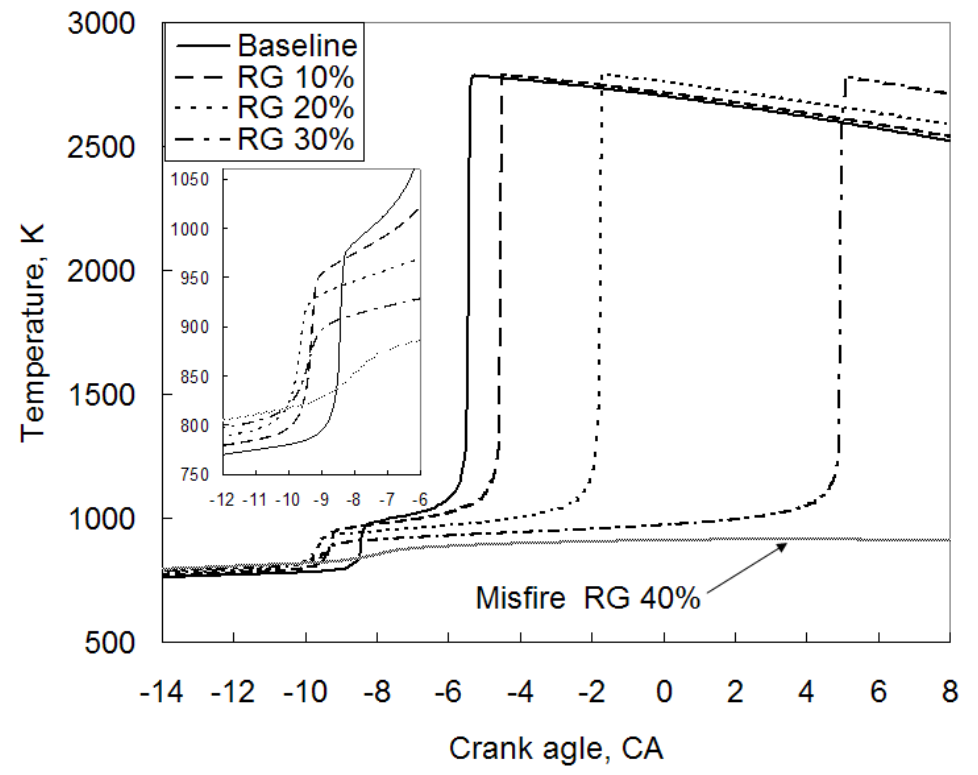

Figure 30 : Temperature curves at $\varphi=0.8$ and different values of RG based on ideal case composition. Baseline $\varphi=0.8$

Figure 31 presents the rate of heat release corresponding to Figure 30 . The maximum value of rate of heat release is advanced in proportion with $R G$ values, up to $30 \% R G$ when the $\mathrm{LTHR}_{\text {max }}$ event is retarded in comparison to $20 \% \mathrm{RG}$. The LTHR region was not present at $40 \%$ $R G$ according to the numerical results. The inhibiting effect on main ignition timing was due to the ability of RG to suppress LTHR reactions. This effect can be observed in Figure 31, where the values of $L T H R_{\max }$ were reduced in direct proportion to $R G$. Numerical values of heat released during the $L T H R$ stage, indicated as $H R_{L}$, were integrated from $S O I_{L}$ up to the crank angle where the LTHR $_{\max }$ event occurred.

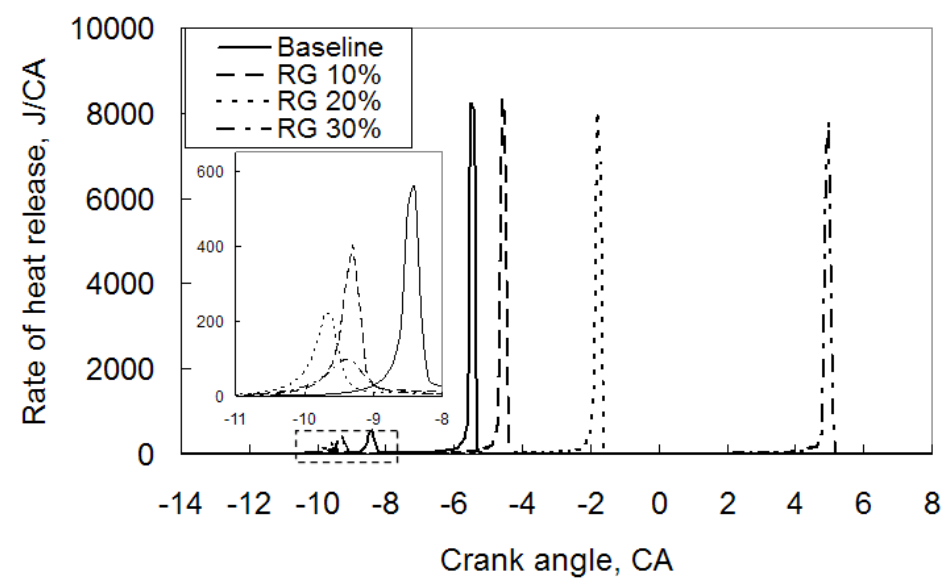

Figure 31 : Rate of heat release for different values of RG based on ideal case composition, $\mathrm{S}: \mathrm{C}=2: 1$. Baseline $\varphi=0.8, \mathrm{~T}_{\mathrm{INT}}=370 \mathrm{~K}, 1200 \mathrm{rpm}$ 
Figure 32 presents the correlation between $\mathrm{HR}_{\mathrm{L}}$ normalized with respect to the total energy released and CA50. The main ignition event was delayed at higher amounts of RG where the fraction of energy released during the LTHR regime was smaller.

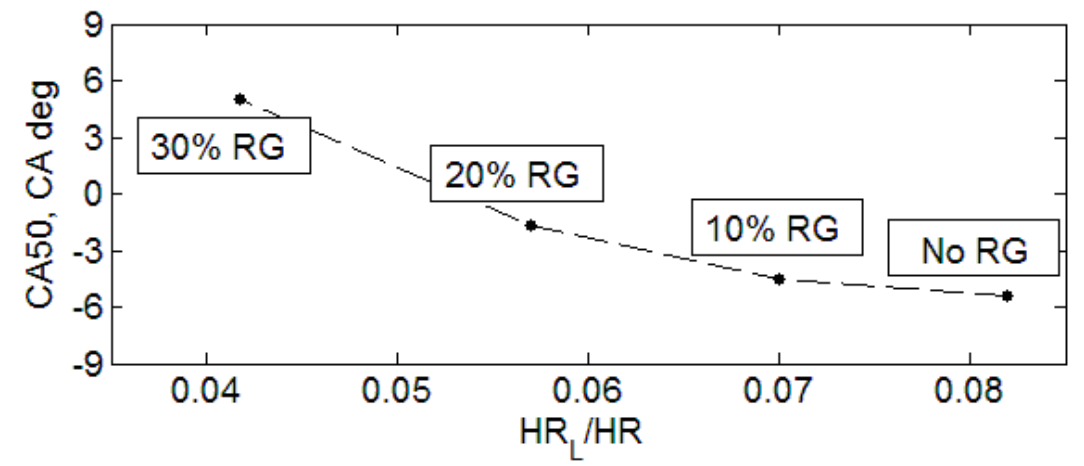

Figure 32 : Relation between $\mathrm{HR}_{\mathrm{L}}$ as a fraction of total heat release $\mathrm{HR}$, and CA50 for different values of $R G$ based on ideal case composition, $S: C=2: 1$. Baseline $\varphi=0.8, T_{I N T}=370$ $\mathrm{K}, 1200 \mathrm{rpm}$

In order to understand the ability of $R G$ to reduce the LTHR magnitude and delay the ignition event, the independent effects of $\mathrm{H}_{2}$ and $\mathrm{CO}$ addition to the reactants mixture were also investigated.

\subsection{4 $\mathrm{H}_{2}$ and $\mathrm{CO}$ addition}

Figure 33 presents the in-cylinder temperature history performing a sweep of $\mathrm{H}_{2}$ composition ( $N o \mathrm{CO}$ or $\mathrm{H}_{2} \mathrm{O}$ added), where the number of $\mathrm{H}_{2}$ moles added to the intake charge corresponded to molar values found in the $R G$ mixture. For each case of $\mathrm{H}_{2}$ addition, the molar composition of $n$-heptane and air was kept at the baseline case $(\varphi=0.8)$.

Two interesting characteristics were observed with the addition of $\mathrm{H}_{2}$. First, the replacement of fuel molecules by diatomic molecules leads to changes in the thermodynamic mixture properties such as the mixture specific heat, $c_{p}$, and hence the mixture ratio of specific heats, $\gamma$. Such effect can be observed in the region a in Figure 33, where the temperature before the cool flame reaction region $(\mathrm{T}<780 \mathrm{~K})$ was higher at higher concentrations of $\mathrm{H}_{2}$. Second, despite the fact that pre-ignition temperature was higher at higher $\mathrm{H}_{2}$ content, CA50 was delayed in proportion to the amount of $\mathrm{H}_{2}$ added. This effect can only be explained under chemical kinetics concepts as can be observed in the region $\mathbf{b}$ of Figure 33, where the LTHR process was proportionally delayed with $\mathrm{H}_{2}$ addition. 


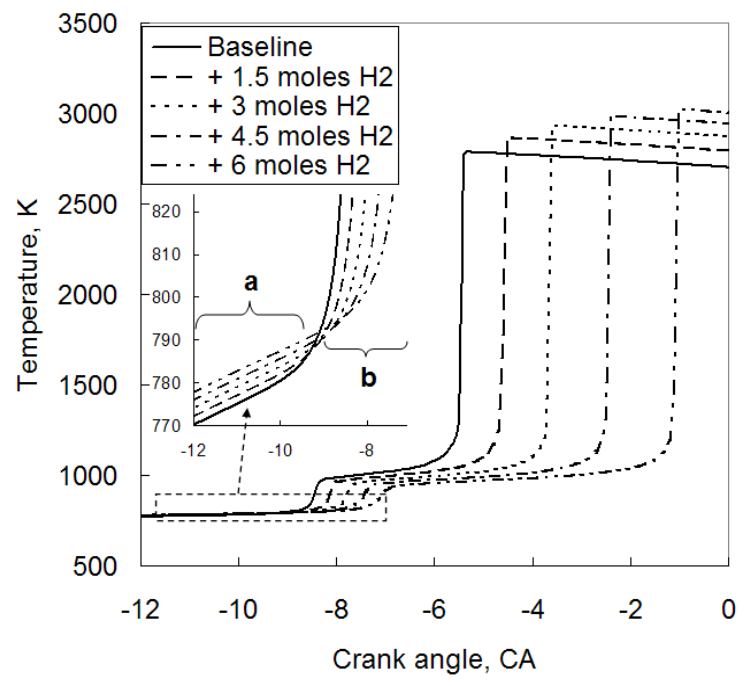

Figure 33 : Temperature curves at different values of $\mathrm{H}_{2}$ addition (No $\mathrm{CO}$ or $\mathrm{H}_{2} \mathrm{O}$ ), Baseline $\varphi=0.8, \mathrm{~T}_{\mathrm{INT}}=370 \mathrm{~K}, 1200 \mathrm{rpm}$

Figure 34 presents the in-cylinder temperature history performing a sweep of CO composition ( $\mathrm{No}_{2}$ or $\mathrm{H}_{2} \mathrm{O}$ added), where the number of $\mathrm{CO}$ moles added to the intake charge corresponded to molar values found in the RG mixture. For each case of $\mathrm{CO}$ addition, the molar composition of $\mathrm{n}$-heptane and air was kept at the baseline case $(\varphi=0.8)$.

The addition of $\mathrm{CO}$ did encourage an earlier low temperature combustion regime, with a slight change in the onset of the main ignition event. The thermal effect of $\mathrm{CO}$ addition, expressed by changes in the mixture specific heat, was small in comparison to the effect produced by $\mathrm{H}_{2}$ addition, as can be observed in the amplified area in Figure 34.

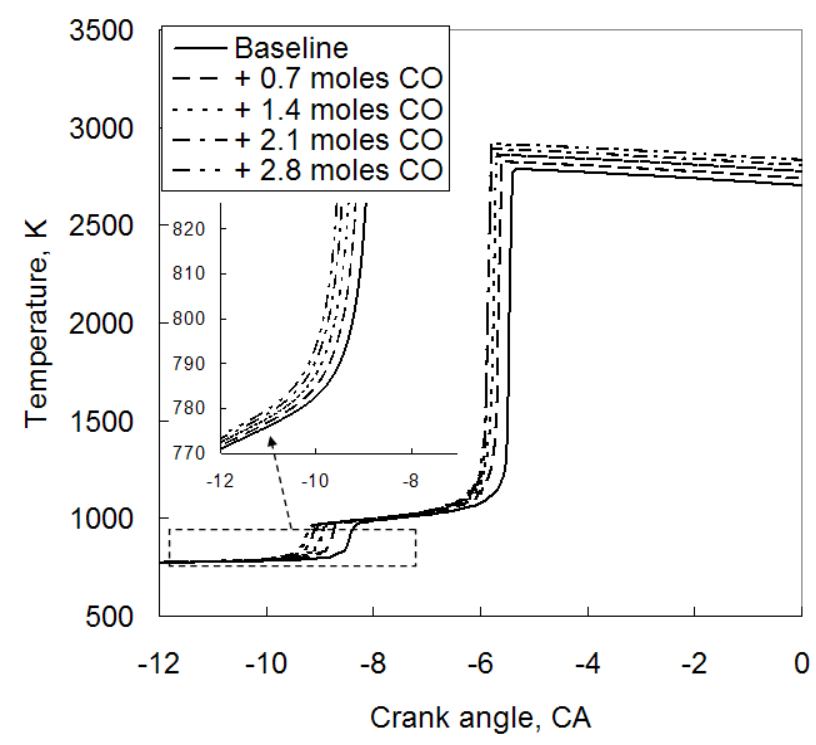

Figure 34 : Temperature curves at different values of $\mathrm{CO}$ addition $\left(\mathrm{No}_{2}\right.$ or $\left.\mathrm{H}_{2} \mathrm{O}\right)$, Baseline $\varphi=0.8, T_{\mathrm{INT}}=370 \mathrm{~K}, 1200 \mathrm{rpm}$ 
Fundamental studies of primary reference fuels (PRFs) have demonstrated that $n$-heptane has a clearly distinguishable two stage ignition. These are the cool flame region or LTHR with a negative temperature coefficient behavior (NTC), and the later main ignition stage or HTHR. Figure 35 shows the rate of heat release for $\mathrm{H}_{2}$ addition corresponding to Figure 33 . The two stage ignition process, LTHR and HTHR can be associated with fast changes in mixture temperature. The addition of $\mathrm{H}_{2}$ delayed the LTHR process proportionally. Any modification in the LTHR regime affects the behavior of the HTHR, as was previously acknowledged by Westbrook [15]. Numerical results show that the LTHR magnitude was reduced and that its occurrence was delayed by $1.3 \mathrm{CA}$ degrees at maximum $\mathrm{H}_{2}$ addition. The HTHR regime was then delayed from -5.5 CA degrees (baseline) to $-1.1 \mathrm{CA}$ degrees at the maximum $\mathrm{H}_{2}$ addition. It should be noted that zero-dimensional $\mathrm{HCCl}$ models generate shorter combustion duration with higher values of rate of heat release when compared to experimental results [44].

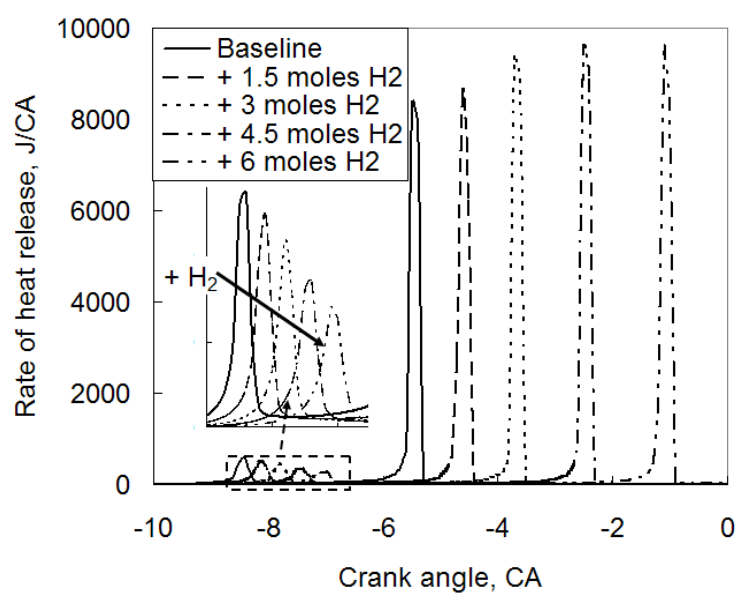

Figure 35 : Rate of heat release for different values of $\mathrm{H}_{2}$ addition (No $\mathrm{CO}$ or $\mathrm{H}_{2} \mathrm{O}$ ), Baseline $\varphi=0.8, \mathrm{~T}_{\mathrm{INT}}=370 \mathrm{~K}, 1200 \mathrm{rpm}$

The addition of CO produced the opposite effect on rate of heat release when compared to $\mathrm{H}_{2}$ addition. The numerical results are shown in Figure 36. In this case, the LTHR was advanced 1 $\mathrm{CA}$ degree at maximum $\mathrm{CO}$ concentration, inducing a HTHR stage slightly earlier than the baseline by 0.5 CA degrees.

Figure 37 presents the effects of $\mathrm{H}_{2}$ and $\mathrm{CO}$ addition on the amount of energy released during the LTHR stage and its correlation with CA50. Values of $H R_{L}$ were normalized with respect to the total energy released $H R$. For $H_{2}$ addition, $H R_{L}$ is reduced as the concentration of $H_{2}$ is increased, and the correlation between $\mathrm{HR}_{\mathrm{L}}$ and $\mathrm{CA} 50$ is remarkably linear. In contrast, the addition of $\mathrm{CO}$ shows no significant impact on the main ignition event, and a non-linear relationship exists between the amount of $\mathrm{CO}$ added and the fraction of $\mathrm{HR}_{\mathrm{L}}$. 


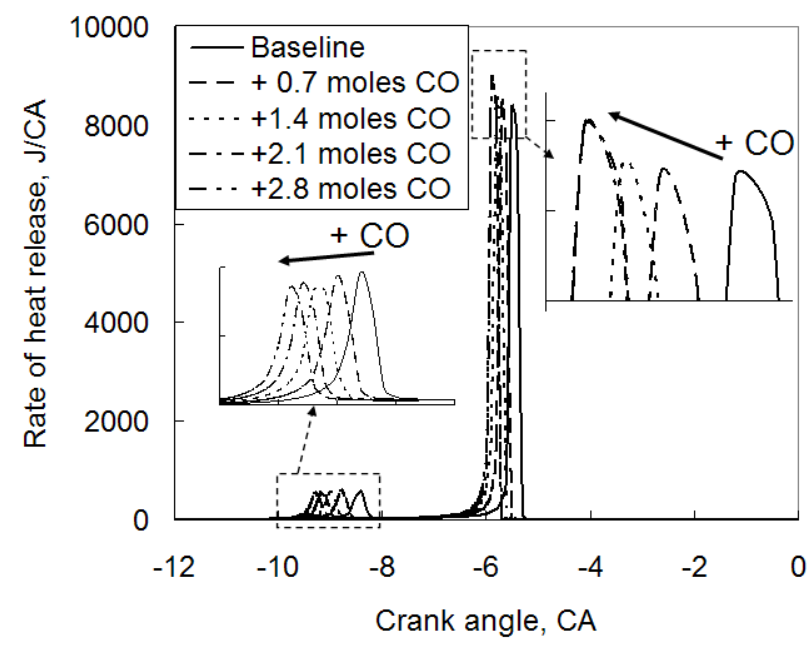

Figure 36 : Rate of heat release for different values of $\mathrm{CO}$ addition (No $\mathrm{H}_{2}$ or $\mathrm{H}_{2} \mathrm{O}$ ), Baseline $\varphi=0.8, \mathrm{~T}_{\mathrm{INT}}=370 \mathrm{~K}, 1200 \mathrm{rpm}$

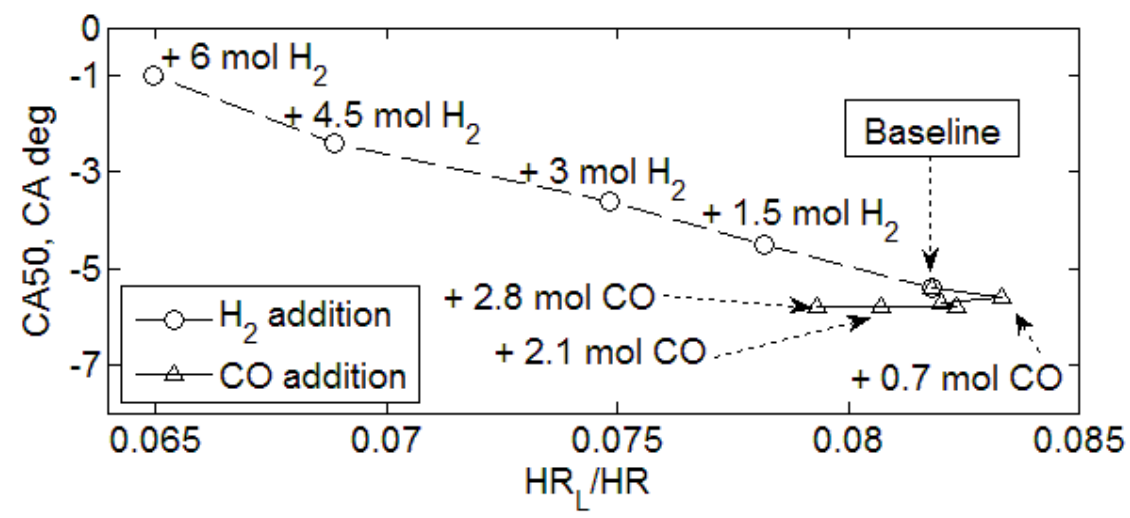

Figure 37 : Relation between $\mathrm{HR}_{\mathrm{L}}$ as a fraction of total heat release $\mathrm{HR}$, and the main ignition event timing, CA50, for different values of $\mathrm{H}_{2}$ and $\mathrm{CO}$ addition $\left(\mathrm{No}_{2} \mathrm{O}\right)$, Baseline $\varphi=0.8, T_{\text {INT }}=370 \mathrm{~K}, 1200 \mathrm{rpm}$

The low temperature combustion regime characteristic of alkenes and the effect of $\mathrm{H}_{2}$ and $\mathrm{CO}$ addition on this phenomenon can be appreciated better in Figure 38, where the rate of change of temperature is plotted against the mixture temperature. Section (a) in Figure 38 shows the rate of temperature change with $\mathrm{H}_{2}$ addition. For the baseline case $(\varphi=0.8)$, the LTHR regime was clearly present along the temperature range from $800 \mathrm{~K}$ to $850 \mathrm{~K}$, where the ignition is controlled by degenerative chain branching processes [15]. As explained by Warnatz et al. [4545], the $\mathrm{RO}_{2}$ • radicals that are produced during this period decompose back to the reactants due to their instability at high temperatures. The radical decomposition then leads the mixture temperature to the NTC region, between 950 and $1000 \mathrm{~K}$, where the rate of change of temperature is reduced at higher values of temperature until the chain branching stops. A subsequent series of chain 
branching reactions in the intermediate temperature range (900 K -1000 K) leads to the build up of $\mathrm{H}_{2} \mathrm{O}_{2}$ concentration. The $\mathrm{H}_{2} \mathrm{O}_{2}$ role during the combustion process is to provide the source for $\mathrm{OH}$ radicals required at the main ignition event. The HTHR was then identified to occur at temperatures higher than $1000 \mathrm{~K}$, as predicted by kinetic theory on large hydrocarbon combustion [15].

The addition of $\mathrm{H}_{2}$ (Fig. 38a) reduced the rate of temperature rise, (expressed as $d T / d C A$ ), during the low temperature reaction stage, and shifted the NTC zone to lower temperatures. As a consequence, the HTHR zone was also shifted towards lower temperature ranges when compared to the baseline mixture, as can be appreciated in Figure 33. CO addition, in contrast, did not show such an important influence during the LTHR regime, as can be seen in Fig. 38b, where the NTZ zones suffered a slight reduction. Its strongest effect was noticeable during the HTHR regime, where the rate of change of temperature, an indicator of rate of heat release, was moved towards higher temperature ranges.

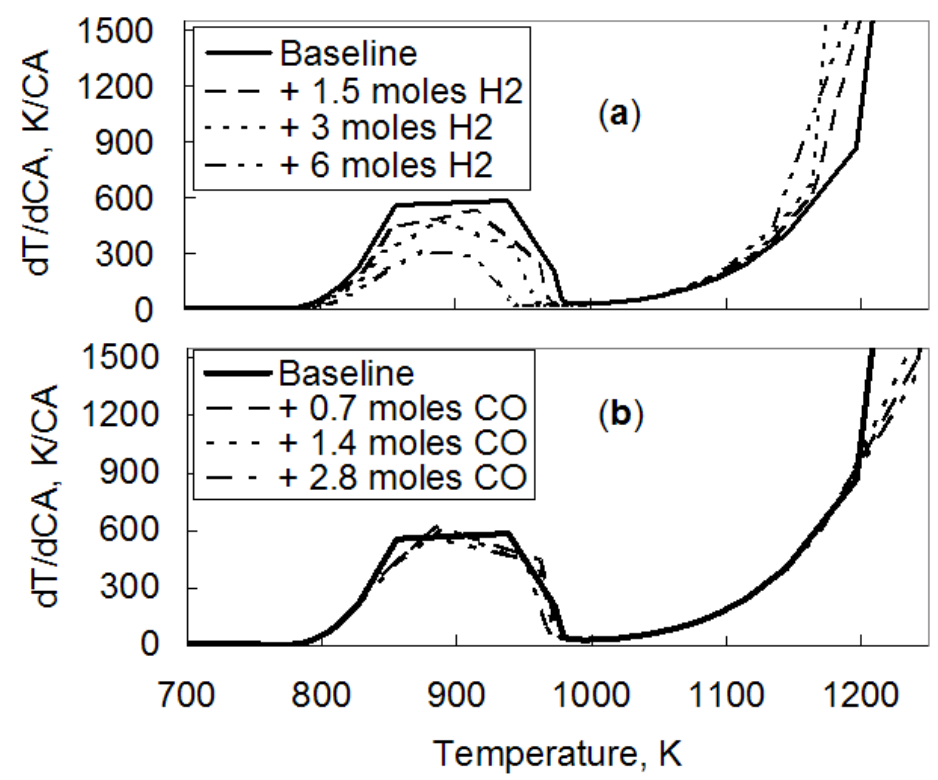

Figure 38 : Rate of change of temperature along the temperature domain. (a) For different values of $\mathrm{H}_{2}$ addition (No CO, $\mathrm{H}_{2} \mathrm{O}$ ), (b) For different values of $\mathrm{CO}$ addition ( $\left.\mathrm{No} \mathrm{H}_{2}, \mathrm{H}_{2} \mathrm{O}\right)$. Baseline $\varphi=0.8, \mathrm{~T}_{\mathrm{INT}}=370 \mathrm{~K}, 1200 \mathrm{rpm}$

The effect of modifying the low temperature reactions (cool flames) regime is to change the time at which $\mathrm{H}_{2} \mathrm{O}_{2}$ decomposition occurs, which is the key reaction for autoignition of hydrocarbon [15]. Numerical results show that ignition was observed when the mixture reached the $\mathrm{H}_{2} \mathrm{O}_{2}$ decomposition temperature, usually around $1100 \mathrm{~K}$. Even though the thermal effects of adding $\mathrm{H}_{2}$ tend to increase the temperature before the pre-ignition combustion regime, the ignition event was delayed. Figure 39 shows the effect of hydrogen and carbon monoxide addition on $\mathrm{H}_{2} \mathrm{O}_{2}$ and $\mathrm{OH}$ molar fraction. 


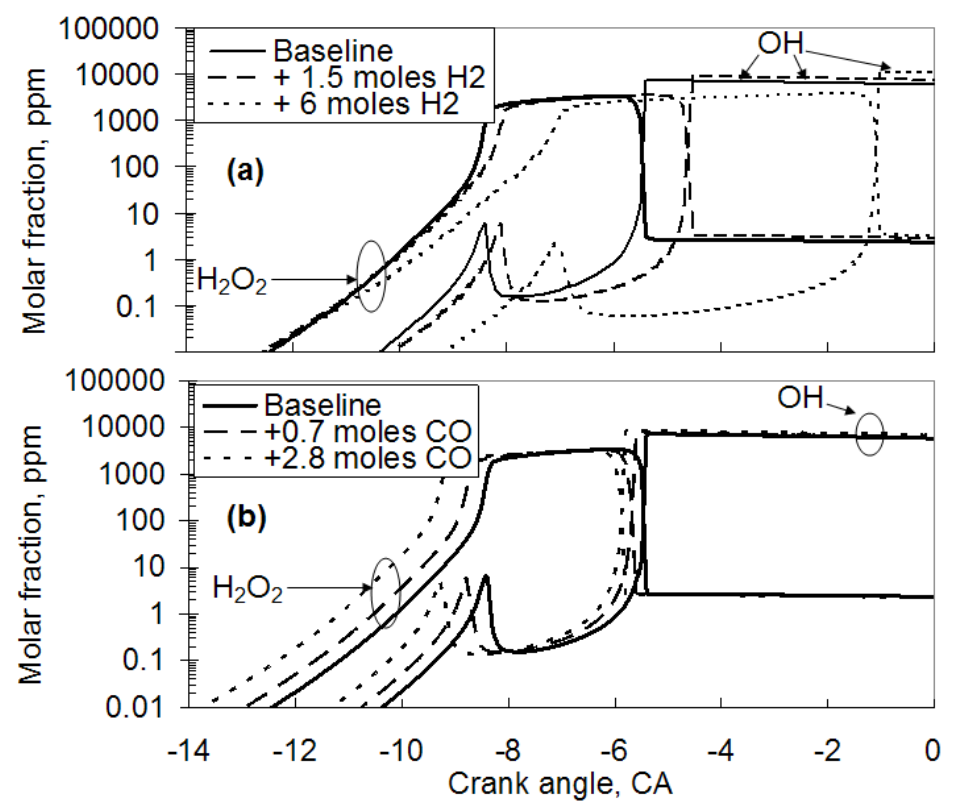

Figure 39 : Computed molar fraction of $\mathrm{H}_{2} \mathrm{O}_{2}$ for $\mathrm{H}_{2}$ addition (a) and for $\mathrm{CO}$ addition (b). Baseline $\varphi=0.8, T_{\text {intake }}=370 \mathrm{~K}, 1200 \mathrm{rpm}$

When the $\mathrm{H}_{2} \mathrm{O}_{2}$ molar fraction depicted in Figure 39 was compared to the rate of heat release for $\mathrm{H}_{2}$ and $\mathrm{CO}$ addition, Figures 35 and 36 respectively, it can be observed that the main ignition event coincides with the $\mathrm{H}_{2} \mathrm{O}_{2}$ consumption. In Figure 35, at maximum $\mathrm{H}_{2}$ addition, the main ignition starts around -1.1 CA degrees, which corresponds to $\mathrm{H}_{2} \mathrm{O}_{2}$ depletion event in Figure 39a. Figure 36 shows that at maximum $\mathrm{CO}$ concentration the main ignition onset was started at -5.9 CA degrees, $0.5 \mathrm{CA}$ degrees earlier than the baseline ignition, which again corresponds to $\mathrm{H}_{2} \mathrm{O}_{2}$ depletion event in Figure 39b. The $\mathrm{H}_{2} \mathrm{O}_{2}$ buildup concentration process differs considerably in each case. For $\mathrm{CO}$ addition, the concentration trend of $\mathrm{H}_{2} \mathrm{O}_{2}$ was almost parallel for each case, suggesting a proportional change in species concentration due to changes on initial concentration of $\mathrm{CO}$. The addition of $\mathrm{H}_{2}$ changed the rate at which the $\mathrm{H}_{2} \mathrm{O}_{2}$ was generated, an indication of additional reactions involved during the cool flames regime. The spike of $\mathrm{OH}$ concentration was related with the LTHR period. The $\mathrm{OH}$ spike was retarded and reduced in magnitude as more $\mathrm{H}_{2}$ was added, a feature that corresponded with the reduction on $H R_{L}$.

From this study, the separate effects of $\mathrm{H}_{2}$ and $\mathrm{CO}$ were clearly defined. The low temperature combustion regime was delayed by $\mathrm{H}_{2}$ addition and advanced by $\mathrm{CO}$. As a result of the change of LTHR timing and magnitude, the HTHR regime was delayed by $\mathrm{H}_{2}$ addition, and slightly advanced by $\mathrm{CO}$ addition. The magnitude of LTHR was $26 \%$ lower than the baseline case at the maximum $\mathrm{H}_{2}$ concentration ( +6 moles $\mathrm{H}_{2}$ ), while the $\mathrm{CO}$ addition reduced the LTHR magnitude by $6.5 \%$. 
Results obtained from the ideal case composition supported accepting the model based on the LLNL kinetics code as a good approximation to experimental results found in the literature regarding the effect of $\mathrm{H} 2$ and $\mathrm{CO}$ in homogeneous charge compression ignition engines fueled by n-heptane.

After the validation process of comparing results from the ideal case composition to experimental results by Hosseini and Checkel [38] was completed, the real case composition was examined.

\subsubsection{Model results: real case composition}

The LTC model was run at different values of RG, based on molar composition summarized in table 2, without including minor species, such as $\mathrm{C}_{2} \mathrm{H}_{2}, \mathrm{C}_{2} \mathrm{H}_{4}$ and $\mathrm{C}_{2} \mathrm{H}_{6}$. Figure 40 shows results corresponding to $10 \%$ of fuel reformed, $R G=10 \%$. Calculated results for the case of $R G=10 \%$ show that the main ignition event can be delayed by one crank angle degree, independent of the expected reformed gas composition. It can be appreciated in the close up frame on Figure 40 that calculated trends show an advance on the low temperature combustion region, which could be generated by thermal effects, but the main ignition was delayed, which was evidence of a kinetic governed main ignition event.

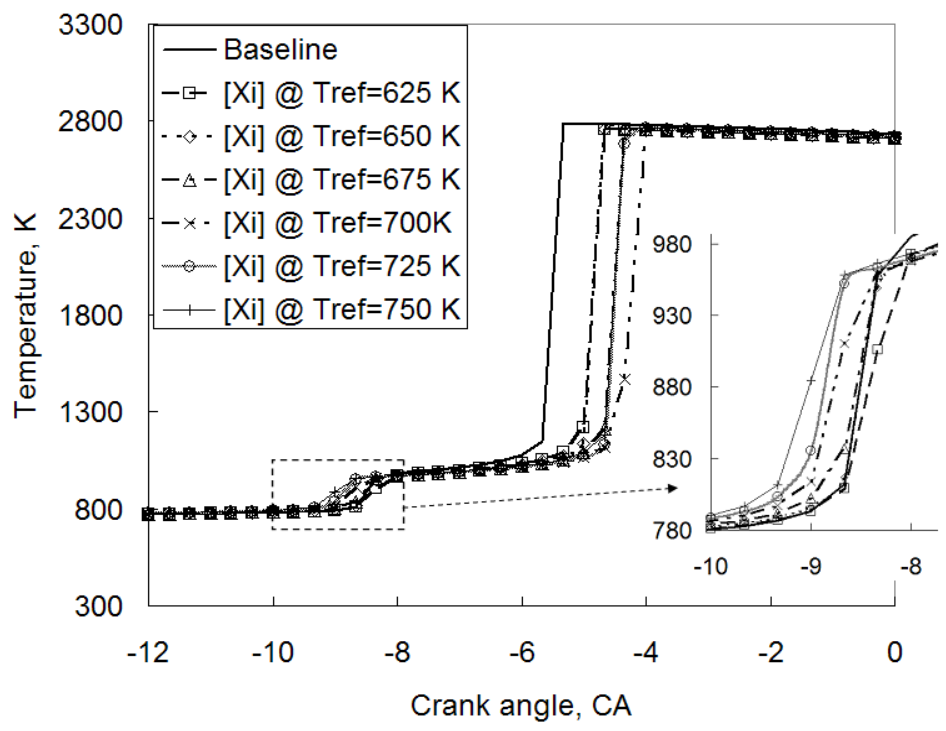

Figure 40 : Computed temperature history for real case composition, $R G=10 \%$, at different mixture composition according to reforming temperature. Baseline $\varphi=0.8$

Calculated results representing taking $20 \%$ of the fuel into the fuel-steam reforming process $(R G=20 \%)$, are presented in Figure 41 . The same trend was found, where the thermal effects favored an earlier low temperature combustion regime, due to higher mixture temperatures, but the main ignition was delayed several crank angles, an indication of a reaction governed by 
chemical kinetics. At this mixture composition the trend was more complex. Despite the fact that at higher reforming temperatures the $\mathrm{H} 2$ concentration was higher, and that from previous model results, higher concentrations of $\mathrm{H} 2$ proportionally delayed the main ignition, the overall effect did not follow this rule.

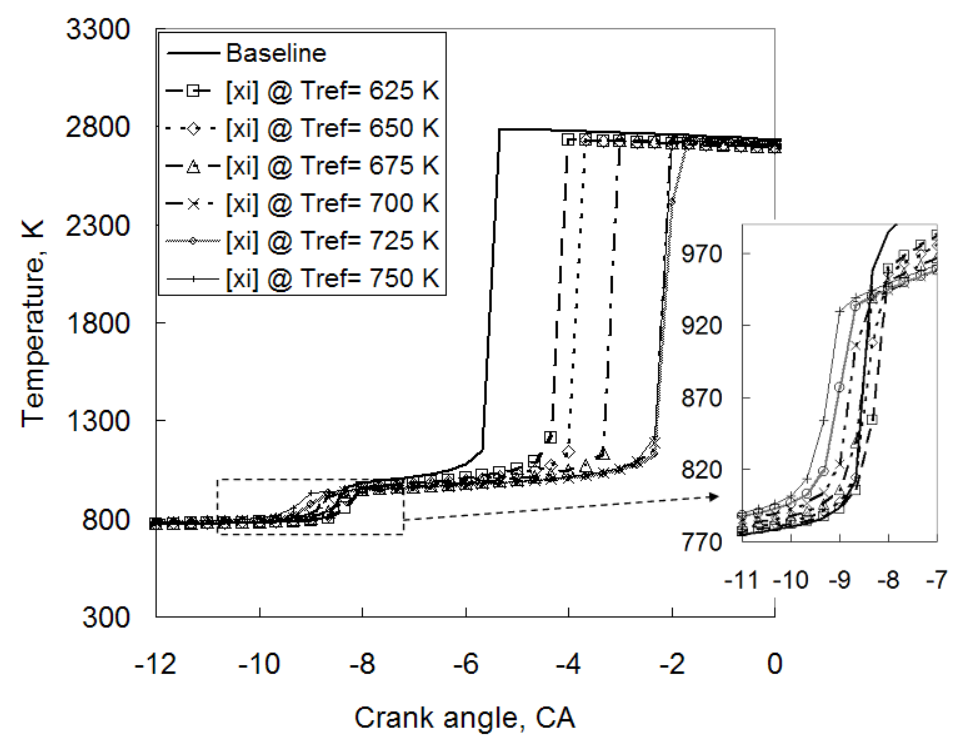

Figure 41 : Computed temperature history for real case composition, $R G=20 \%$, at different mixture composition according to reforming temperature. Baseline $\varphi=0.8$

The trends in Figure 41 show that very similar values of ignition delay were achieved at different concentrations corresponding to different reforming temperatures. It was found that the thermal effects that favored an earlier low temperature combustion regime with increased values of $R G$ were reduced by the concentration of $R G$, which generated a slower rate of change of temperature, as was explained by Figure 38a above. The reduction of dT/dCA forced a delayed HTHR stage at the $R G$ concentration corresponding to low $\mathrm{H}_{2}$ and $\mathrm{CO}$ concentrations $\left(\mathrm{T}_{\text {ref }}=625 \mathrm{~K}\right.$ and $650 \mathrm{~K})$. CA50 was delayed several degrees $\mathrm{CA}$ and the influence of specific reforming composition was more evident at this value of $R G$. It can be observed that the delay was proportional to the $\mathrm{H}_{2}$ content of the reformed gas, which increased with $\mathrm{T}_{\text {ref, }}$, but the influence of other species also affected the main ignition timing, as can be derived by the trends at $T_{\text {ref }}=700$ $\mathrm{K}, 725 \mathrm{~K}$ and $750 \mathrm{~K}$.

Calculated temperature curves at $R G=30 \%$ are presented in Figure 40. At this value of $R G$, the ignition onset was found after TDC for three cases of reforming composition corresponding to reforming temperatures of $700 \mathrm{~K}, 725 \mathrm{~K}$ and $750 \mathrm{~K}$. Those results show a start of LTHR earlier than the baseline case, with an overall temperature trend lower than the values reached by the baseline case. This tendency of a general lower temperature history is similar to previous results based in real case composition.. 


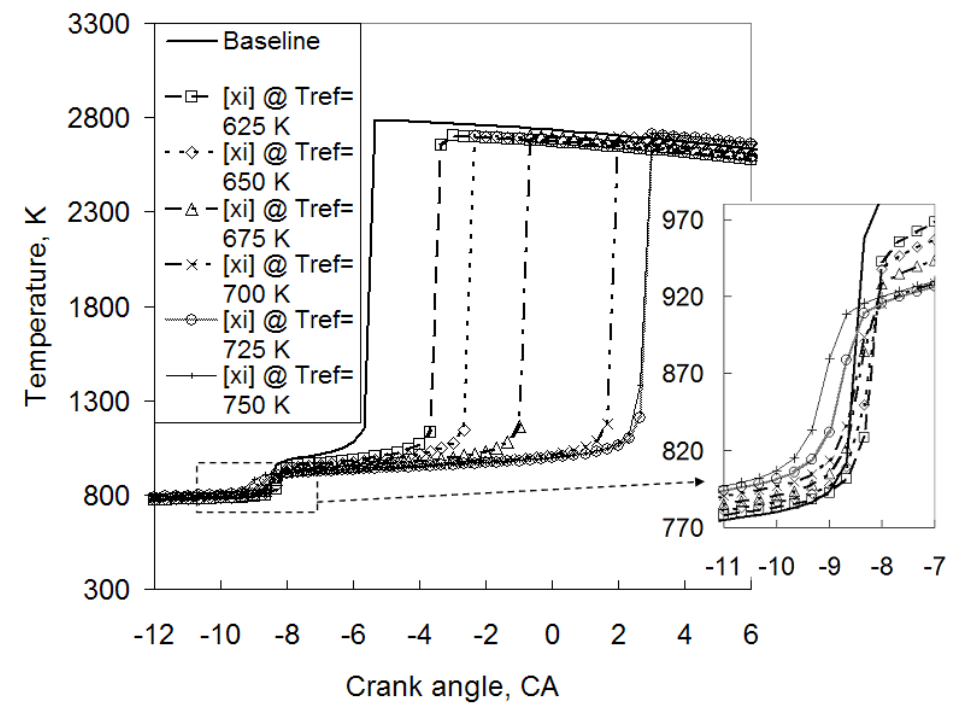

Figure 42 : Computed temperature history for real case composition, $R G=30 \%$, at different mixture composition according to reforming temperature. Baseline $\varphi=0.8$

Figure 41 presents results at $R G=40 \%$. The trend of increasing delay in proportion to increased values $\mathrm{H} 2$ from reforming process was confirmed again. It is evident that higher amounts of fuel reformed will render higher molar amounts of $\mathrm{H} 2$, which compensates the lower reforming efficiency achieved at lower reforming temperatures. There were cases of misfire, at the maximum values of $\mathrm{H} 2$ and $\mathrm{CO} 2$ concentrations.

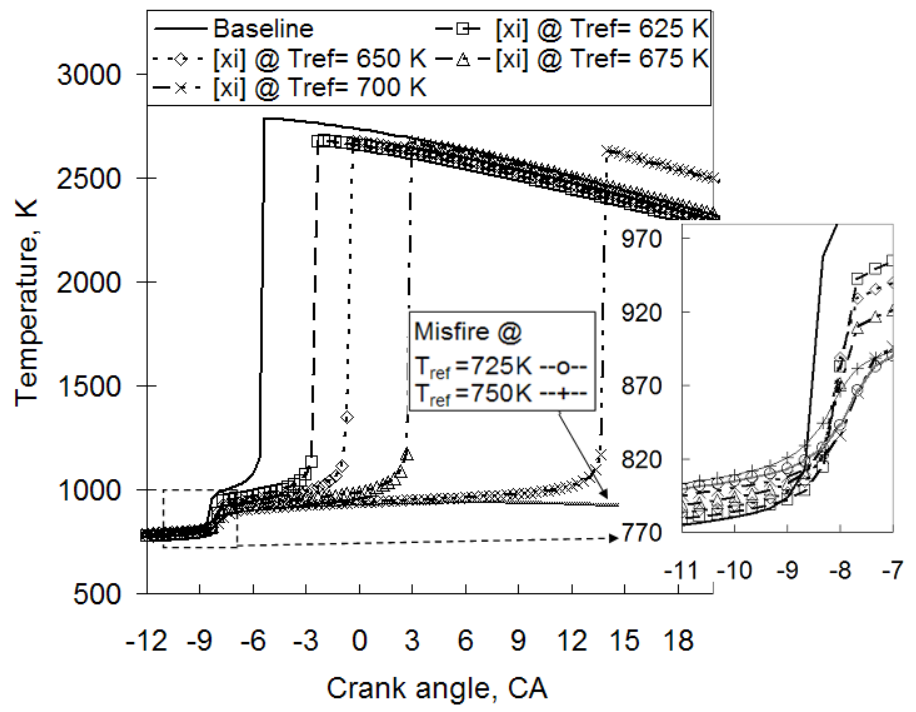

Figure 43: Computed temperature history for real case composition, $R G=40 \%$, at different mixture composition according to reforming temperature. Baseline $\varphi=0.8$

Based on numerical calculations, it was concluded that the addition of fuel-steam reforming products to the premixed mixture on a LTC engine modified the ignition timing and produced an 
overall lower temperature than the baseline air-fuel mixture. The addition was, therefore, a useful tool in managing LTC by manipulating the heat release event.

\subsection{Discussion}

A better insight into the effects of RG substitution is revealed by Figure 44. The LTHR start of ignition occurred at higher temperatures according to changes in the mixture specific heat and incylinder density due to the addition of RG. The ideal case composition did show the higher thermal effect (almost $0.7 \mathrm{~K}$ per \%RG). The change on $\mathrm{T}_{-} \mathrm{SOI} \mathrm{L}$ was not as significant as the change which occurred at the start of ignition for HTHR regime. The temperature at which high temperature reaction starts, or $\mathrm{T}_{-} \mathrm{SO} \mathrm{I}_{\mathrm{H}}$, was reduced in proportion to $\mathrm{RG}$, a clear evidence of kinetic effect derived from the presence of $\mathrm{H}_{2}$, as was observed in Figure 38. Again, the strongest effect was produced by $R G$ at the ideal case composition, where the $\mathrm{H}_{2}$ concentration was the highest, with a reduction of $1.725 \mathrm{~K}$ per \%RG. The real case composition behavior approached the ideal case trend, for RG compositions produced at reforming temperatures above $675 \mathrm{~K}$.
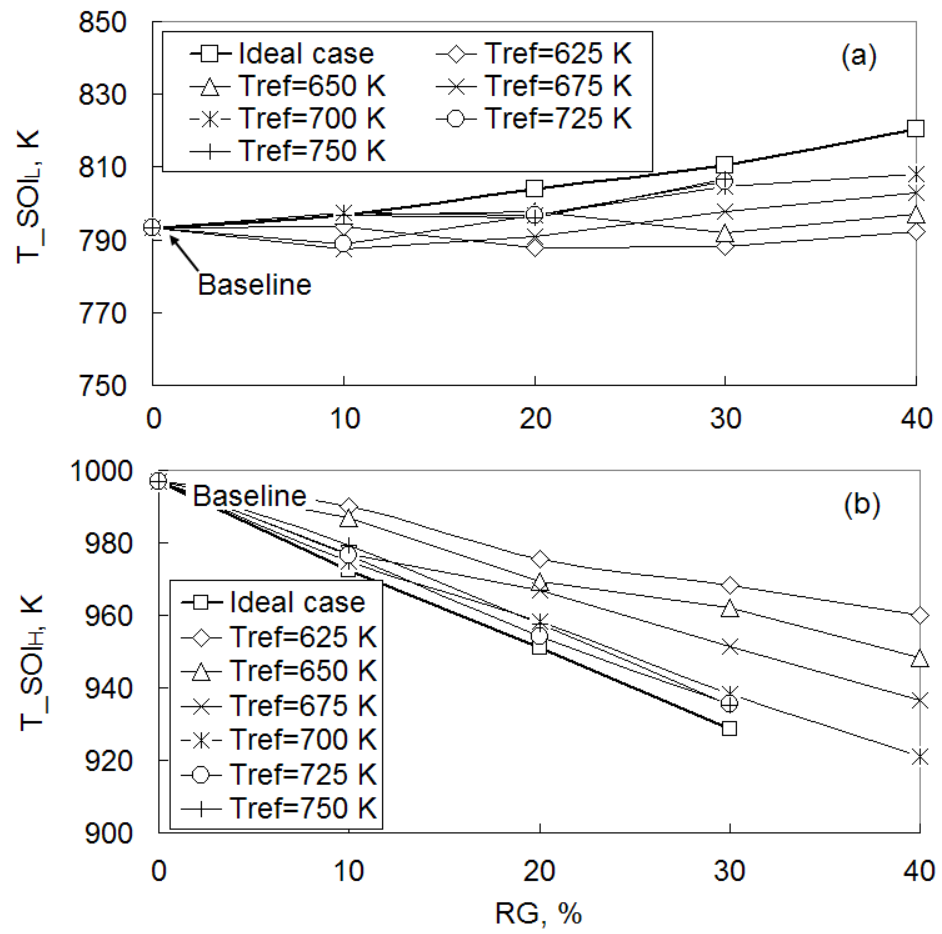

Figure 44 : Computed start of ignition temperatures as a function of RG at constant composition cases: (a) T_SOI $\mathrm{L}_{\mathrm{L}}$ at LTHR regime and (b) T_SOI $\mathrm{H}_{\mathrm{H}}$ at HTHR regime. Baseline $\varphi=0.8 . \mathrm{T}_{\mathrm{INT}}=370 \mathrm{~K}, 1200 \mathrm{rpm}$ 
Figure 45 summarizes the effects on combustion phasing, using CA50 criteria, for all the cases studied under the real case composition of RG. The ideal case composition effect was also included in this plot as a reference point. At lower values of $R G$ addition the retarding effect observed in CA50 was very similar for all cases of RG composition.

The reduction of $H R_{L}$ approached the ideal case composition trend in proportion to increased values of reforming temperature (and higher $\mathrm{H}_{2}$ concentration). Similar effects were obtained at higher amounts of RG addition. For RG $20 \%$ and RG $30 \%$, the delay of CA50 and reduction of $H R_{L}$ offered by $R G$ produced at reforming temperatures higher than $700 \mathrm{~K}$ were very similar. At reforming temperatures higher than $700 \mathrm{~K}$ the $\mathrm{n}$-heptane conversion reached the experimental maximum value, and the presence of secondary species like $\mathrm{CO}_{2}$ and $\mathrm{CH}_{4}$ became less significant. At $40 \%$ RG substitution the ideal case concentration and the cases with reforming temperatures higher than $700 \mathrm{~K}$ resulted in misfire. The highest retardant effect was achieved with the $R G$ produced at $T_{\text {ref }}=700 \mathrm{~K}$, which allowed $40 \% R G$ substitution with no misfire, although the combustion occurs extremely late, which suggest the necessity of further testing to proof this rare behavior

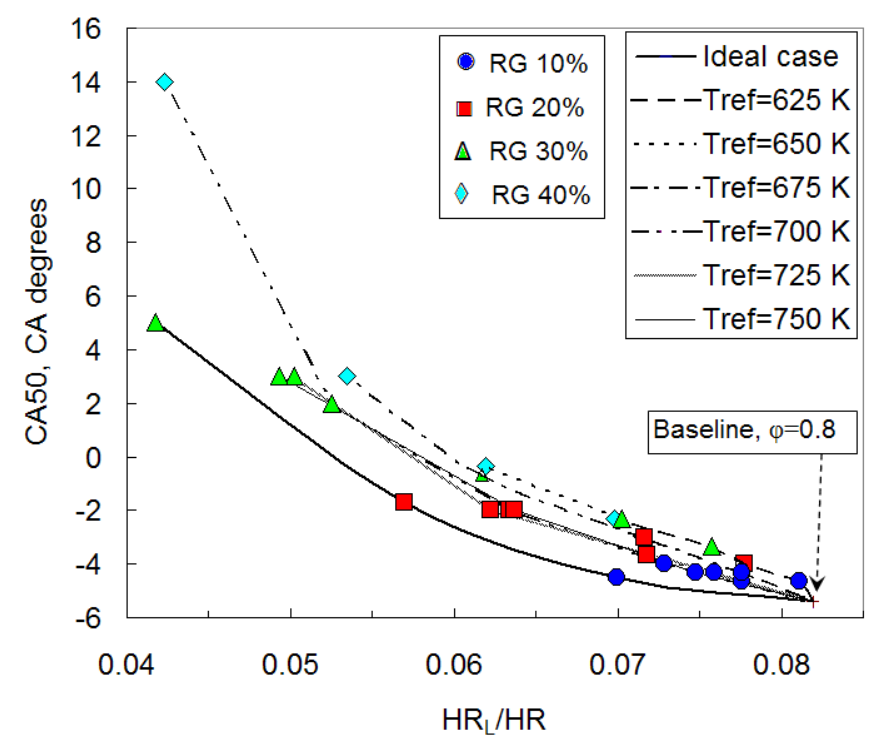

Figure 45 : Computed combustion phasing (CA50) and LTHR fraction (HR/ $/ H R$ ) for different values of RG. Each line represents a single mixture composition. Baseline $\varphi=0.8$. $\mathrm{T}_{\mathrm{INT}}=370 \mathrm{~K}, 1200 \mathrm{rpm}, \mathrm{P}=1 \mathrm{~atm}$

Figure 44 presents the effect of $R G$ addition on CA50 as a function of RG. The highest impact on ignition onset was produced by the ideal case concentration trend. The trend on CA50 retardation is proportional to $R G$ substitution for all cases of $R G$ composition. It was possible to obtain a polynomial fit for CA50, as a function of RG for the ideal case composition. 


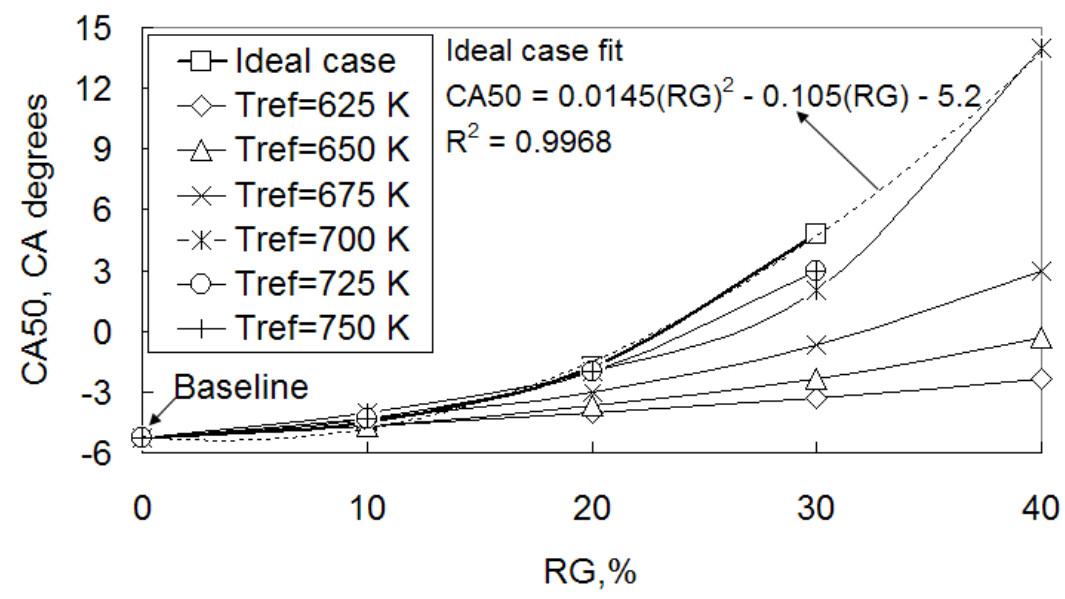

Figure 46 : Computed combustion phasing (CA50) as a function of RG. Each line represents a single mixture composition. Baseline $\varphi=0.8$. $T_{\mathrm{INT}}=370 \mathrm{~K}, 1200 \mathrm{rpm}$

A similar fit could be applied for each case of $R G$ composition based on specific reforming temperatures. For a given engine geometry, running at certain speed and intake conditions $\left(P_{\mathrm{INT}}\right.$, $\mathrm{T}_{\mathrm{INT}}$ ), CA50 can be estimated as a function of equivalence ratio, and RG substitution, and RG composition which is function of reforming temperature.

$$
\left.C A 50\right|_{g e o m, r p m, T_{I N T}, P_{I N T}}=f\left(\phi, R G, T_{r e f}\right)
$$

The correlation between $R G$ and $C A 50$ allows for prediction of the main ignition event according to specific engine operational conditions. Prediction over the main ignition event implies control of the LTC engine which was the main objective of this study.

The reduction on LTHR magnitude is an important characteristic to be exploited for LTC engine applications. [46]. Experimental work on LTC engine performance regarding fuel characteristics has demonstrated that a fuel with high amount of energy released during the LTHR stage promotes faster HTHR rates, leading to knock $[47,48,49]$. The ability of RG to reduce the LTHR behavior of $n$-heptane (Fig. 32) suggests that $R G$ has the ability to reduce the knocking tendency and therefore changing the octane index $(\mathrm{OI})$ of the fuel mixture. The octane index is an empirical measurement of the fuel resistance to autoignition [14]. Experimental work developed by Kalghatgi et al. [49] regarding OI for fuels in LTC engines concluded that the operational range between high and low load is likely wider for sensitive fuels, where sensitivity is defined as $\mathrm{S}=\mathrm{MON}-\mathrm{RON}$. Fuel sensitivity is higher for aromatic, olefins and oxygenates fuels, which bear little or no LTHR behavior, than for n-paraffines with high LTHR [48]. From this, it can be concluded that any added species showing LTHR inhibitor effects on the baseline fuel would 
reduce the knocking tendency of that particular fuel and expand its operational range for LTC operation.

Based on numerical calculations, it was concluded that the addition of fuel-steam reforming products to the premixed mixture of air/n-heptane running on LTC mode modified the LTHR regime behavior and therefore affected the ignition timing of the baseline air-fuel mixture. The ability to control ignition timing, without the loss of lower heating value associated with EGR (internal or external), suggest that the use of fuel reforming technologies to produce $\mathrm{H}_{2}$ on board can be used to control the ignition timing of LTC engines. 


\section{Conclusions}

Combustion models for LTC and diesel $\mathrm{Cl}$ were developed and integrated with friction and cooling models to compare efficiency, friction and auxiliary losses, and cooling burden between the two combustion technologies. The modeling demonstrated that LTC shows a higher overall efficiency, with lower cooling and friction losses for a given amount of fuel when compared to $\mathrm{Cl}$ diesel combustion. The main findings in this study were:

1. The influence of intake temperature, equivalence ratio and EGR were evaluated and the results obtained demonstrated that the simple zero dimensional model can predict the influence of these variables on the ignition event.

2. Values of heat release at different load conditions were evaluated for both the CIDI engine and the LTC engine and the results showed that the amount of heat release was significant at higher load. In this case the heat transfer at $43.57 \mathrm{mg}$ of fuel per cycle was $41.1 \%$ higher for the CIDI engine than for the LTC engine.

3. Slight differences were found in the final value of friction losses for both the CIDI engine and the LTC engine operating at the same amount of energy input. Maximum differences of $4.9 \%$ and $6.7 \%$ were found between the CIDI and LTC engines for the low and high load cases, respectively.

4. The total balance of cooling burden, including heat transfer and frictional losses was favorable for the proposed LTC engine at double displacement when it was compared to the diesel engine under the same energy input base.

5. Mechanical efficiencies at low load were similar between the CIDI and the LTC engine. At high load the calculated difference is $4.4 \%$ higher for the LTC engine.

To achieve LTC over a broader operating range, and to use waste engine heat constructively, TCR was explored to provide two separate, adjustable fuel streams for the engine. Experimental results showed that TCR could produce a hydrogen-rich reformer fuel at various exhaust temperatures by steam reforming of liquid $n$-heptane.

1. Equilibrium model results based on the global reaction of steam and n-heptane produced good results for $\mathrm{H}_{2}$ yield when compared to experimental data. Predicted values were offset due to the reforming temperature selected and the appearance of $\mathrm{CO}_{2}, \mathrm{CH}_{4}$ and nonreformed $\mathrm{nC}_{7} \mathrm{H}_{16}$.

2. For steam/heptane mole ratio of 15 , complete heptane conversion was expected for temperatures slightly above $700 \mathrm{~K}$.

3. Steam/heptane ratio could be optimized in order to maximize heptane conversion.

4. Appropriate catalyst should be selected for higher heptane conversion at low temperature. 
Further combustion modeling to describe the effects of Reformed Gas products into the LTC engine show:

1. $\mathrm{H}_{2}$ was found to be the main species to alter the LTHR regime, by changing the temperature range where this event occurred and by reducing the magnitude of the energy released. In consequence, the HTHR was progressively delayed at higher concentrations of $\mathrm{H}_{2}$ in the cylinder charge.

2. CO did not show a strong influence on the LTHR and its impact on combustion phasing was a very modest advance of CA50.

3. Reductions on magnitude of heat released during the $L T H R$ regime $\left(H R_{L}\right)$ were obtained with addition of $R G$ for ideal case composition, as well as for the cases with composition corresponding to reforming temperatures higher than $675 \mathrm{~K}$.

4. Numerical results show that CA50 was delayed in proportion to the amount of RG added. A general correlation between $C A 50$ and $R G$ was found for each case of RG concentration at specific speed and intake temperature.

5. Numerical results on heat release and CA50 obtained for ideal case RG composition were similar to results for real case $R G$ only for compositions corresponding to reforming temperatures higher than $675 \mathrm{~K}$.

6. Future work on employing $R G$ to control $\mathrm{HCCl}$ combustion of $n$-heptane includes solving the system energy balance and RG effect on engine performance parameters.

In summary, it is concluded that the proposed concept of using thermo-chemical recuperation to recover and utilize exhaust energy to increase in-use engine efficiency has a thermodynamically sound foundation and offers the potential for significant fuel savings, even as a standalone technology. The concept could be combined with the concept of running larger displacement, lower power density engines in an LTC mode as an alternative to commonly accepted CIDI combustion. 


\section{References}

1. Onishi S., Jo S.H., Shoda K., Jo P.D., Kato S. "Active Thermo-Atmosphere Combustion (ATAC)-A New Combustion Process for Internal Combustion Engines," SAE Paper 790501, 1979.

2. Najt P.M and Foster D.E. "Compression-Ignited Homogeneous Charge Combustion," SAE Paper 830264, 1983.

3. Thring R.H. "Homogeneous Charge Compression Ignition ( $\mathrm{HCCl})$ Engines," SAE Paper 892068, 1989.

4. Aoyama T., Hattori Y., Mizuta J., Sato Y. "An experimental study on Premixed-Charge Compression Ignition Gasoline Engines," SAE Paper 960081, 1996.

5. Ishibashi Y., Isomura S. Kudo O., Tsushima Y. "Improving the Exhaust Emissions of TwoStroke Engines by Applying the Activated Radical Combustion," SAE Paper 960742, 1996.

6. Christensen M. and Johansson B. "Supercharged Homogeneous Charge Compression Ignition (HCCl) with Exhaust Gas Recirculation and Pilot Fuel," SAE Paper 2000-01-1835, 2000.

7. Ryan III T. W., Gray A.W. "Homogeneous Charge Compression Ignition ( $\mathrm{HCCl}$ ) of Diesel Fuel," SAE Paper 971676, 1997.

8. Olsson J., Tunestal P., Haraldsson G., Johansson B. "Boosting for High Load HCCI," SAE Paper 2004-01-0940, 2004.

9. Sjoberg M., Dec J.E., Babajimopolus A., Assanis D. "Comparing Enhanced Natural Thermal Stratification Against Retarded Combustion Phasing for Smoothing of $\mathrm{HCCl}$ Heat-Release Rates," SAE Paper 2004-01-2994, 2004.

10. Dec J. E., Hwang W., Sjoberg M. "An Investigation of Thermal Stratification in $\mathrm{HCCl}$ Engines Using Chemiluminescence Imaging," SAE Paper 2006-01-1518, 2006.

11. Olsson J., Tunestal P., Haraldsson G., Johansson B. "A Turbocharged Dual-Fuel $\mathrm{HCCl}$ Engine," SAE Paper 2001-01-1896, 2001.

12. Kalghatgi G. T., Risberg P., Angstrom H." Partially Pre-Mixed Auto-Ignition of Gasoline to Attain Low Smoke and Low NOx at High Load in a Compression Ignition Engine," SAE Paper 2007-01-0006, 2007.

13. Su W., Wang H., Liu B. "Injection Mode Modulation for HCCI Diesel Combustion," SAE Paper 2005-01-0117, 2005.

14. Heywood J.B. "Internal Combustion Engine Fundamentals," McGraw-Hill, Inc. ISBN 0-07028637-X, 1988.

15. Westbrook C. K. "Chemical Kinetics of Hydrocarbon Ignition in Practical Combustion Systems," 28th International Combustion Symposium. Edinburgh, 2000.

16. Fish A., "The cool flames of hydrocarbons" Angewandte Chemie International Edition, Vol. 7, pp.45-60, 1968.

17. Pollard R., T., Hydrocarbons. Bamford C. H. and Tippe C. F., (Ed), Comprehensive Chemical Kinetics, Vol. 17- Gas Phase Combustion, Chap. 2, pp. 249-367, 1977.

18. Dryer F.L. and Glassman I., "Combustion Chemistry of Chain Hydrocarbons. Progress in Astronautics and Aeronautics", Vol 62, pp.255-306, 1978.

19. Nebojsa M. and Chen R. "A Review of Experimental and Simulation Studies on Controlled Auto-Ignition Combustion," SAE Paper 2001-01-1890, 2001.

20. Ogawa H., Miyamoto N., Kaneko N., Ando H. "Combustion Control and Operating Range Expansion in an $\mathrm{HCCl}$ Engine with Selective Use of Fuels with Different Low Temperature Oxidation Characteristics," SAE Paper 2003-01-1827, 2003.

21. Zhong S., Wyszynski M. L., Megaritis A., Yap D., Xu H. "Experimental Investigation Into $\mathrm{HCCl}$ Combustion Using Gasoline and Diesel-Blended Fuels," SAE Paper 2005-01-3733, 2005.

22. Shaver G.M., Gerdes J.C., Jain P., Caton P.A., Edwards C.F.,Modeling for control of $\mathrm{HCCl}$ engines, Proceeding of the American Control Conference. Denver, Colorado. June 4-6, 2003.

23. Westbrook C.K. and Dryer F.L., Simplified reaction mechanisms for the oxidation of Hydrocarbon fuels in flames. Combustion Science and Technology, 1981, Vol. 27, pp.31-43. 1981. 
24. Dryer F. L. and Glassman I., High-temperature Oxidation of $\mathrm{CO}$ and $\mathrm{CH} 4$. Fourteenth Symposium (International) on Combustion. The Combustion Institute, Pittsburgh, p. 987. 1972.

25. Sun F., Chen X., Ting D.S, Sobiesiak A., Modeling operation of HCCl engines fueled with ethanol. 2005 American Control Conference. Portland, Oregon. June 8-10, 2005.

26. Chang J., Guralp O., Filipi Z., Kuo T.W., Najt P., Rask R., Assanis D., "New heat transfer correlation for an $\mathrm{HCCl}$ engine derived from measurements of instantaneous surface heat flux". SAE paper 2004-01-2996, 2004.

27. Woschni G.,"A Universally Applicable Equation for the Instantaneous Heat Transfer Coefficient in the Internal Combustion Engine", SAE paper 670931, 1967.

28. Brunt M. and Platts K., "Calculation of Heat Release in Direct Injection Diesel Engines", SAE Paper 1999-01-0187, 1999.

29. Joyce A., Thermodynamic Mathematical Modeling, Chapter $6^{\text {th }}$ of Diesel Engine Reference Book. Bernard Challen, Rodica Baranescu. Second edition. ISBN 076800403 9, 1999, pp 139-141.

30. Wolfer H. H., The ignition in a Diesel Engine., CDI-Forschungsheft 392, 15-24, 1938.

31. N. Watson, A.D. Pilley and M. Marzouk. "A combustion correlation for Diesel engine simulation". SAE Paper 800029, 1980.

32. Bryzik, W., Henein, N., Taraza, D., "Friction Losses in Multi-Cylinder Diesel Engines", SAE Paper 2000-01-0921, 2000.

33. Fraas A. P., Ozisik M. N., "Heat Exchanger Design" John Wyley \& Sons, Inc., New York. London. Sydney. ISBN 0-471-27432-1, 1965.

34. Kays W. M. and London A. L., "Heat transfer and Flow Friction Characteristics of Some Compact Heat Exchanger Surfaces", Trans. ASME , vol.72, 1950, p. 1075.

35. Jones M. R. and Wyszynski M. L., "Exhaust-Gas Reforming of Hydrocarbon Fuels", SAE Paper 931096, 1993.

36. Ramírez P., Homs N., "Alcoholic Fuels," Taylor and Francis Group, LLC, 2006.

37. Dorf, R. C. "The Engineering Handbook, Second Edition," CRC Press, LLC, 2005.

38. Hosseini V. and Checkel M. D., "Effect of Reformed Gas on HCCl Combustion - Part II: Low Octane Fuels", SAE Paper 2007-01-0206, 2007.

39. Olson J., tunestal P., Ulfvivk J., Johanson B., "The effect of cooled EGR on Emissions and Performance of a Turbocharged HCl engine", SAE Paer 2003-01-0743, 2003.

40. Engine Research Center, The University of Wisconsin at Madisson, Modeing of Engine Process http://www.erc.wisc.edu/modeling/modeling index.htm

41. Patel A., Kong S.C., Reitz R.D., "Development and Validation of a Reduced Reaction Mechanism for HCCI Engine Simulations," SAE Paper 2004-01-0558, 2004.

42. Lawrence Livermore National Lab web site http://wwwcmls.Ilnl.gov/?url=science and technology-chemistry-combustion-nc7h16, Apr, 2008.

43. Posada F., Bedick C., Clark N.N., Kozlov A., Linck M., Boulanov D., Pratapas J., "Low Temperature Combustion with Thermo-Chemical Recuperation," SAE Paper 2007-01-4074, 2007.

44. Aceves, S., Smith, J. R., Westbrook, C, and Pitz, W., 1999, "Compression Ratio Effect on Methane $\mathrm{HCCl}$ Combustion," ASME Journal of Gas Turbines and Power, Vol. 121, No. 3, July 1999.

45. Warnatz J., Maas U., Dibble R. W., "Combustion Physical and Chemical Fundamentals, Modeling and Simulation, Experiments, Pollutant Formation", $2^{\text {nd }}$ edition, Springer, 1999. ISBN 3-540-65228-0

46. Dec J. and Sjoberg M., "Isolating the Effects of Fuel Chemistry on Combustion Phasing in an $\mathrm{HCCl}$ Engine and the Potential of Fuel Stratification for Ignition Control", SAE Paper 2004-010557, 2004.

47. Aroonsrisopon T., Sohm V., Werner P., Foster D., "An Investigation Into the Effect of Fuel Composition on HCCl Combustion Characteristics", SAE Paper 2002-01-2830, 2002. 
48. Shibata G., Oyama K., Urushihara T., Nakano T., "The Effect of Fuel Properties on Low and High Temperature Heat Release and Resulting Performance of an HCCI Engine", SAE Paper 2004-01-0553, 2004.

49. Kalghatgi, G.T., Risberg P. and Ångström H.E, "A Method of Defining Ignition Quality of Fuels in HCCI Engines," SAE 2003-01-1816, 2003.

50. Easley, W. L., Agarwal, A., and Lavoie, G. A., "Modeling of $\mathrm{HCCl}$ Combustion and Emissions Using detailed Chemistry." SAE Paper 2001-01-1029, 2001.

51. Komninos, N.P., Hountalas, D.T., and Kouremenos, D. A., "Development of a New Multi-zone Model for the Description of Physical Processes in HCCI Engines." SAE Paper 2004-010562, 2004.

52. Curran, H. J., Gaffuri, P., Pitz, W. J., and Westbrook, C. K., "A Comprehensive Modeling Study of n-Heptane Oxidation." Combustion and Flame, no. 114 (1998): 149-177.

53. Hulkvist, A., Endgar, U., Johanson, B., and Klingmann, J., "Reacting Boundary Layers in a Homogeneous Charge Compression Ignition (HCCl) Engine." SAE Paper 2001-01-1032, 2001

54. Yang, J., and Martin, J.K., "Approximate Solution One Dimensional Energy Equation for Transient, Compressible, Low Mach Number Turbulent Boundary Layer Flows." Journal of Heat Transfer Vol 11 (1989): 619-624 